Mariella Nocenzi

Alessandra Sannella Editors

Perspectives

for a New

Social Theory

of Sustainability

Foreword by

Enrico Giovannini

Springer 
Perspectives for a New Social Theory

of Sustainability 
Mariella Nocenzi • Alessandra Sannella Editors

\section{Perspectives for a New Social Theory of Sustainability}

Foreword by

Enrico Giovannini

望 Springer 


\author{
Editors \\ Mariella Nocenzi \\ Department of Communication \\ and Social Research \\ Sapienza University of Rome \\ Rome, Italy
}

\author{
Alessandra Sannella \\ Department of Human, Social \\ and Health Sciences \\ University of Cassino \\ Cassino, Italy
}

\section{ISBN 978-3-030-33172-6 \\ ISBN 978-3-030-33173-3 (eBook) \\ https://doi.org/10.1007/978-3-030-33173-3}

(C) Springer Nature Switzerland AG 2020

This work is subject to copyright. All rights are reserved by the Publisher, whether the whole or part of the material is concerned, specifically the rights of translation, reprinting, reuse of illustrations, recitation, broadcasting, reproduction on microfilms or in any other physical way, and transmission or information storage and retrieval, electronic adaptation, computer software, or by similar or dissimilar methodology now known or hereafter developed.

The use of general descriptive names, registered names, trademarks, service marks, etc. in this publication does not imply, even in the absence of a specific statement, that such names are exempt from the relevant protective laws and regulations and therefore free for general use.

The publisher, the authors, and the editors are safe to assume that the advice and information in this book are believed to be true and accurate at the date of publication. Neither the publisher nor the authors or the editors give a warranty, expressed or implied, with respect to the material contained herein or for any errors or omissions that may have been made. The publisher remains neutral with regard to jurisdictional claims in published maps and institutional affiliations.

This Springer imprint is published by the registered company Springer Nature Switzerland AG The registered company address is: Gewerbestrasse 11, 6330 Cham, Switzerland 


\section{Foreword}

When I joined the Organization for Economic Co-operation and Development (OECD) as Chief Statistician in January 2001, the organization was running an innovative project on "sustainable development," the first large-scale project run by an international organization on this theme. It was a challenging project, both politically and analytically. At that time, some countries (especially the USA) were clearly against the involvement of the OECD in a project dealing with sustainable development, and thus the trade-off between economic development and the protection of the environment. Other countries supported the project (even financially), as they were convinced that only a holistic approach to sustainable development would allow for a true "paradigm shift" in policy making.

From an analytical perspective, the project was also extremely challenging. The Statistics Directorate was responsible for defining a statistical framework to measure the sustainability of a socio-economic system, which implied the design of a conceptual framework (in line with the Brundtland Report published in 1987) to fully integrate the economic, social, and environmental dimensions of sustainability. While running the project, we discovered a fundamental obstacle in developing such a fully integrated approach to sustainable development due to "theoretical asymmetry": while in the economic and environmental domains the concept of "thresholds" was widely used to identify possible points beyond which a system becomes unsustainable (planetary boundaries, debt/GDP ratio, etc.), in fact, the absence of a "theory of revolution" able to predict when a society reaches a tipping point, and thus initiating a revolution, was preventing us from elaborating a reliable definition of "social sustainability." We also tried to define social sustainability through the economic sustainability of institutions in charge of specific welfare pillars (pensions, health etc.), but this approach was inevitably unsuccessful.

At the end of that project, we worked hard with other institutions (the United Nations, the European Commission, etc.) and OECD countries to develop a measurement framework for sustainable development based on the "capital approach," looking at four fundamental types of capital: economic, human, social, and natural. The framework developed at that time ${ }^{1}$ was quite influential, and since then, some

\footnotetext{
${ }^{1}$ https://www.unece.org/fileadmin/DAM/stats/publications/2013/CES_SD_web.pdf
} 
countries have used it to measure the sustainability of their socio-economicenvironmental conditions. But while the measurement of economic and natural capital (at least in physical terms) was improved in several ways, the measurement of human capital, and especially that of social capital, did not reach a satisfactory level, conceptually or in practice.

With the signature of the 2030 Agenda for Sustainable Development, ${ }^{2}$ officially agreed upon by the United Nations in September 2015, the measurement of sustainability received a significant impetus. Since then, the international community of statisticians has multiplied its efforts to develop indicators concerning the 17 Sustainable Development Goals (SDGs) and the 169 Targets to be met by all countries in the world by 2030. Models have been developed, or are being developed, to evaluate alternative pathways towards the SDGs, or to simulate the impact of different policies on them.

Notwithstanding these important developments, the social dimension of sustainability is still far from being fully understood and measured. This book therefore represents an important contribution. The idea of developing a "new sociological theory of sustainability," as the title of the first chapter of this book underlines, is very appealing, and thus deserves special attention. The contents of this book could also promote a better understanding of the relationships among the various dimensions of sustainable development, and so shape economic and social policies from an innovative perspective.

It is clear that, to bring the world onto a sustainable path, we need adequate technologies, a radical change in people's mindsets, and a redesign of governance, in both public and private institutions. Understanding how sociology can help to stimulate this change is key to avoiding the development of abstract solutions that do not work in practice, as well as to recognise how a global effort can be implemented in societies with very different cultural backgrounds. The mental and cultural changes that we, as individuals and communities, need to make towards sustainability are profound, and all disciplines need to be involved, to possibly overcome the narrow borders of academic classifications and work according to innovative interdisciplinary and transdisciplinary approaches. This is why, for that matter, Ilaria Capua and I recently wrote a proposal, published in Nature, ${ }^{3}$ to include a reference to the SDGs addressed by the research in all papers published by international scientific journals, as this would provide an overview on how scientific research deals with the multifaceted characteristics of sustainable development.

In conclusion, the effort towards sustainable development should be a priority for all of us, both individually and as members of the scientific community. This book addresses one of the weaknesses of the approaches followed so far to deal with sustainability, and I sincerely hope its contents can stimulate important advancements towards a fully integrated conceptual and policy approach to sustainable development.

Faculty of Economics

Enrico Giovannini

University of Rome Tor Vergata

Rome, Italy

\footnotetext{
${ }^{2}$ https://www.un.org/sustainabledevelopment/development-agenda/

${ }^{3} \mathrm{https}: / / \mathrm{www}$. nature.com/articles/d41586-019-02367-0
} 


\section{Preface}

This book is the result of some years of our work. We, the two editors, are researchers of sociological theory who share a scientific interest in social change and social diversity, and our approach is interdisciplinary.

Our common background has driven us to a critical analysis of the basic sociological concepts, initiated by a desire for collaboration with other disciplines and a large dose of what the Romans called curiosity. Sustainability, as a paradigm strategic for our society - and so for sociology — has inspired us firstly to actualize this research for our students, and then to advance the debate in the scientific community in our society and in sociology.

Indeed, this book is the outcome of discussion about these issues, among colleagues, sociologists and lay people, and it attempts to facilitate wider debate that we consider strategic for our society and our sociology.

Several individuals played an important role in the completion of this book: all our colleagues and contributors to this debate that we offer to our readers-eminent academics, young researchers who are the "soul of sociology"; our students who shape our thought every day; Sapienza University of Rome and the University of Cassino, both of which support our work, as well as Lilith Dorko at Springer for her professional patience and trust. Finally, we acknowledge our families-sons and husbands, siblings and parents, even those who have already left us - have been enormously supportive throughout this process. We can all breathe a sigh of relief now that Alessandra and Mariella's book is complete!

Rome, Italy

Cassino, Italy
Mariella Nocenzi

Alessandra Sannella 


\section{Introduction}

Sociology is commonly defined as the discipline that arose in direct response to the social problems of Modernity, namely the social conditions and processes that resulted during the Age of Enlightenment, a period decisively more dynamic than any previous cultural or social phase. However, there is no consensus amongst sociologists about how we should label or describe contemporary society, which, in turn, resulted from several social changes (the more recent being very radical). It is impossible for them to agree upon a definition, especially in relation to the sociological benchmark of Modernity. Originating in the 19th century, sociology announced itself as being Second Modernity, Radical Modernity, or Post-Modernity. Current society rejects the notion that Modernity proposed, defining Modernity as the hyper-advanced present we live in and the future we expect.

This book's main purpose was to outline some of the theoretical and practical implications of the recent technological revolution, referring to contemporary human/non-human relations, for social researchers and for readers of sociological analysis. The main hypothesis is that the rising entanglement of human and nonhuman elements, but also an increasingly common awareness of the limitations of human development, require an adaptation - if not a regeneration —of epistemological and methodological tools for the interpretation of current social processes. The environmental strategies for balancing human actions and the earth's resources by means of a sustainable approach can inspire fresh new conceptualizations, and, therefore, a new sociological paradigm. Not only are the modernist theories of unlimited wealth and progress no longer sustainable, but their theoretical and empirical settings also need to be revised, starting from a necessary rethinking of the dualism between nature and culture, and of the human relations in a hyperconnected society, increasingly composed of non-human elements.

The assumption of new sociocultural settings, subsequent to the pervasive, rapid yet not fully understood modification of the ecological system by human activity, is increasingly shared by several disciplines that define the last five decades as "Anthropocene." The exploitation of all our material and non-material resourcesfood, water, energy, land, but also time and social space-for the well-being of humankind has been revealed as ineffective and unsuccessful as we see poverty and pollution both rise dramatically. 
For the social sciences, all these changes are fundamentally different from anything seen before in human history, yet unexpectedly following traditional paradigms. If there is an increasing trend to change the situation through political, economic, and social strategies, all the disciplines must adopt more adequate theoretical and methodological models to describe the social transformations and to investigate perspectives and consequences. While several ideas and a lot of embryonic theoretical schemes are in the planning phase, the social sciences seem, paradoxically, to be fearful of interpreting the current social processes and to adapt their scientific efforts of observation and investigation. While some natural scientists such as James Lovelock (2019) are predicting the end of the Anthropocene era and an approaching age of hyperintelligence-when artificial intelligence (AI or cyborgs) will play a central role thanks to rapid processing and strategic cohabitation with humans in keeping the planet cool for their own survival-the social sciences struggle even to name this period, resorting to prefixes and suffixes (Nocenzi, 2019) and doubting the new era depicted in Lovelock's Novacene.

From a social point of view, the solution for a more incisive analysis of reality is to take advantage of our own theoretical and methodological resources. Sociology, in particular, as a discipline of second-level analysis, arose from specific investigation of a radical change in human relations, residence, production, and development, more than a century ago; it can manage data, models of interpretation, and even the analytical tools that current and expected changes demand.

This book therefore attempts to explore the social sciences, paying particular attention to sociology and to the internal relations among all the disciplines, for the purpose of deciding which intrinsic tools could be used and what the most effective paradigm would be that could lead social research and facilitate the interpretation of the current radical changes.

Part I is the starting point of this scientific endeavor-prior to a discussion of the actual project. Some of the fundamental theoretical frameworks of traditional sociology are discussed, providing background to their development, function, and theories on capitalism, consumption and globalization. An exploration of the basic structure of the social disciplines facilitates the discussion of their origin, future applications, and different strategies for adapting to changing reality. The title Theoretical Overview on Social Sciences and Sustainability assumes that sustainability is not only the end result of the evolution of the social analysis - from Modernity to present society-but is a permanent reference point for the social interpretation that has confronted itself with opposite and/or parallel paths, during the growing crisis of all in their efforts to adapt to social change. This adaptation is inevitable and unsurprising, because, as the contributions in Part I highlight, the cohabitation of humans in a wider and more populated environment, the natural limitations of their actions, the anticipation of future perspectives, and the abandoning of contemporary formula, require a reformulation of the basic concepts analyzed (see above) and of Modernbased approaches. Mariella Nocenzi's paper details the epistemological process, leading to an exploration of some current social environments, especially urban ones, as well as the theoretical spaces of sociology, and assesses the changing society through the revised meaning of fundamentals such as time, space, and relations. 
Surprisingly, the sustainability approach that the author suggests corresponds with the theoretical model outlined in Paolo De Nardis's review of the traditional sociological theory of functionalism. Although seemingly tangential to a balanced vision of society and the environment through their functions, this is a prevailing traditional theory that is opposite to sustainability, the goal of which is to gain a more effective idea of the quality of life based on solidarity, equality, sociability, and all the trends that might characterize the social individual. The author begins this review from the stance of a traditional theory that pre-dated functionalism, which was recommended in the Marx's Critics of the Political Economy. Marx's work is one of the most important sources for social research about capitalism, as is Bauman's. The first paper is Uliano Conti's: he compares traditional and contemporary capitalism. He argues that, thanks to technical progress and scientific research, the latter could better redefine the idea of human life and the conditions of existence of human beings on earth, while the capitalist productive system co-evolves from the perspective of environmental awareness. The second paper is Paolo Corvo's proposal for a theoretical model that uses Bauman's opera as its main reference point. The Polish sociologist, indeed, depicts society in a way that is not very familiar to the traditional observer: consequently, he suggests the use of a critical and innovative sociological imagination to interpret developments and transformations based on the issues of freedom, justice, morality, and the suffering of human beings.

These reflections about the crucial role of sustainability for the revision of some of the traditional social perspectives are the basis for the assembly of a more efficient theoretical and methodological resource. Part II, Methodological Paths and Perspectives for a New Social Theory of Sustainable Development, attempts to address this issue. The contributions of Part II set out to propose analytical paths for social research that could promote and reinforce sustainability, using three different approaches. In Delli Paoli, Addeo, and Mangone's papers, the assumption that sustainability is a multidimensional but not directly measurable (apart from indicators and indexes) concept, enables a more efficient methodology for assessing the different moral dimensions of sustainability: it could produce usable knowledge for policy and also be used to assess European Member States' performance on single imperatives while identifying priorities and deficits that prevent the achievement of sustainability. Maurizio Esposito's paper analyzes the outcomes of the implementation of the Project Cycle Management strategies in Western societies' policies, with specific attention to "sustainable welfare" programs. In this case study, the social sciences can also recommend a methodological path for a phase of executive application, and not only for the definition of statistical tools, as in the previous contribution: both are strategic supplies of social research for the public assessment of social and natural resources. The final contribution provides a psychological analysis of a changing society, looking at some of the most common effects and problems, from a macro-dimension to individual ones. Cianconi, Tomasi, Morello, and Janiri examine some psychopathological syndromes encountered along the troubled pathway of adaptation, and consider those methodologies that can explain how psychopathology moves, reacts, and expands through technological, political, communicative, and economic domains for a new understanding in a changing society. 
These methodological analyses and tests allow for the development of analytical structures that the social sciences could use for the definition of the theory of sustainability, which is the focus of Part III. It is as an ambitious but essential goal for the social sciences: the reasons have been outlined at the beginning of this Introduction. All the contributions stress the difficulties but also the opportunities of this self-reflexive work on the structures and perspectives of the social sciences, adopting a sustainable approach in thinking about the future. Franco Ferrarotti, one of the fathers of European contemporary sociology, reflects at length on the difference between the natural and social sciences, recalling the specific question for the social sciences about a sustainable paradigm for the interpretation of change. What is important for the author is to prove that now is finally the time for moving forward from the achievements of 19th-century physics and natural science: the sociologist has realized that his most indispensable and irreplaceable instrument of research is his own experience as a social being, totally involved with the reality being investigated. This could be useful for all the social sciences, because sociology grasps, at a single glance, a total view of the human sciences, and can compare their results. This positive attribute of the discipline could be reinforced by the sophisticated theoretical — and sociological—rationale, investigated in Lombardo and Sabetta's paper, that by linking emancipatory catastrophism (as in Beck's acceptation) and unintended consequences, it is possible to initiate an effective transformation of modern societies, thus effecting what would be the crowning achievement of the social sciences (in the view of the two authors) — "Sustainability through unsustainability"- but also "sociology among all the other social disciplines," including the natural sciences. This could bring about a transdisciplinary perspective, as Alessandra Sannella argues in her concluding contribution-one of the most effective proposals for the analysis and interpretation of society, too complex and continuously varying for a fragmented science.

\author{
Mariella Nocenzi \\ Sapienza University of Rome \\ Rome, Italy \\ Alessandra Sannella \\ Department of Human, Social and Health Sciences \\ University of Cassino \\ Cassino, Italy
}

\title{
References
}

Lovelock, J., \& Appleyard, B. (2019). Novacene: The coming age of hyperintelligence. Cambridge, MA: The MIT Press.

Nocenzi, M. (Ed.) (2019). Verso una società sostenibile. (Non) umani, reti, città e la sfida del cambiamento. Roma: Nuova Cultura.

Sannella, A. (2019). Sviluppo sostenibile e innovazione sociale per la promozione della salute. In M. Esposito \& A. Sannella (Eds.) Social innovation nelle politiche della sanità. Rivista Salute e Società. 2/19: 68-82. 


\section{Contents}

Part I A Theoretical Overview on Social Sciences and Sustainability

1 Some Remarks for a New Sociological

Theory of Sustainability . . . . . . . . . . . . . . . . . 3

Mariella Nocenzi and Alessandra Sannella

2 Sustainability and the Crisis of the Theoretical

Functional Model ........................... 15

Paolo De Nardis

3 Environmental Sustainability and the Evolution

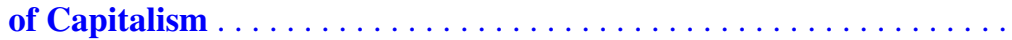

Uliano Conti

4 The Thought of Zygmunt Bauman as a Key for Introducing

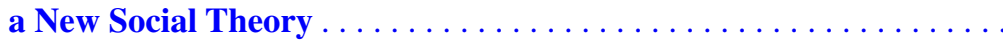

Paolo Corvo

Part II Methodological Paths and Perspectives for a New Social Theory of Sustainable Development

5 Sustainability and Sustainable Development Goals (SDGs):

From Moral Imperatives to Indicators and Indexes.

A Methodology for Validating and Assessing SDGs

Angela Delli Paoli, Felice Addeo, and Emiliana Mangone

6 Sustainability as a Key Imperative in Project Cycle

Management: Sociological Considerations.

Maurizio Esposito

7 Toward an Understanding of Psychopathological

Syndromes Related to Social Environments.

Paolo Cianconi, Federica Tomasi, Manuela Morello, and Luigi Janiri 


\section{Part III Which Social Science About the Sustainability?}

8 Social Research: On Participation and Critical Detachment . . . . . . 95 Franco Ferrarotti

9 Sustainability Through Unsustainability? Unintended Consequences and Emancipatory Catastrophism . . . . . . . . . . 103 Carmelo Lombardo and Lorenzo Sabetta

10 Sociology and Sustainable Development: The Paradigm Is Going to Change . . . . . . . . . . . . . . . . . . . . . . . . . . . . . . . . . . . 115 Alessandra Sannella

Index. . . . . . . . . . . . . . . . . . . . . . . . . . 125 


\section{Contributors}

Felice Addeo University of Salerno, Salerno, Italy

Paolo Cianconi Cattolica University “A. Gemelli” Hospital, Rome, Italy

Uliano Conti University of Perugia, Department of Philosophy, Social Sciences and Education, Perugia, Italy

Paolo Corvo Università degli Studi di Scienze Gastronomiche, Bra, Italy

Paolo De Nardis Sapienza University of Rome, Rome, Italy

Maurizio Esposito University of Cassino, Cassino, Italy

Franco Ferrarotti Sapienza University of Rome, Rome, Italy

Luigi Janiri Cattolica University “A. Gemelli” Hospital, Rome, Italy

Carmelo Lombardo Sapienza University of Rome, Rome, Italy

Emiliana Mangone University of Salerno, Salerno, Italy

Manuela Morello Palermo, Italy

Mariella Nocenzi Department of Communication and Social Research, Sapienza University of Rome, Rome, Italy

Angela Delli Paoli University of Salerno, Salerno, Italy

Lorenzo Sabetta Institute for Analytical Sociology, Linköping University, Linköping, Sweden

Alessandra Sannella Department of Human, Social and Health Sciences, University of Cassino, Cassino, Italy

Federica Tomasi A.T. Beck Cognitive Behavior Therapy Institute, Rome, Italy 


\section{About the Editors}

Mariella Nocenzi, $\mathbf{P h D}$, is a research fellow at Sapienza University of Rome in the Department of Communication and Social Research. She is the scientific director of the International Observatory of Social Theory on New Technologies and Sustainability-Sostenibilia, as well as a founding member of the Scientific Council of the Inter-University Observatory of Gender and Equal Opportunity (GIO). Among her research interests in national and international projects are social history and theory, with a specific link to gender studies, sustainability and social diversity, and risks and conditions of security and safety in globalization. She is an assistant editor of the International Review of Sociology and has edited several publications, drawn from research on environmental issues, risk, Europe, young people, equal opportunities, and gender policies. Among her latest publications: Verso una società sostenibile. (Non)umani, reti, città e la sfida del cambiamento (ed.) [Towards a sustainable society. (No)humans, networks, cities and the challenge of the change], 2019.

Alessandra Sannella, $\mathbf{P h D}$, is a social theory researcher at the Department of Human Sciences, Society and Health at the University of Cassino and Southern Lazio, Italy. She is the coordinator of the University Committee for Sustainable Development (CASe) and represents the University in the Italian Network of Sustainable Universities (RUS). In addition, she is active in the teaching programs of the Faculty of Medicine and Dentistry at the Sapienza University of Rome. Her scientific research and activities center on the reduction of inequality in international migration, health and global health policies, and structural violence, with specific attention paid to sustainable development in these areas. In line with these aims, she has coordinated national and European research projects on issues related to migration and the associated questions of bioethics. Her recent publications include articles on vulnerability and violence in society and the book La Violenza tra tradizione e digital society. [Violence between tradition and the digital society] (2017). Sannella has also been the editor of a wide range of sociological journals and academic volumes. 
Part I

A Theoretical Overview on Social Sciences and Sustainability 


\title{
Chapter 1 \\ Some Remarks for a New Sociological Theory of Sustainability
}

\author{
Mariella Nocenzi and Alessandra Sannella
}

\subsection{Introduction}

This paper explores theoretical and methodological strategies for rethinking some principles of sociological theory in the light of the fact that the basic sociological concepts - for instance, time, space, and relations among individuals and groupscould facilitate better observation and understanding of contemporary societies.

Thanks to a selected literary review and an analysis of some representative social phenomena-such as the Internet of Things (IoT), Big Data and smart cities-we can hypothesize that sustainability could be an effective strategic paradigm for the exploration of new social structures and processes, and the revision of sociological tools for their analysis, as well as the development of a draft sociology of sustainability. The concept of network is an appropriate starting point.

The paper uses an inductive structure that is based, firstly, on the hypothesis that contemporary social analyses of society are inadequate. The frequent use of prefixes and suffixes - added to classical sociological concepts, to describe social actors, processes, and relations - reveals how inconsistent current production of epistemological categories is, as well as how dependent current researchers and scholars are on the legacy of their "fathers." A brand new set of theoretical schemes and methodological tools is required to facilitate interpretation of the effect of the modern revolution as well as the rapid development of contemporary changes. These new schemes

\footnotetext{
M. Nocenzi $(\bowtie)$

Department of Communication and Social Research, Sapienza University of Rome, Rome, Italy

e-mail: mariella.nocenzi@uniroma1.it
}

\author{
A. Sannella \\ Department of Human, Social and Health Sciences, University of Cassino, Cassino, Italy \\ e-mail: alessandra.sannella@unicas.it
}


and tools should be implemented in conjunction with currently existing ones, which should not necessarily be discarded, but rather adapted to a changing reality.

The growing question of sustainability as a principle to be applied to accommodate for changes in society-assumed to be an integrated network of processes and relations (Habermas, 2003) — could suggest that existing definitions, elements, and dimensions are no longer convenient, and that change is inevitable in order to reflect different time, space, and relations criteria. Revised definitions, elements, and dimensions might contradict the one that evolved in the Modernity era, but might better reflect current conditions and future irreversible shifts. They might appear to be similar to those used in pre-Modernity definitions of reality. They might even deal with problematic interpretations that resulted from rapid transformations during the era of Modernity and even more recently, and eliminate contradictions.

While the sustainability principles are very difficult to define and understand, they could be accepted as interpretative tools for describing the future evolution of human-and now we can rightly also say non-human-relations. They make up all the universal elements of the human condition and adjust those aspects that could irreversibly modify society: this is evident from the extreme compression of time and space that began with the Modern urban and economic revolutions.

As a new social paradigm, sustainability could establish those temporal and spatial dimensions of human processes and of the relational environment created by recent universal conditions. Implementation of the new social paradigm in several social processes, such as, inter alia, the Internet of Things (IoT), Big Data and smart cities, to which traditional temporal and spatial sustainability principles and dimensions do not seem pertinent (even with the use of prefixes or suffixes), could suggest that a sociology of sustainability could effectively describe the social transformations in progress, inherited from Modernity with all its implications.

\subsection{A Glance at the "Inadequacy" of Contemporary Social Analysis}

The origins of sociology as a science date back to the nineteenth century with the inception of Modernity, capitalism, urbanization, rationalization, secularization, colonization, and imperialism; these were the most representative processes emanating from the radical transformations in society that occurred after the Enlightenment. As a result of this tremendous cultural renewal, the evolution of Modernity was characterized by some influential values such as critical reason, humanitarianism, and positivism. Those who observed the massive social changes leading up to the modern world adapted these principles in order to analyze the lives of humans, groups, societies, and their interactions.

Karl Marx, Emile Durkheim, and Max Weber were considered the founding fathers of the "new" discipline (despite their use of diverse principles and methods), the aim of which was to observe the very rapid changes in society, including their 
consequent political, economic, and social implications. These implications were often interpreted as social problems the world was suffering under, and the role of sociology as a scientific discipline was considered crucial for the purpose of their interpretative analysis. This scientific study of society facilitated the discovery of natural solutions.

After some decades characterized by a prevailingly positive public and internal trust in the authority of sociology (Durkheim, 1895; Weber, 1922, p. 1978), the most relevant consequence was considered the same role that society and science recognized in this emerging discipline: "Sociology is a science concerning itself with the interpretive understanding of social action and thereby with a causal explanation of its course and consequences. We shall speak of action insofar as the acting individual attaches a subjective meaning to his behavior..." (Weber, 1968, p. 4).

The observation and interpretation of a social action, based on analytical scientific methods, made easier the comparison of sociology with other disciplines and the direct application of norms, rules, and methodological paths to a real case under the lens of the microscope, broken down into its single components. For the "objects" of social analysis, this is not possible though: social facts cannot be broken down into parts that can be analyzed individually or in terms of their correlations or relatedness to each other. Even the perceived discrete parts of a social fact require observation through integrated analysis done by a variety of scientific disciplines and methods (Weber, 1922). This makes the interpretation of a fact, and, possibly, its assessment toward a solution very ambitious or challenging. It means that what seemed possible for sociology-according to optimistic public expectation from the sciences during the first stages of Modernity - became very problematic in Late Modernity.

As a result of growing difficulties with the implementation of the "welfare" program in Western societies as well as the puzzling process of decolonization in the Global South, a large number of social problems appeared and were submitted to social scientists for investigation: poverty, racial segregation and discrimination, higher levels of crimes and violence, urban decay, human and mechanical pollution of the environment, limitations of natural and human resources, demographic decline, and inefficient transportation. They represented the opposite of what the Modernity program had promised, namely well-being and growth for all, thanks to the rejection of previous models.

The emergence of these social problems highlighted a twofold challenge for sociology that is still prevalent today: sociology is a discipline that was instituted to analyze the modern transformation of society and to develop a theoretical and methodological set of tools that — even in the era of Late Modernity — was found to be inadequate and ineffective for the solution of the problems that arose so unexpectedly.

The sociological thought and theoretical processing that marked the passage from Modernity to Contemporaneity underlined this impasse. It was as if the discipline could not compare two different points of view on social processes-functional or conflictual, integrated or apocalyptic. We are witnesses to a fragmentation of the research schools of thought, the most representative results of which have 
been different definitions of the same Modernity. The latter has been defined as the "first" Modernity, because we are now seeing its evolution, with positive and negative effects, into a radical, self-reflexive or "second" Modernity (Giddens, 2013). However, it should still be considered as incomplete, not "concluded," being succeeded by current Postmodernity (Bauman, 1997), or even as completed and now followed by "dopomodernità" (Donati, 2011). In addition to those interpretations, there is also Latour's description of a Modernity that has, in fact, never started (Latour, 1993).

A subsequent evolution of Modernity (self-reflexive, radical, or totally different) has been - and still is - sociology as a shared representation of discontinuity with the previous social system, but, at the same time, the reproduction of all its epistemological categories, following critical analysis.

The assumption of concepts as limitation (Meadows, Meadows, Randers, \& Behrens, 1972) - to growth, to the exploitation of resources, to human time and space, etc.- or the uncertainty of the science in a risk society (Beck, 1992) and the "non definition" of complex systems (Luhmann, 1997), are only some of the frameworks that have called into question the entire Modern project and its concepts and interpretative categories. The growing possibility of alternative concepts, such as dysfunctionality, insecurity, post-Fordism, liquefaction of relations, and many others, is symbolic of a society (with its scientific interpretations) that seems to still be a living example of Modernity on the difficult path toward a new model that can only be reached via a brand new set of values that reflect current society.

At this stage, sociological contributions to the solution of social problems seems far off. In actual fact, the process of applying the required new strategies for solving these problems is, itself, a problem in social science.

\subsection{The "Question of Sustainability": Definition, Elements, and Scope}

One of the most challenging problems for contemporary societies-indeed for all the social sciences-seems to be the changing ecological conditions that humans are confronted with, while, paradoxically, it becomes more and more evident that the causes of these ecological changes are the actions of these same humans. Consequently, natural scientists define the specific geological era labelled Anthropocene (Crutzen \& Stoermer, 2000) as one in which the centrality of human knowledge, skills and discoveries are going to be scaled down, and, with them, that "exuberant growth imbuing sociology with a worldview or paradigm which impedes recognition of the societal significance of current ecological realities" (Catton \& Dunlap, 1980, p. 15).

A mere four decades ago, Catton and Dunlap themselves, with certain other researchers of relevant ecological issues (see Stoermer, Kociolek, Theriot, \& Stevenson, 2009), predicted a social and sociological amendment to the paradigm 
that, since the beginning of Modernity, had oriented scientific inquiry of reality in the sphere, on account of specific problems that emerged as well as prevailing inexplicable facts. Environmental concerns together with strong anthropocentric scientific knowledge made this evident. Their very interesting effort started from the same paradigm considered as an assumption, following the Ritzer definition: "A paradigm is a fundamental image of the subject matter within a science. It serves to define what should be studied, what question should be asked, how they should be asked, and what rules should be followed in interpreting the answer obtained. The paradigm is the broadest unit of consensus within a science and serves to differentiate one scientific community (or subcommunity) from another. It subsumes, defines, and interrelates the exemplars, theories, and methods and instruments that exist within it" (Ritzer, 1975, p. 7). Assuming a paradigm, not as a theory, but as the "broadest unit of consensus" within sociology or other disciplines, Catton and Dunlap vociferously criticized the Modern paradigm-i.e., its prevailing theoriesthat entrenched a part of society (the environment) and of sociology (the natural sciences). They exchanged this modern "human exceptionalist paradigm" for a "human exemptionalism paradigm," the aim of which was to promote understanding of the nature of all the "unforeseen" changes that the previous paradigms (theories) were not able to explain because they did not take environmental issues into consideration.

This strong warning for sociology was not the first or only one during those decades. Indeed, only a few years before this, the similar reflections of a natural scientist, Alexander King, and of an industrialist, Aurelio Peccei, highlighted how the emerging, most common definition of social facts as problematic was based on viewing them as "problems capable of being solved in their own terms" (Özbekhan, Jantsch, \& Christakis, 1970, p. 15), while these facts-environmental depletion, ill-health, urban blight, criminality, poverty, etc.- - should have been assessed in an interrelated way among all the disciplines. In their Rome meetings at the end of the Sixties, scientists, business leaders, economists, high-level politicians, and government officials, as well as diplomats from all over the world, affirmed that it was urgent to regenerate the human system, using those limitations and constraints that had been natural until an anthropocentric vision had erased them with all the nonhuman elements and processes. Thanks to the collaboration of all the scientists and technicians of this Club of Rome, the multidisciplinary research outputs underlined that the human-based assumptions about the trends of the main variables of growth-population, food production, industrialization, pollution, and consumption of non-renewable natural resources-were destined to fail in the changing temporal and spatial dimensions. The removal of the barriers among disciplines and between the human and non-human dimensions could delineate human actions, solving those processes that, otherwise, seemed to be problematic (Meadows et al., 1972).

If sociologists started to "retool" their theoretical and methodological settingsand they were still working towards this goal—all the other stakeholders of the Club of Rome re-assessed the principles on which their activities were based. Those who are mentioned in this overview drew up one of the most well-received formalized 
proposals for dealing with the problematic conditions, assuming a different approach for analyzing, interpreting, and then managing them. As a result of the outcomes of the previous Conference on the Human Environment in Stockholm (Meadows et al., 1972), the United Nations charged the World Commission on Environment and Development (WCED) with the exploration of strategies to implement the political agendas along more compelling paths, namely environmental conservation and the interdependence of nations and political and socio-economic actors in the search for development. In particular, the main WCED aims were: the raising of "the level of understanding and commitment to action on the part of individuals, voluntary organizations, businesses, institutes, and governments (...) to focus attention in the areas of population, food security, the loss of species and genetic resources, energy, industry, and human settlements - realizing that all of these are connected and cannot be treated in isolation one from another" (World Commission on Environment and Development, 1987a, p. 347). They recognized the environmental limitations on economic growth in industrialized and industrializing societies and that a balance between economy and ecology is requested (World Commission on Environment and Development, 1987a, p. 361).

Unsurprisingly, the removal of barriers (between the economy and ecology, and also between institutional and common social actors in the challenge to face problems and crises) gave politicians and economists, officials and scientists latitude to consider human action in the present and to develop effective perspectives for the future. Overcoming the "modern exuberance" of unlimited human action was possible thanks to interdependence among disciplines and actors and the recognition that many crises and "problems" facing the planet are interlocking crises that are in fact elements of a single crisis of the whole.

While barriers fell and limitations were put in place, some radical changes became evident: the plural definition of the principles of knowledge, the position and relevance of man in a wider and more complex environment, as well as the importance of the temporal dimension-not only the present. In the report Our Common Future, the WCED, led by the former Norwegian Prime Minister Gro Harlem Brundtland, confirmed this shift, declaring the importance of "development that meets the needs of the present without compromising the ability of future generations to meet their own needs (...) and the recognition of the vital need for the active participation of all sectors of society in consultation and decisions" (World Commission on Environment and Development, 1987b, p. 3) as well as the urgency of orienting human action toward its own sustainability.

\subsection{From the Traditional to the New Social Paradigm of Sustainability: The Basic Concepts of Time, Space, and Network}

Should sustainability therefore be assumed as a social paradigm according to the Ritzer definition? There is some evidence in favor of this hypothesis when we consider what has been said in the previous two paragraphs. When the principles of 
Modernity failed in their efforts to meet the challenges of increased crises and problematic processes, the social sciences started to explore more effectual interpretations, first using traditional concepts, and then—arguing that these would be defined in the coming Modernity—calling into question this same Modernity (see Sect. 1.2). Only a handful of social scientists considered a review of their own theoretical and methodological instruments for more effective analysis of a changing society.

The few scientists, politicians, and economists who believed in a different interpretation of social processes, such as the Club of Rome and the Brundtland Commission, introduced alternative conceptual dimensions that were received with suspicion (Sannella, 2019). How could resorting to a strong connection among economic, environmental, and social strategies possibly ameliorate social development—or facilitate the facing of crises and problems? How could efficiency and the exploitation of resources be assured at the same time? How could the disease of the present be rectified by long-term planning of human activities? How could current society assist future generations in following a path of equity and justice? These are questions that the Club of Rome publication and the WCED Report Our Common Future addressed, some years later, despite public opinion and scientific skepticism.

While this widespread reticence for change gradually abated — events such as the Bhopal gas tragedy in 1984 and the nuclear accident in Chernobyl in 1986 influenced, to some extent, the common people-social scientists realized that a more pertinent interpretation of human agency was required, even though they did not necessarily believe that a new paradigm needed to be adopted (see Catton \& Dunlap, 1980). It became clear that the role of social scientists, and especially sociologists, needed to be re-evaluated. Thanks to its tools, sociology, as a science, can go beyond the limits of the pure sociology of common sense, and can question reality, engage in theoretical reflection in the face of questions, as well as collect data and information systematically (Cavalli, Bagnasco, \& Barbagli, 2007, p. xii). Reviewing its theoretical and methodological approach and paradigm in order to define its main object, namely society, has been challenged. At the end of the "Modern" era, the challenge has been to assume the main object, society, as the population-that collective group resident in a delimited territory for a period that allows for their relations, reproduction, satisfaction of basic needs, establishment of a common culture and a social practice from which values, rules, and norms are derived for the regulation of their social life and for the planning of their future (Wagner, 2008).

We can increasingly discern an emerging re-opening and re-evaluation of basic sociological concepts that look beyond traditional approaches-especially in Durkheim's and Weber's work-to argue for the importance of mechanisms in society and in sociological theory, that promote practices of double hermeneutics, with an interpretive and dialectical relationship between social scientific knowledge and human practices (Giddens, 1996). It has allowed for a perception of reality without a pre-given universe of objects, but rather as the outcome of human agency, and also acknowledgement of a growing body of non-human agency.

Sociology thus stopped using the traditional hermeneutics of an interpretative science with a unique point of view, and should highlight the limits of human agency: individuals produce society, but they do so as historically located actors, 
and not under conditions of their own choosing (Giddens, 2013). In the age of information and communication technologies and digital life, software codes, sensors, big data, algorithms, artificial intelligence, and other platforms (Accoto, 2017) join and modify human action, beginning with its most basic components: temporal and spatial dimensions and even shape. It is no longer possible to define time in a linear or circular way such as Nietzsche's (1964) assumption for Modernity, when it was compressed to the "now, the very soon." Thanks to the digital revolution, projection to the future and the disintegration of the present fostered a rethinking of this basic sociological category, and also a re-interpretation of the other constituent concept, namely space. Subsequent to globalization and the coexistence of human and nonhuman actors, the compression and extension of time has affected the spatial dimension of the agency, position, and role of non-human actors, their shape and the dynamics of their relations. It was so effective that, taking into account temporal and spatial dimensions, we can now consider social relations as another essential element of society, probably the most strategic for the profile of a new social paradigm to adopt in an interpretation of current society.

If we assume, following the crisis of Modernity four decades ago, the warning regarding the interaction of single parts of society and the sciences, mid- and longtime planning, equity of access to resources for all, as well as contamination by factors such as time, space, individuals, things, non-human elements, and arrangements regarding sustainable development, sustainability could be what Ritzer called a paradigm, namely "a fundamental image of the subject matter within a science (...) what should be studied, what questions should be asked, how they should be asked, and what rules should be followed in interpreting the answer obtained"? (see Sect. 1.3).

\subsection{Some Implementations for a New Social Paradigm Towards a Sociology of Sustainability}

The efforts of sociologists in including new approaches, if not a brand new paradigm, in their interpretation of society in recent decades have been as various as they have been original (see Sect. 1.2). It could be concluded that the most interesting attempts really come from the application of the paradigm in terms of the representation of the "image of the subject matter within this discipline," in Ritzer's assumption. The scientific observation of society in the specific processes that portray the current social change remains a creative opportunity for the re-evaluation of some of the most important sociological categories.

With reference to the concepts of time and space, for instance, their individualbut especially interrelated-meaning in the interpretation of the changing social processes has been adopted differently to describe the agency of human and nonhuman beings. If we follow the previously mentioned Giddens-one of the most influential sociologists in terms of attempting to adopt pertinent categories in 
contemporary society-human and non-human agency can be determined "as a transformative capacity to intervene in a given set of events so as if in some way to alter them (...) the power of agency must to be related to the resources that agents employ in the course of their activities in order to accomplish whatever they do (...) the sources of this power depend in large degree upon the management of timespace relations" (1987, p. 7). This moderate openness to the centrality of resources in the determination of human (as well non-human) agency redefines the position and role of the actors in the social processes, and also influences the meaning of the sociological concepts of time and space. The anthropocentric vision is substituted by an interconnected environment, the essential components of which are all the actors, and all the objective, material dimensions and structures, without a hierarchical order.

When this social environment changes, so-called hierarchies, centralized dimensions, and prevailing agencies seem to be inadequate, and some adjustments are needed. This is the case in some new social scenarios of contemporary societies where we are suggesting significant changes that could probably substantially influence aspects, such as the fundamental image of the subject matter, what should be studied, what questions should be asked, how they should be asked, and what rules should be applied in interpreting the answers obtained for sociologists (Nocenzi, 2019).

The first one is the Internet of Things (IoT), namely the "network of physical objects that contain embedded technology to communicate and sense or interact with their internal states or the external environment. The IoT involves extending Internet connectivity beyond these standard devices (desktops, laptops, smartphones and tablets) that can communicate and interact over the Internet, and they can be remotely monitored and controlled (Jones, 2015). Therefore, not only human beings, but also objects that are no more than machines could access the web; they could communicate among themselves, create information, and add value. The spatial and temporal dimensions of these relations are completely different from the traditional ones: a different sociological perspective needs to observe and interpret how objects communicate with humans and how humans tell objects their intentions, as if they were one of us, as well as how they contribute-human with nonhuman, non-humans among themselves - to building the social agency (Karimova, Shirkhanbeik, \& Alvares, 2015). The evolution of Internet connections and the redrawing of the space populated by humans and "things," as well as compression of the time, requires sociology to engage with questions not only about the social identity of these "new actors," but also about the nature of the relations among all these actors in a transformed social environment.

Many of these "things" are data, or rather, big data—data sets that are too large and complex for traditional data-processing application software to deal with adequately. Generally, these "things" include captured data, data storage, data analysis, searches, sharing, transfer, visualization, querying, updating, information privacy, and data source, the prevalent traits of which relate to their velocity (time), their large volume (space), and their variety, in forms of integration that provide insights 
from datasets (relations, networks). While engaging with the characteristics of these "things" that enliven social relations, sociologists run into identities and agencies that need to be defined, not only in terms of their dissimilarity to human ones.

This is clearly evident in social research involving the latest urban spaces, called "smart cities," where information and communication technologies (ICT), the IoT, and big data are incorporated to enhance the quality and performance of urban services such as energy, transportation, and utilities in order to reduce resource consumption, wastage, and overall costs (Sandel, 2017). Even though the overriding aim of the smart city is to enhance the quality of living for its citizens through smart technologies, what is important for sociologists is to thoroughly revisit and update the traditional definition of the social space: "great cities have always been melting pots of races and cultures. Out of the vivid and subtle interaction of which they have been the centres, they have come the newer breeds and the new social types" (Park, Burgess, \& McKenzie, 1925). Today, there are new social types that affect human beings and that require the application of new categories for their interpretation: the determination of time in all its projections, space as an outcome of social networks among humans and things, and equity in a no longer anthropocentric world requiring sustainable dimensions.

\subsection{Some Concluding Remarks}

The inadequacy of traditional basic concepts for observing and interpreting the social transformation in contemporary society is pervasive in the social sciences, even though, among sociologists in particular, their responses or reactions, hypotheses and their criticism about it have been as numerous as heterogeneous.

During the last few decades, brand new scenarios have often been outlined by social changes, and some scholars believed that the era of Modernity had passedand with it sociology —or it has going to start. Attempts to rethink the social settings have sought to update or reform the use of the basic categories of time, space, and relations. These theories and theoretical proposals have opposed a more pertinent sociological interpretation for a changing society in terms of problematization of the modern society and the "modern" concepts.

This is the main reason for the assumption of sustainability as a very effective principle for the analysis of contemporary society, especially in the light of the new agency of non-human things, the articulated temporal dimensions and the limitations of Anthropocene space.

It is inevitable that the use of basic sociological concepts in relation to the prevalent changes will promote the social sciences, and especially sociology, as an analytic science among the other disciplines. Unequivocally, limits will be put on the human dimensions of social agency, and it will favour not the weakening of sociology, but the hoped integration between sociology and other disciplines: an effective framework for the scientific research will be encouraged. 


\section{References}

Accoto, C. (2017). Il mondo dato. Cinque brevi lezioni di filosofia digitale. Milano: Egea, Milano. Bauman, Z. (1997). Postmodernity and its discontents. London: Polity Press.

Beck, U. (1992). The risk society. Towards a new modernity. London: Sage.

Catton Jr., W. R., \& Dunlap, R. E. (1980). A new ecological paradigm for post-exuberant sociology. The American Behavioral Scientist, 24(1), 15-47.

Cavalli, A., Bagnasco, A., \& Barbagli, M. (2007). Corso di sociologia. Bologna: il Mulino.

Crutzen, P. J., Stoermer, E. F. (2000). The Anthropocene. IGBP Newsletter, No. 41, May, 15-34.

Donati, P. (2011). Sociologia della riflessività. Come si entra nel dopo-moderno. Bologna: il Mulino.

Durkheim, E. (1895). Les Règles de la Méthode Sociologique. Paris: Alcan.

Giddens, A. (1987). The nation-state and violence. Vol. 2: a contemporary critique of historical materialism. Los Angeles: University of California Press.

Giddens, A. (1996). Defence of sociology. Cambridge: Polity.

Giddens, A. (2013). The consequences of modernity. London: Wiley.

Habermas, J. (2003). The future of the human nature. London: Polity Press.

Jones, N. (2015). Internet of things survey 4Q14. Industry and regional perspectives. Gartner Research. Retrieved from https://www.gartner.com/en/documents/2992432/ internet-of-things-survey-4q14-industry-and-regional-per.

Karimova, G. Z., Shirkhanbeik, A., \& Alvares, C. (2015). Society of things: An alternative vision of internet of things. Cogent Social Sciences, 1. https://doi.org/10.1080/23311886.2015.1115654

Latour, B. (1993). We have never been modern. London: Harvard University Press.

Luhmann, N. (1997). Theory of society. Stanford: Stanford University Press.

Meadows, D., Meadows, D., Randers, J., \& Behrens III, W. W. (1972). The limits to growth. New York: Potomac Associates-Universe Books.

Nietzsche, F. (1964). Frammenti postumi, (tr. it. di S. Giametta). Sull'utilità e il danno della storia per la vita. Opere. Milano: Adelphi.

Nocenzi, M. (Ed.). (2019). Verso una società sostenibile. (Non) umani, reti, città e la sfida del cambiamento. Roma: Nuova Cultura.

Özbekhan, H., Jantsch, E., Christakis, A. (1970). The predicament of mankind. Quest for structured responses to growing world-wide complexities and uncertainties. A proposal. Retrieved June 28, 2019, from https://web.archive.org/web/20140203125912/http://sunsite.utk.edu/ FINS/loversofdemocracy/Predicament.PTI.pdf.

Park, R., Burgess, E., \& McKenzie, R. (1925). The city. Chicago: University of Chicago Press.

Ritzer, G. (1975). Sociology: A multiple paradigm science. Boston: Allyn \& Bacon.

Sandel, D. (2017). Smart cities are $90 \%$ sociology and $10 \%$ infrastructure. In K. T. Vinod (Ed.), Smart economy in smart cities. Advances in 21st century human settlements (pp. 1033-1036). Singapore: Springer.

Sannella, A. (2019). Sviluppo sostenibile e innovazione sociale per la promozione della salute. In M. Esposito \& A. Sannella (Eds.), Social innovation nelle politiche della sanità (Vol. 2/19, pp. 68-82). Rivista Salute e Società.

Stoermer, E. F., Kociolek, J. P., Theriot, E. C., \& Stevenson, R. J. (2009). Diatom taxonomy, ultrastructure, and ecology: Modern methods and timeless questions: A tribute to Eugene F. Stoermer. Berlin: J. Cramer.

Wagner, P. (2008). Modernity as experience and interpretation. A new sociology of modernity. Cambridge: Polity.

Weber, M. (1922). Economy and society (p. 1978). Los Angeles: University of California Press.

Weber, M. (1968). Basic sociological terms. In Economy and society; An outline of interpretive sociology (pp. 65-78). New York: Bedminster Press.

World Commission on Environment and Development. (1987a). Our common future. Oxford: Oxford University Press.

World Commission on Environment and Development. (1987b). Our common future, from one earth to one world. From A/42/427. Retrieved from http://www.un-documents.net/ocf-ov.htm\#1.2. 


\title{
Chapter 2 \\ Sustainability and the Crisis \\ of the Theoretical Functional Model
}

\author{
Paolo De Nardis
}

\subsection{Sociological Functionalism: Theory or Paradigm of Western Societies?}

For some time, especially in the Western modern culture, North American structural functionalism was the prevailing "Sociological Theory," and its ideology, having effectively taken root, was widespread in several fields and cultures, forming the impetus and orientation of much social research. In North America and elsewhere, this theory and its methodological approach were effectively posed as a cultural and ideological imperative.

A critical review of this theory thus seems to be a stimulating and worthwhile exercise. In itself, the theory denounces possible aporias in the explanation of a very complex representation of an advanced industrial and welfare society. Researchers who, a long time ago, undertook this exercise, declaring that they were not convinced by the theory of structural functionalism, believed that social analysis, even if only morphological, could have positive consequences and result in the development of effective concepts for theoretical and empirical research. At that time, researchers who wished to explore alternative theories made only fleeting criticisms of the pervading sociological theory, because of its general acceptance in sociological theorizing worldwide. They took several ideas from worldwide research into account, incorporating these into their criticism of the theory.

It is important to point out, even briefly, that (in addition to some methodological and philosophical contradictions). there is an essential aporia in the theory of structural functionalism. It pertains to a scant determination of concepts and their implementation in some of the basic categories regarding the Welfare State, due to the centrality of the concept of function in the theory.

\footnotetext{
P. De Nardis $(\bowtie)$

Sapienza University of Rome, Rome, Italy

e-mail: paolo.denardis@uniroma1.it
} 
In fact, sociological functionalism rarely (and, in these few cases, too superficially) engages with a sociological study of institutions and organizations that arise, grow, and die in a modern or post-modern advanced industrial society. The analysis of the State and its structure has also been too vague, being reduced to a general phraseology on the distribution of power. The juridical mechanisms - the public and non-public, State/civil society institutions-were rarely and superficially explored in terms of their more complex structures: they were linked to traditional postulates not pertinent for a sociological theory of the analysis of these institutions, even though this theory was particularly careful to isolate specific phenomena of modern society.

For a sociological theory that was presumed "paradigmatic" even by its critics, the proposal of a socio-institutional analysis (unacknowledged at that time), or, better, of a theoretical scheme (with all its possible limitations, incomplete and ineffective as an analysis of the institutions) and, in conclusion, the proposal of an all-encompassing critical sociology and/or social science-as a discipline that examines all the representative institutions of modern society-risked formulating this theory very distantly from social reality. This was the reason it became important to add to the expression "social theory" to the phrase "socio-institutional analysis": it drew attention to the strong link between them, by incorporating the second into the first and into general social science.

The concepts "institutional" and "institutions" were thus used in their non-formal sense, without direct reference to a more general meaning than those of the sociological concepts (even though this general meaning was considered). Their main use was in terms of their ordinary meaning, representing the juridical and political institutions actually existing in modern society. If a more "technicalized" language had been used, the represented institutions were positive/intentional (as opposed to natural/genuine): for them, generally, the main component of the constitution is the juridical norm (Gallino, 2014, word: Institution).

For these reasons, a study of Parsons, Merton, and other North American researchers' bodies of work-considered expressions of structural functionalism in the analysis of institutions - is the underlying theme of these reflections. Both positive and negative aspects of the sociological theory of structural functionalism, one of the fundamental theories of sociological thought, are identified.

\subsection{Functionalism as the Ideology of the "Problem of Order"}

Some years ago, it was noticed (De Leonardis, 1976) that Parsons' general theory explained an organic and self-regulated system that, even if not described by a detailed theory (or "big theory", according to Mills), and abstraction from the empirical and historical-social tangibility, emphasized the supremacy of society and of the advanced capitalistic State. 
According to this theory, "society"- a simple product of casual aggregation and stratification due to several phenomena ${ }^{1}$ in traditional liberal thinking, including Weber's-was transformed by Parsons (unlike other structural functionalists, such as Merton) into an object of general social theory. Society was the main entity that arranged or brought order to confused social actions, making them functional for achievement of their goals and giving precise roles or role systems to the social actors involved.

As is generally known, Parsons criticized Weber for the methodological limitations of his construction of a general social theory (Ferrarotti, 1960; Parsons, 1970). This criticism did, however, recognize Weber's thought as the fundamental point of no return to a positivistic sociological theory (Comte, Spencer, and, mutatis mutandis, Durkheim), or to an idealistic sociology inspired by Hegel or Kant. All the previous philosophical and ideological schemes that Weber developed were renewed in a new, coherent setting, without the traditionally prevailing positivism or the neoidealistic, irrational solutions (see Dilthey's theory about Erlebnis). In any case, Weber's approach, while attempting to save some positivistic premises (Barber \& Hirsch, 1962; Hempel, 1959; Nagel, 1968; Statera, 1974)² and to consider historical and social facts as scientific, sacrificed the more dependable point of view of knowledgeable, more informed individuals - the scientists. This point of view remained, therefore, subjective. Searching for a sense of the historical facts - where totality is infinite and made little sense-this perspective needed to define logical or "ideal typical" parameters, based on the value hierarchy posed by the scientist (subjective) who lived in a specific social context (objective). Therefore, these logical parameters were pure models, and were thus not ontologically verified.

This limitation provided the opportunity to make use of a unit of measurement of historical-social reality, that was more or less detached, and that could be duplicated, thanks to a sequence of cause-effect links, as is done in the natural sciences (Weber's positivistic application). In this way, the social facts, objective in themselves, became scientific, and, even if sectorial, could be ordered and logical or "ideal typical" categories. ${ }^{3}$

Parsons believed that Weber should be applauded for resisting the intuition and "non-realism" of German Idealism (even though he belonged to this school of thought) in methodological approach and knowledge: "the generalization of the human things could mean you know only some cultural totalities", and this becomes

\footnotetext{
${ }^{1}$ In the nineteenth century, liberal intellectuals referred to the concept of "present harmony" (Bentham).

${ }^{2}$ These positivistic premises, according to De Leonardis, could be summarized in "the substantial identity between natural and social sciences," in "the demand...of defining universal norms, where validity is based on logic-formal coherence; the idea of a cumulative development of the scientific knowledge"; then, the non-problematic and immediate correspondence between the empirical reality and thinking categories; and, also, the "irreducible detachment and mutual unfamiliarity between subject and object (De Leonardis, 1976, p. 130).

${ }^{3}$ It is clear that, again, the parameter of scientificity is guaranteed by the logic-formal coherence of the causal determinations' links.
} 
an immediate intuition, "an immediate comprehension of the meaning without using concepts" (Parsons, 1970, p. 720). However, Parsons also pointed out that Weber, even though he promoted scientific control of social knowledge, ran into an irrational impasse: he stated that this social science control was not similar to natural science's control in the laboratory, "because a social phenomenon is not reproducible." It could be only a purely rational control, "based on the elaboration of concepts, marked by values that are not empirically, experimentally verified: from the science it falls down in the ideology, in the philosophy and, finally, in the irrationalism-relativistic" (Parsons, 1970, p. 720).

This happens because the scientificity is reduced to the rationality of the scientific research tools, based on the ubiquitous individuality of the social facts and the relativism of the concepts (which are dependent on logic and thus not ontological, that is, non-real): they are deceptive for the goals (values) of the individual. The knowledge, therefore, is not genuinely scientific, but only suitable for the goals defined in a purely rational way: theoretical, and so, once again, philosophical (Cerroni, 1976, pp. 41-42).

As Parsons stated, Weber's work was limited by its persistent analytical approach to an individual, subjective social action: as it was observed, his analysis focused on "principles, ideals, norms, values present to the human awareness and for this reason it is impossible that, in this ideal level of the social coexistence, it could find a suitable verification model" (Cerroni, 1976, pp. 42-43). Yet society cannot be reduced to subjective awareness, to an unclear and ideological operation: it simply overturns the sociological problem of awareness and social theory, in a sort of psychological sphere of the particular individual (at the specific time when the rational choices were made, and based on the values underpinning the conceptual categories), thus underestimating actual and objective time (Cerroni, 1976, p. 43). Parsons did, in fact, verify the limits of the theoretical partial schemes used by Weber, taking into consideration the type of social action defined by the German sociologist (Ferrarotti, 1960). In the transition from the analysis of the structure of the action to the social system, Parsons effectively overcame the positivistic and naturalistic reduction of the social system. However, rather than taking this further, as observed, "Parsons beat another route": on the one hand, he depicted the search for models of "motivational and cultural (or symbolic) components, unified in an ordered system"; on the other, he defined a normatively oriented action a system of expectation. Since the social actor had a precise role, the problem was still the elaboration of ideal cultural models to apply in the social system. Thus the problem of social objectivity escaped Parsons "in so far as it was transformed in the traditional question of the form of the social institutions as simple fulfilments of cultural behavioral models" (Cerroni, 1976, p. 49).

Parsons subsequently fixed the culturological character of social phenomena, and, after publishing The Social System, he promoted analysis of the structural characteristics of the system: they were required to fulfil the basic function of integration, protected by a series of social control mechanisms. The same social system provided only for an inner change linked to its axiological and structural framework. Parsons's ideological operation is clear: his analysis is a-historical and 
meta-temporal, and his social system is artificially built, even as a heuristic model. As will be observed, there was a continued trend from which to abstract or extrapolate, even though it needed to be suitable for the social systems of all times and places. In this manner, its purely heuristic identity should have fallen, and the ontological abstraction highlighted this effect: the system postulated its conditions and these conditions postulated the system (Cerroni, 1976, p. 51). This is extremist functionalism at its best.

In conclusion, Weber had to give up on the idea that the social order is chaotic and irrational. It is important to remember that Weber wrote in a time period dominated by a liberal market economy and the so-called "anarchy of production"- -even though at the first sign of a crisis, he denounced the ineffectuality of the extravagant concept of "pre-established harmony." The subject who made choices rationally, influenced by values, could order the social chaos; it was represented by a series of social actions significantly influenced by values. And, in this way, the circle is closed. (Someone has accurately observed - in the concept of social action-an ideological mask of the individual action of the exchange, and so, the foundation of the market.)

\subsection{The Functionalism Between Power and Money}

Parsons' structural functionalism insists on the centrality of objectivity for the society, regardless of the subjective and individual rationality of who wants to know the society (researcher or scientist), so that the uniformity of society is not chaotic and senseless, but objective (Habermas, 1970; Izzo, 1974). For Parsons, this is possible, because with his structural-functionalist hypothesis, "he projects the systematic links in the reality and not only in an analytical function. This hypothesis allows, then, to interpret the full-sense functional link among the variables, formulated in the enunciation of the laws, starting from a wider functionalistic link for the conservation of the system" (De Leonardis, 1976, p. 131).

Thus order is within the social object itself: what is real is rational, and the thought, the intelligible, is the automatic mirror of historical sense, of the social reality that is the empirical and actual—no longer without it—reference for the new scientific condition. In this way it is possible to attribute meaning to the different causal relations that occur in society, relating them to what is intellectually perceived as the cause and the aim of society; that is the social system - not a model of logic.

The society, then, is the system, and it is the aim, the a priori of the actions of its social units. The concept of "function," borrowed from the biological and natural sciences (as is evident, there is positivistic organicism that seems to come through the back door in disguise, having left through the front), "embodies the social connection, manifests its separated and autonomous existence from the historical existence of the members of the same society. Since it derives from the society as a system, it is the premise and the repeated form of the human being in the society ..." 
(De Leonardis, 1976, p. 138). ${ }^{4}$ Therefore, it is the dictatorship of the function in the free market (methodological individualism) or in the social system (holistic structuralism), or-maybe-both.

Parsons emphasizes that social action "consists in the structures and in the processes that the same human beings create for their substantial intentions and that they make concrete" (Parsons, 1965, p. 11). This contrasts with behaviorism, because expectations and rules are emphasized, as compared to Weber's historicism, which does not accept that human action is linked to formalized rules and values, as proposed by Parsons. This is the reason for the common designation of Weber as the sociologist of free competition and of market capitalism. So, in terms of the amount of institutionalization of behavior expectations, social agency is interpreted according to normative models. It becomes the agency in a role that is "what the social actor is in the social relations, in its meaning for social system" (Parsons, 1965 , p. 12). This is the reason, therefore, for the commonly held position that Parsons was the sociologist of capitalism subsequent to the inception of the free competition era. The social agency has a crucial meaning if it promotes a positive function for the social system, and it is a conditioned situation for the agency, because it is entrapped in the ideological cage of the "role" (De Leonardis, 1976).

The difference between Parsons and Weber is evident. The German sociologist promoted the free-trade ideology of traditional liberal thought that strayed from predefined models. Parsons, on the other hand, thanks to having dealt with the competitive structure, promoted the ideology of the planning State - a State that intervenes in guaranteeing the principal aim of the social system: the society and its ramifications are subsumed by the same system and by the supremacy of the "function." What is evident is the progression from an individual perspective-in which the object is the social actor and his/her role-to a universal one that highlights the structural and environmental parts of the social system, no longer in a microsociological perspective, but a macro-sociological one. Indeed, the sociological analysis no longer emphasizes the social project and its several alternatives represented by the popular pattern variables, but rather the larger sub-systems as features of the social system with their functions. Subsequent to Parsons's work, the political sub-system must fulfil the function of achievement of the aims of the social system. In the political sub-system, for European researchers, the State generally has a central role in the entire political system. Parsons, in step with North American political thinkers, reduces analysis of the "political" to the phenomenology of power: in particular, he emphasizes the dissemination of power in a pluralistic vision of society, where several institutions operate. He does not, however, claim that the pluralism of contemporary society is given by the current interventionist power, or by the specific "welfare state" form or the social state, a matter that is generally played down in functionalist North American sociology.

\footnotetext{
${ }^{4}$ The author emphasizes that Parsons's theory, in its effort to be globally relevant, is the best reproduction of current society: it is a representation of the control of monopolistic capitalism on empirical reality. It is possible to deduce Parsons's descriptive quality and compare it to Merton's views. The latter is not able to formulate a general theory that has long-term relevance.
} 
His analysis, on the contrary, highlights all the exterior aspects of the political; that is, the dissemination of the "power," for several reasons. It is not always assumed, artificially, in a fixed quantity that is possible to transfer in more or less defined doses from one center to another, without its quantity changing. Again, it is not particularly important to determine the real origin of the power or of its dissemination. This investigation, however, leads to the identification of a real historicalsocial category; that is, the State as the main representation of political organization and one of the most fundamental sources of power. Its phenomenology is analyzed from a pluralistic approach that aims to observe the structure of the market and the division between the economic and political spheres in Parsons' comparison of power and money. This analysis is supported in the era of advanced capitalism, in the analogy between political interests, exemplified in the concept of power, and economic interests, exemplified in the concept of money (Parsons, 1969).

Although he subscribed to a precapitalistic, traditional "liberal" vision, in a strange way, it is clear that Parsons' theory on the social system is in line with a sociological theory suited to the era of advanced capitalism, in terms of both a juridical understanding and institutional organization. Indeed, his "liberal" vision has two evident theoretical limitations: in the analysis of the law, he underlines the State monism (while he does not mention the State, it is central to the description of a Liberal State or rule of law) and normativism (moreover not appreciated). Today, this interpretation promote the use of the functionalist approach to analyse the exploitation of human and natural resources and the maximization of profit through the validation of the categories "function" and "profit."

While a more thorough analysis of the "welfare state" 5 in its traditional form ameliorates these limits, it is necessary to realize that this criticism of Parsons stems from his theory and his "culture." This criticism, thus, makes use of categories that are foreign to North American thought (in sociology and in political science): for instance, the State doctrine, according to European political philosophy, does not highlight the genetic links between causes and effects, and studies the pure morphology of the fact, ordering their components to allow for a satisfactory analysis.

\subsection{Merton's Functionalism: The Category of Success}

Merton developed a deviant behavior theory, using Durkheim's theoretical schemes as a starting point. According to the North American sociologist, the best analysis of a social problem involves a distinction between three things. Firstly, in a social

\footnotetext{
${ }^{5}$ This analysis is typical of legal and political sociology that studies the "welfare state" in terms of its nature, interventionism, inspection of the social organization and creation of several resources, but also as the distributor and supplier. From this point of view, it is important that the organizational dimension of the State and of the law that structuralism seems to conceal, is different from contemporary German structuralism (see Luhmann), which thoroughly and elegantly analyzes the State and the contemporary institutions.
} 
system, there are specific cultural goals and ambitions based on values typical of a specific "cultural structure" (Merton, 1970). Secondly, there are the "rules" that social actors might legitimately use for the achievement and fulfilment of their goals. Finally, there are elements, generated by the so-called institutional instruments, which are the product of the conciliation of the instruments for the fulfilment of goals, whilst observing the rules. According to Merton, if there is conflict among these three variables, deviant behavior could result in individuals or social units in a given social system.

The cultural structure serves the goals to be achieved: this structure might call for similar goals for everyone in the social system, or different ones. According to Merton (in the North American social system), for the general population, success is pre-eminent, especially economic success (Merton, 1970). The consequences of this goal for the members of the "inferior" classes-who have fewer opportunities for access to institutionally approved instruments-is anxiety and frustration.

According to Merton, it is the gap between the instruments and the goals (with the resulting tension) that causes diminished diligence in these individuals with reference to the goals required by the values of a given social system or the instruments institutionally permitted. This, in turn, might lead to a lack of standards that could result in several forms of deviant behavior in such a society. Depending on the particular case, it could diminish approval, bring dissent, and frustrate the cultural goals or instruments (institutionalized, according to the scheme of norms, since, for analytical convenience, "institutionalized instruments" and "rules" are distinguished as a unique category-the category of "instruments" referred to in the social structure of the analyzed system).

\subsection{Conclusions}

It is clear that traditional functionalism is a largely obsolete philosophy of a bygone era, of a false lost paradise that has killed itself with the new anthropology of debt (everyone is born, not as a citizen, but as a borrower) and with the exploitation of natural resources in the name of profit.

Nature, work, capital: these three factors of production, according to the "principles" of traditional political economy, as they are so smugly defined, consume their productive power in the crush of the first two factors and in the concentration of wealth in the hands of a few people.

Already reduced to an "ideology," the functionalist theory, in the concept of function, grasped the meaning of what works, of what is useful and of what has application. Therefore, in Parsons' hyper-socialization, everything is about what can be applied. The social system, as mechanistic engineering of the systemic model, therefore becomes the new machine to destroy. In opposition to the theoretical world of functionalism, it is time for a new sociological imagination to provide a new theory, both relevant and sustainable. 


\section{References}

Barber, B., \& Hirsch, W. (Eds.). (1962). The sociology of science. New York: The Free Press.

Cerroni, U. (1976). Introduzione alla scienza sociale. Roma: Ed. Riuniti.

De Leonardis, C. (1976). Economia e stato sociale. In Per la critica della teoria strutturale-funzionale. La Nuova Italia: Firenze.

Ferrarotti, F. (1960). L'intento di Talcott Parsons: dalla «teoria dell'azione» al «sistema sociale». Rassegna Italiana di Sociologia, 1, 7-21.

Gallino, L. (2014). Dizionario di sociologia. Torino: UTET.

Habermas, J. (1970). Logica delle scienze sociali. Bologna: il Mulino.

Hempel, C. (1959). The logic of functional analysis. In L. Gross (Ed.), Symposium on sociological theory. New York: Harper \& Row.

Izzo, A. (1974) (ed.). Storia del pensiero sociologico. I. Le origini. Bologna: Il Mulino.

Merton, R. M. (1970). Teoria e struttura sociale (Vol. 2). Bologna: il Mulino.

Nagel, E. (1968). The Structure of Science. London: Routledge.

Parsons, T. (1965). Il sistema sociale. Milano: Comunità.

Parsons, T. (1969). Politics and social structure. Glencoe: The Free Press.

Parsons, T. (1970). La struttura dell'azione sociale. Bologna: il Mulino.

Statera, G. (1974). La conoscenza sociologica. Napoli: Liguori. 


\title{
Chapter 3 \\ Environmental Sustainability \\ and the Evolution of Capitalism
}

\author{
Uliano Conti
}

\subsection{Origins and Horizons}

The concept of environmental sustainability is multidisciplinary, and combines historical, sociological, economic, and philosophical dimensions. In Europe, during the early decades of the nineteenth-century, with its sudden and far-reaching industrialization, critical issues emerged as a result of exploitation, pollution, consumption of natural resources, and unsustainable economic growth. In general terms, sociology was born in the nineteenth-century as a pathogenesis of the modern world, as a discipline that co-evolved with the onset of social, health, and environmental problems resulting from industrialization (Lovejoy, 1948; Weber, 1904-1905).

The capitalist anarchism of the first entrepreneurs led the British Parliament, for example, to deal with the problem of how to prevent worker exploitation before tackling other issues - such as environmental resources as well as the social conflict—which had put a brake on economic growth. Life inside the factory and life outside it were closely connected: if the conditions of capitalist work and growth changed, the surrounding social and environmental context also changed (Horner \& Cousin, 1838; Marx, 1867-1894). Since the earliest decades of the industrial revolution, a relationship emerged between capitalist industrialization and the environment. For example, Villermé (1840) demonstrated how intensive labor exploitation led to a decline in health and life conditions, as well as to premature deaths.

According to de Tocqueville (1835), because it was unsustainable, the consequences of the emerging capitalist economic growth would be dire. During the twentieth-century, Western citizens were increasingly affected by factors such as the warming of the oceans, the "greenhouse effect," and the progressive reduction of

\footnotetext{
U. Conti $(\bowtie)$

University of Perugia, Department of Philosophy, Social Sciences and Education,

Perugia, Italy

e-mail: uliano.conti@unipg.it
} 
biodiversity, all of which emerged as growing problems. In the second post-war period, an unprecedented economic growth of the productive forces was witnessed in the West. However, this growth was accompanied by social inequality and other effects on the environment (Lovejoy, 1948).

To formulate a general view of capitalist growth, Kondratiev (1935) considered the long-term trends of capitalism, and he identified the following economic phases (or cycles): the Industrial Revolution (from 1771); the Age of Steam and Railways (from 1829); the era of steel, electricity, and heavy engineering (from 1875); the era of oil, automobiles, and mass production (from 1908); and the era of information technology and telecommunications (from 1971). Considering the changes from one cycle to the next, it is clear that the heaviest environmental impact resulted from the first four cycles, the effects of which are still visible today. Contemporary society is in the sixth wave of Kondratiev's phases, a cycle in which change is much more sudden and rapid than in preceding ones. Thanks to technical evolution, however, it is possible to produce less and less pollution, and thus have a progressively lower impact on the environment. According to Wallerstein's perspective (Hopkins \& Wallerstein, 1997), where the idea of Kondratiev's cycles were explored, from the sixteenth-century onwards, the capitalist world economy (also called the "world system") took shape as an evolving complex. A phase of expansion began in 1945 and culminated in an historical period that lasted from 1967 to 1973; it was the phase that had the greatest impact in environmental terms.

According to this initial concept, capitalism was the transformative engine of the world, a conquering driving force that modified everything around it: capitalist production and consumption modified the environment and altered the balances of nature. It was commonly accepted, in the twentieth-century, that capitalism changed the environment. The metaphor of the myth of Oedipus was used to describe these characteristics (Demichelis, 2018): like the Greek mythological character, twentiethcentury capitalism is a competitive and acquisitive power; it is always conquering and expanding. Capitalism and the analysis of the means of production thus lend themselves to an Oedipal interpretation of society.

For the Oedipal individualist, the world is a landscape that should be dominated by man. For the oedipal-acquisitive homo faber, the world is an environment to be rationally modelled, according to his own will. Societies with these characteristics stimulate the competitive impulse to conquer and modify the environment and its ecosystems. People rely on themselves and their efforts, and on competition. The Oedipal society, conquering and competitive, is an affirmation of the human will. In the twentieth-century, the category of instrumental rationality (Touraine, 1997) materialized, and was embodied by the concrete human capacity to modify the surrounding world. Instrumental rationality presides over the areas of human action linked to the rationalization of the industrial and economic world and living environments: it is the category considered as the basis of rationalized industrial production. 


\section{Sensitivity and Awareness}

Since the expansive phase (1945-1973), environmental sensitivities and awareness have increased in Western societies. From the expansive phase of capitalism, there are three concepts that acquire relevance in relation to the environmental issue, namely growth and its limits, the human being and his place in the ecosystem, as well as risk. Firstly, the problem of the finiteness of natural resources for economic growth emerged. Towards the end of the 1960s, the notion of Gross Domestic Product was questioned, since this indicator did not consider the costs of pollution or environmental degradation (Boulding, 1966). As early as the beginning of the 1960s, the danger of chemical substances, used, for example, in agricultural and industrial production (Carsons, 1962), was brought to the attention of the public. The cultural climate of 1968, especially in Anglo-Saxon countries, was also reflected in environmentalist terms, and on 22 April 1970, the first Earth Day was held, a sign of the collective awareness of the ecosystem's problems.

The 1970s also witnessed the ushering in of activity by environmental movements such as Greenpeace. During the 1970s, there was a proliferation of scientific analysis and original interpretations on growth, its limits, and the social, economic, demographic, and environmental risks of endless development (Forrester, 1970). The concept of being human and what man's position in the world is also changed. The relationship between human beings, society, and nature was redefined: human beings and the surrounding environment are linked to each other; human beings are irremediably linked to the fate of the ecosystem (Bateson, 1979).

Towards the end of the 1970s, confronted by a capitalist system that showed its potential for the destruction of ecosystems, the principle of responsibility as a guide for action was proposed (Jonas, 1979). Indeed, a new ecological paradigm developed from the awareness that human beings are not at the center of the world, but merely one of its many components. This led to the analysis of the unexpected consequences of economic growth - from the acknowledgment of the limited number of natural resources, to the superiority of natural biological laws over scientific research (Catton \& Dunlap, 1980).

A succession of social, environmental, and economic crises led to the emergence of the concepts of risk and of risk society. Natural disasters - tragic events linked to incidents in the field of industry and energy - make capitalism and human growth not only a factor of environmental degeneration, but also of destruction and death (Beck, 1986; Luhmann, 1991).

This second concept brought an increasing awareness of the capitalist growth that had developed during the second half of the twentieth-century. The idea of environmental sustainability introduced by this vision of capitalism had been largely ignored by Western governments. There are, in fact, numerous environmental crisis fronts, which are visible to everyone, from the greenhouse effect to urban pollution. Sustainability has not acted as a bulwark against capitalist growth. From this perspective, environmentalism is not only to be understood as a set of problems and as a social movement for environmental protection-on the contrary, thanks to 
technical and scientific progress, capitalist production now has less of an impact than it did in the past. The evolution of capitalism - thanks to scientific progresshas allowed us to reduce the environmental impact, for example, with the adoption of renewable energy sources or with the use of electric cars. Capitalism creates value, goods, and services in an ecological way. Thus, environmental sustainability corresponds to the evolutionary form of capitalist production and consumption. If, on the one hand, environmentalism tries to present itself as being opposed to acquisitive capitalism, a form of production that disrupts and pollutes the natural environment, environmentalism itself is a consequence of the evolution of capitalism, and a premise for its continuing success.

\subsection{A Society of Consumption and Waste}

Since the 1970s, the consumer society has been, first and foremost, a society where the consumption of goods and services takes priority, not their production. Secondly, productive work has progressively lost social significance, and over the decades, thanks to technological progress and the competition of globalization, problems related to the lack of work and the waste of human resources have emerged in the West (Baudrillard, 1970).

Capitalist changes in production and employment have contributed to a shift in the employment system towards greater flexibility. The capitalism of flexibility, the increasing precariousness of work, as well as the mobility of biographical paths have corroded the nature and ethics of work of twentieth-century origin (Klein, 2007; Sennett, 1998). Work identity has become less relevant in defining people's identity (Bauman, 2003). People have fragmented biographical experience, and their expectations for the future have waned. In this sense, capitalist economic growth does not only affect natural resources, the environmental ecosystem, but also transforms human anthropology, and the human being is the most wasted and abused resource. Indeed, the primary natural resource to be affected is people. Also, with technological progress, lack of work and youth unemployment have emerged as social problems, as reflection of a waste of resources.

This shift corresponds to the social transition from the work ethic to the consumption aesthetic (Bauman, 2005) - to the social passage from the myth of Oedipus to the myth of Narcissus. Narcissism is the conceptual category forming the basis of the logic of consumption and appearance. For the narcissist, the world is a mirror of his own desires. The society of narcissism is a society of individual consumption; of people consuming goods and services, who increasingly live alone and spend more than families do. The metaphor of narcissism reflects the drift of society that is characterized by a weakening of social ties, that risks reducing society to an aggregate of individuals - consumers (Cesareo \& Vaccarini, 2012). The single person earns more, saves more, and at the same time produces more refuse and wastes more, compared to what happens in families or other social groups. 
The culture of narcissism opposes the twentieth-century oedipal-acquisitive culture (Lasch, 1979; Secondulfo, 2011, p. 54). Narcissistic capitalism does not consider the environment as one of its problems. For such people, the priority is to spend and consume, and environmental problems are an unwanted, secondary effect, not just of the production of goods, but particularly the consumption of goods and services. The environment is not considered to be a social problem-it is just consumed, as a human product. Furthermore, the 1970s and 1980s marked a turning point in the relationship between capitalist growth and environmental sustainability. On the one hand, globalization, based on the delocalization of production, has contributed to advantages for countries like Brazil, India, and China, yet at the same time causing an explosion of environmental problems in these countries, where global manufacturing production is concentrated. Concurrently, finance capitalism glorifies the role of global finance that produces value, regardless of the so-called real economy. Financial capitalism maximizes value, both when extracted from people and when derived from environmental ecosystems; it is based on finance and political-economic deregulation (Gallino, 2011).

Neoliberalism, deregulation, and productive delocalization are the basis of the need for continuous economic growth, which has contributed to environmental problems. Since the 1980s, the tools of economic management and the progressive deregulation of financial systems have intensified risk as a value, and contributed to the transition to capitalism of unlimited debt.

Risk is exalted as a value (Beck, 1986; Magatti, 2009; Stiglitz, 2010). People experience it with disempowering fatalism. Twentieth-century instrumental rationality has deteriorated into a mere unregulated speculative strategy, into pure market, into an extreme fulfilment of unbridled desire for rapid enrichment. Environmental problems are endured with fatalism, as something that is inevitable, an ineffable fate. Financial crises, such as that of 2008, are systemic crises; that is, they are economic, social, and environmental. In narcissistic and fatalistic societies, economic-financial actors take dangerous risks and rely on luck: the environmental problem becomes a "dice game" with fate. It seems that global actors, from multinationals to states, rely-since scientific research has now shown the anthropic impact on ecosystems — on fate (Caillois, 1958).

\subsection{Evolutions}

In Kondratiev's fifth cycle, as well as in the current one, the sixth cycle of capitalism or the Network economy (composed of the Internet of Things, 3D printing, robotics, virtual reality, apps, artificial intelligence, machine learning, Big Data), it is possible to generate value, without polluting the natural environment as much. It is no longer the human being, producer, Promethean, who produces value, modifies the natural environment and pollutes, but it is technology, to which everything is delegated, that produces value and changes the natural environment. Technology can create life (Demichelis, 2018, p. 13). In the Factory-network, every human being 
connected to the Network-whether as a user of social networks and apps, as a user of online buying services, required to transfer personal data and information, or as a worker using email and platforms - contributes to generating value with his clicks, ensuring that habits, opinions, and knowledge, one's attitudes and lifetime, one's preferences and relationships, are engaged in an effort to value, design, produce, distribute, and advertise goods and services (Demichelis, 2018, p. 16).

The algorithm is the key through which the Net's platforms can perform the function of delegating human activities to design, produce, distribute, and advertise goods and services. The delegation of production and control (3D printing, robotics, Internet of Things); of distribution, learning, and knowledge (machine learning and artificial intelligence); interaction and relationship (apps, Big Data) to technology is the heart of techno-nihilist capitalism (Magatti, 2009), a system born and evolving thanks to neoliberalism in Western economies and economic policies. The gap between the rapid evolution of technical potentialities and the profoundness of economic transformations and people's living and cultural conditions is a sign of the unsustainability of an endless economic growth, both in social and in environmental terms.

Contemporary capitalism seems to present, thanks to technical and scientific progress, the possibility for people to see their wishes (which were previously illusory or fantastic) fulfilled. The environmental problem, today, is part of this capitalist cultural structure.

In capitalism, oedipal, narcissistic, and other dimensions coexist. Capitalism does not merely create things; it modifies the world and its landscape, as was the case in the twentieth-century. It does not restrict itself to merely mirroring the individual consumer lost in the consumerist reflection of their own desires, but it is also an anarchical agent of transformation of reality and human life. The contemporary capitalist model not only changes nature, it creates it.

Capitalism creates nature; it has the power, thanks to techno-scientific progress, to create life. Contemporary capitalism, scientific research, and technical progress redefine the idea of life and humanity; they can transform and redefine them thanks to genetics, artificial intelligence, and learning machines. The environmental context in which human beings live thus emerges as a bond, as a link to the concreteness of the history of humanity. Pygmalion's capitalism has the ability to redefine the conditions of existence of human beings on earth, of the very idea of society as a form of coexistence. In this perspective, the natural environment is an identity and cultural anchor of the human in his very essence. Contemporary capitalism is the capitalism of Pygmalion, the sculptor artist who creates works that are more real than reality and who gives life to illusion (Demichelis, 2018). 


\subsection{Conclusions}

The environmental demonstrations of young Greta Thunberg have caught the attention of the major international media, as well as of the European political, cultural, and religious world. Thousands of very young people demonstrate every week in defense of the environment and to help promote eco-sustainable behavior. The Fridays for Future social movement represents a sociological sphere of increasing interest. In this perspective, the environmental problem is unsolvable without a complex vision supported by political-economic and cultural tools, in relation to the evolution of capitalism.

In other words, the protection of non-renewable resources, the green economy (based on clean energies, as well as sustainable consumption and local production systems) should be the evolution of a capitalism capable of redefining and transforming human life and society into their founding dimensions. Environmental protection requires not only an adequate political, economic, and cultural context, but also needs an in-depth understanding of the evolution of the capitalist system and its transformative power.

This understanding is based on the integration of economic policies to manage responsible development aimed at protecting non-renewable resources. The welfare system - founded on the responsibility of states, families, and people — has emerged as a field of ecological reconversion of everyday consumer behavior, as well as stable or temporary occupations that are rich from an economic and formative point of view, and which support policies for families and lower income groups that contribute to sustainable and responsible consumption behavior.

Democracy - as a policy of listening to social issues, associations, the world of volunteering, as well as civil society-thus becomes a counter-movement or moral actor (Touraine, 2013), and should promote the rights of people against groups oriented solely toward their own profit. After the industrial society, and also the postindustrial one, a post-social situation was formed, but the new actors, who can no longer be social, and who are "more moral," can also establish themselves on the scene (Id.). The economic system has been reduced to seeking the greatest profit, as do the actors who make an appeal for human rights and respect for people.

Capitalism is an economic (but, also ideological, cultural, and political) system of production and consumption, and has taken the environmental issue on board. Goods and services, whose production and consumption have strong environmental impacts, are replaced by "green" goods and other services-always, however, within a capitalist logic: profit is the objective of economic activities. A critical rethinking of the relationship between economy and everyday life places the human being at the center of social reflection. The transformation of the relationship between the economy and human beings, intended as the first resource to consider, can only take place within a new political, cultural, and economic paradigm.

The European Union has traditionally paid attention to this issue, as stated, for example, in the Charter of Fundamental Rights of the European Union (CFR): economic activity is functional for human beings. The roles of citizen, worker, and 
consumer, from this perspective, do not separate people from their connection with nature. The ecosystem includes all the dimensions of human coexistence, including productive and working ones. A holistic view of the different fields of human activity favors a better understanding of the relevance of the natural environment and its role in human life and societies. A fragmented view of human activities - a vision that separates work, consumption, everyday life, and nature-prevents people from appreciating their potential in relation to improving living conditions on earth.

The holistic view of the relationship between capitalist economic growth, human beings, and the environment does not hide any of these components. The holistic vision combines sustainable development with benefits for people and the natural environment through economic growth. To accept a holistic view, the objective must be replaced: in this perspective, the first objective is not money, but the human being.

The reductionist view does not favor an understanding of the relationship between capitalist economic growth, human beings, and the environment. The reduction of environmental problems to one of these components risks denial of the profound interconnection between all of these aspects. Without a new political and cultural paradigm, production, consumption, risk for financial gain, as well as exploitation of people will continue to be the drivers of economic activities. Rethinking the place of the human being on earth, and promoting (in Western and Eastern societies) normative behavior deriving from environmental sensibility, as well as living with awareness of the roles of workers, consumers, and savers, represents an opportunity for the environmental protection of our ecosystem.

\section{References}

Bateson, G. (1979). Mind and nature: A necessary unity. New York: Dutton.

Baudrillard, J. (1970). La société de consommation Ses mythes, ses structures. Paris: Éditions Denoël.

Bauman, Z. (2003). City of fears, City of hopes. London: Goldsmiths' College. Centre for Urban and Community Research.

Bauman, Z. (2005). Work, consumerism and the new poor. Maidenhead: Open University Press.

Beck, U. (1986). Risikogesellschaft. Auf dem Weg in eine andere Moderne. Frankfurt am Main: Suhrkamp.

Boulding, K. (1966). The economics of the coming spaceship earth. In H. Jarret (Ed.), Environmental quality in a growing economy. Baltimore: Johns Hopkins University Press.

Caillois, R. (1958). Les jeux et les hommes: le masque et le vertige. Paris: Gallimard.

Carsons, R. (1962). Silent spring. Boston: Miffin.

Catton Jr., W. R., \& Dunlap, R. E. (1980). A new ecological paradigm for post-exuberant sociology. American Behavioral Scientist, 24(1), 15-47.

Cesareo, V., \& Vaccarini, I. (2012). L'era del narcisismo. Milano: FrancoAngeli.

de Tocqueville, A. (1835). Memoire sur le pauperisme. Cherbourg: Société académique de Cherbourg.

Demichelis, L. (2018). La grande alienazione. Narciso, Pigmalione, Prometeo e il tecnocapitalismo. Milano: Jaca Book.

Forrester, J. W. (1970). World dynamics. Portland, OR: Productivity Press.

Gallino, L. (2011). Finanzcapitalismo. La civiltà del denaro in crisi. Torino: Einaudi. 
Hopkins, T. K., \& Wallerstein, I. (Eds.). (1997). L'era della transizione. Le traiettorie del sistemamondo 1945-2025. Trieste: Asterios.

Horner, J. M., \& Cousin, V. (1838). On the state of education in Holland, as regards schools for the working classes and for the poor. London: John Murray.

Jonas, H. (1979). Das Prinzip Verantwortung. Versuch einer Ethik fur die technologische Zivilisation. Frankfurt am Main: Inser Verlag.

Klein, N. (2007). Shock economy. L'ascesa del capitalismo dei disastri. Milano: Rizzoli.

Kondratiev, N. D. (1935). The long waves in economic life. The Review of Economics and Statistics, 17, 105-115.

Lasch, C. (1979). The culture of narcissism: American life in an age of diminishing expectations. New York: Norton.

Lovejoy, A. O. (1948). Essays in the history of ideas. Baltimore: Johns Hopkins University Press. Luhmann, N. (1991). Soziologie del Risikos. Berlin: de Gruyter.

Magatti, M. (2009). Libertà immaginaria. Le illusioni del capitalismo tecno-nichilista. Milano: Feltrinelli.

Marx, K. (1867-1894). Das Kapital. Kritik der politischen Ökonomie. Hamburg: O. Meissner Verlag.

Secondulfo, D. (2011). Per una sociologia del mutamento. Milano: FrancoAngeli.

Sennett, R. (1998). The corrosion of character. The personal consequences of work in the new capitalism. New York, London: Norton.

Stiglitz, J. (2010). Bancarotta. L'economia globale in caduta libera. Torino: Einaudi.

Touraine, A. (1997). Pourrons-nous vivre ensemble? Égaux et différents. Paris: Fayard.

Touraine, A. (2013). La fin des sociétés. Paris: Seuil.

Villermé, L. R. (1840). Tableau de l'état physique et moral des ouvriers employés dans les manufactures de coton, de laine et de soie. Paris: Jules Renouard et C.

Weber, M. (1904-1905). Die protestantische Ethik und der Geist des Kapitalismus. Tübingen: J.C.B. Mohr. 


\title{
Chapter 4 \\ The Thought of Zygmunt Bauman as a Key for Introducing a New Social Theory
}

\author{
Paolo Corvo
}

\subsection{Introduction}

Bauman has been a teacher for several generations of sociologists and certainly also for mine. In the academic world, it is not necessary to visit a teacher personally to identify him as a teacher. It is more than enough to have a long-distance relationship, with intense and frequent readings of his writings and interviews. I was privileged to meet Bauman in Milan in the summer of 2015, at the Milanesiana. After his intense and passionate lecture on the effects of globalization, I invited him to the University of Gastronomic Sciences in Pollenzo. With great courtesy, he told me that he would think about it and that he knew our university. I did not want to insist; it seemed only right to respect such an intellectual who, despite his advanced age, had such a bright mind. Some in the audience were not as considerate, harassing him with requests for autographs and photographs. I found them irritating, but Bauman was unruffled, and always replied with elegant kindness.

From these traits we can see the greatness of the person he was, always available and cordial, in perfect harmony with his way of thinking and writing. Bauman changed the relationship between the intellectual and the public, thanks to his colloquial style-his ability to make complex concepts simple. Another great attribute of the Polish sociologist was his ability to intervene, effectively and incisively, in the fundamental problems of a globalized society.

Of course, he did this without ever renouncing to the Weberian authenticity, and without fear of taking a clear position. In a society under siege, the sociologist cannot ignore the sufferings of individuals and humanity; he cannot fail in his task of defending discarded lives - the poor, the elderly, and immigrants. And Bauman achieved this with creativity and sociological imagination. He changed our way of

\footnotetext{
P. Corvo $(\bowtie)$

Università degli Studi di Scienze Gastronomiche, Bra, Italy

e-mail: p.corvo@unisg.it
} 
understanding sociology, creating the conditions for a new social theory, with an innovative language, method, and argument.

It is in this vein that, in Modernity and the Holocaust (Bauman, 1989), he overturned the usual interpretations of Nazism, revealing them to be the triumph of modernity, with the coldly rational use of technologies and the obfuscation of individual conscience in the name of a superior system.

His analysis of globalization is also original, because it concerns the effects thereof on individual lives, as well as ethical considerations rather than economic and financial dynamics. The concept of liquid society made Bauman famous far beyond the worlds of academia and science. This term refers to a society in which "the situations in which people act change before their ways of acting are even able to consolidate into habits and procedures, [...] the liquid character of life and that of society feed and reinforce one another" (Bauman, 2005, p. VII, Author's translation). The Polish sociologist defines "creative destruction" as the typical way liquid life unfolds, because creation destroys other forms of life and human beings. The real issue at stake is temporary salvation from elimination or "ending up in the waste."

Furthermore, the consumer society engenders a lack of satisfaction, which elicits an impulse for perpetual purchase of goods. The satisfaction of every need and desire is realized in such a way that it provokes new needs and new demands. In this pervasive mechanism, the individual appears to be in great difficulty, not least because he tries to solve problems on his own, whereas he or she actually requires the involvement and support of society. This is a ruthless yet realistic analysis of contemporary Western society, which, even with high levels of economic wellbeing, has not achieved true happiness.

\subsection{Consumption and Work}

According to Bauman, consumption is closely linked to destruction, because objects are either exploited physically until their complete annihilation, or they wear out, becoming unusable, losing charm and any ability to excite attraction or desire (Bauman, 2008). Moreover, people's needs are unstable and insatiable, and lead to the immediate abandonment of consumption objects, in full harmony with the liquidity of their lifestyle context. The accumulation of goods is a heavy burden rather than a valuable load.

For Bauman, in the liquid-modern society, there is no space for planning and long-term investment. In other words, the deferment of pleasure is deprived from the gratification that it formerly had in terms of prudence and reasonableness. This scheme is functional in the mechanism of turbo capitalism production, since the consumerist economy is based on the replacement of goods, and its prosperity is directly proportional to the amount of money that is exchanged. Money passes from hand to hand every time that consumer products are carried to the landfill. 
These phenomena should make us reflect on universal themes such as justice and solidarity. However, they also concern happiness, because every person should at least have the chance to be happy and to hope for a better future, for prosperity and freedom. But in an unfair reality, being happy is difficult, because-as was already argued by the ancients - it is impossible to achieve happiness to the detriment of another individual or many other individuals. There is no happiness without justice.

Two main phenomena mark the current socio-cultural context and have increasingly been interacting with each other: the processes of globalization at the macrosocial level and the dynamics of individualization at the micro level. It should be noted that global reality, as its name suggests, invests in all parts of the world, albeit in radically different ways. On the other hand, the society of individuals is widespread, mostly in the "West" - a term implying those countries based on advanced Post-Fordist capitalism and post-modern culture, or in the mature phase of modernity.

Clarification is needed, because some aspects of the subjectivism typical of Western societies derive, as we will see, from a consumerist approach to social living. In other parts of the world, even those that are reaching considerable levels of growth, there are still significant imbalances, and most of the population must solve pressing and urgent problems. As a result, in some middle-income countries such as the BRIC group (Brazil, Russia, India, China, and South Africa), certain phenomena of subjectivism are related mainly to the expanding middle-to-higher classes, at least for the moment. Moreover, some characteristics of globalization call into question the economic welfare and future perspectives of the so-called developed countries, and gradually make their citizens insecure and anxious, for example, about the impact of the economic dimension on the world of production and labor, on the relationship between institutions and businesses, and on personal life and relationships.

Nowadays, even successful companies have been closed and moved to places where the cost of labor is lower. In this way, workers risk losing their jobs overnight, without being responsible for such loss, and with the company claiming no accountability, nor leaving workers any recourse. Formerly, it was possible to organize collective bargaining talks in which companies and trade unions, with the mediation of institutions, at least attempted to find a solution to problems of employment. Today, multinational companies are seldom willing to "discuss," as they can easily release themselves from the pressures of both governments and trade unions, which defend only national interests. As a result, these institutions have lost their credibility, because they are no longer able to guarantee the rights of workers who find themselves unemployed after many years of work and who often struggle to acquire the new skills that would be required to find a new job. Markets are irregular and selfreferential, and require stronger policy and new methods of intervention. The decisions are often taken at the international level, and in that context, mediation might be the answer. At the local level, there might be the opportunity of organizing retraining and professional education programs to support people who are excluded from the labor market. 
In many economic sectors, the prevailing conviction is that the best way to manage cruel international competition involves the diffusion of flexible working. Leaving aside the debate about the effectiveness of flexible working conditions, here we underline its impact on people's lives, especially when it means precariousness and jobs of short duration — very short, one might add — which do not allow for any life planning, even in the medium term. Many factors make it difficult to plan anything regarding emotional life: firstly, the lack of job security; secondly, a realestate market often inaccessible to younger generations not financially supported by their parents; and lastly, a pervasive lack of confidence in the likelihood of change. And even when economic conditions improve, at the age of 30 or 35 years, individuals already have established ways of thinking and living that are related to precariousness. It is very difficult to change this mentality. Moreover, as we will see, this is further nourished by the consumerist model and by a specific communication system.

In addition, personal savings, which represent an investment for the future, are threatened by international financial speculation. This can cause problems for the economies of many medium-sized countries as well as create a dangerous and worrying domino effect on all world markets. Unrelenting problematic factors then force the individual to live only for the present moment, without any specific prospects apart from insecurity, uncertainty, and vulnerability (Bauman, 2000).

Anguish and fear result, and are experienced mainly by people who have fewer socio-economic and cultural resources, who are forced to cling to their territory in order to have some hope for the future. In contrast, those who belong to the upper social classes and to the economic, financial, and cultural elite can take advantage of delocalization, playing freely in the global market and using the flows of capital, goods, knowledge, and ideas to their own advantage. In practical terms, social stratification holds the risk of further strengthening and widening the gap between those who have the proper tools to face the challenges of globalization and those who do not and are therefore destined to suffer its consequences.

\subsection{Liquid Relationships}

Current relationships are brief but intense, consumed in quick succession, according to the dictates of aesthetic space. This consumerist approach to relationships profoundly influences the psychology of individuals, who already have difficulties resulting from the loss of confidence they have in their abilities as a result of globalization. To be "deleted" or rejected by someone involves a loss of self-esteem, and for the most sensitive individuals, can also lead to a profound depressive crisis. The feeling that human beings are reduced to objects is certainly not pleasant, both at the social level and at the individual level, and this, in turn, reinforces feelings of insecurity, fear, and loneliness. It is not only jobs that are precarious, but also friendships and feelings; everything is tremendously liquid, according to Bauman (2000). 
But the individual seems to be embedded in this mechanism that he is unable to control, and extreme individualism prevents him from finding a way out. Neglecting individual interests in order to increase the power of the group and sacrificing present happiness for future happiness do not appear to be attractive or sensible prospects.

Every missed opportunity is a lost opportunity, and this becomes something unforgivable, not easily excusable, and even less defendable (Bauman, 2008). Thus the aesthetic dimension prevails despite its obvious limitations, and the individual fails to find a remedy for his anxieties apart from being dominated by desires and emotions. Increasingly focused on himself, he becomes pre-social on the one hand, because he lives in the moment without involvement or responsibility, and a-historical on the other, because he focuses on the emotional intensity of the moment, regardless of what might have happened before.

Without the protection of society, tradition, and relations, the general Ego is likely to fall victim to its own fragility, as stressed by Beck, who points out that the do-it-yourself biography is simultaneously a "risk biography" and a "hazard biography": it is a state of permanent danger that can degenerate very quickly into a biography of bankruptcy (Beck, 1994). And the feeling of failure cannot be allayed by money and consumption, because the individual is affected in the deepest part of his being; he feels he has failed at life, at producing something valuable, at livingrather than just existing. Existential questions emerge, despite the consumerist spiral and precisely because of it; the individual can meet his own desires and whims, but focuses on the present, forced to look for new emotions in order not to feel excluded and to remain afloat. He has been socialized since he was a child to think that consumption is the true engine of the economy, the most important social right and obligation.

Thus he behaves accordingly, then is regularly disappointed by the continuous chase for and abandonment of sensations, people, activities, and interests. At a certain point, the sense of emptiness becomes unbearable and happiness seems remote, despite the obsessive search for novelty that consumed the individual until that very moment. The paradox is revealed: the excessive individualism, adopted and "taught" by the consumer society, makes the individual less free than he thinks himself to be; he is at the mercy of uncertainty and insecurity. The individual becomes aware of his frailty and stops his aimless race for a moment, searching for alternatives to a situation that no longer holds his fascination, at least not as it did before.

He then desires to have more stable bonds again; to rediscover the pleasures of faithful and sincere friendship; to reconsider the function of social life. Sometimes there is also an attempt to recover, in some way, the "solidity" of an ethical concept or religious view of life and of the world. Essentially, the individual attempts to find his identity — which has been fragmented and weakened - through relationships and in the dimension of community.

This renewed attention to otherness, however, is difficult to find in daily life, because people, companies, and institutions are enveloped by the dynamics discussed above. It is, however, not so simple to make a turnaround and to meet other people who share the same needs and have the same courage to show their 
vulnerability. Hope is thus directed towards free time, when people are more likely to abandon their weekday habits and seek greater authenticity in their behavior and interpersonal relationships. Therefore, free time, holiday, and tourism represent for the individual the kóipós, the time deemed most appropriate for finding a response to the needs of expressiveness and sense, so that the individual can move closer to a happier life (Corvo, 2011).

The effort of individuals in their search for social bonds and community may also consolidate into social groups showing "tribal" traits, characterized by a high degree of uniformity with respect to a topic, product, or "passion" (Maffesoli, 1995). Marketing has understood this trend, and increasingly deals with new market niches, since such individuals are prone to having strong loyalty to a product or a tourist destination, and can belong to several communities at the same time. The "tribes" that feed the market are very different-from lovers of detective stories, thrillers, and mysteries, to enthusiasts of modeling, sports, and music, to collectors of various objects, as well as lovers of virtual games - and all are in search of a sense of belonging to a reality and are willing to spend time and money to obtain it.

It is interesting to note that often the members of these "tribes" only share that specific interest and a yearning for belonging. There are no other common points: the transversality of social class, age, lifestyle, and way of thinking is a common feature, but it does not create barriers to meetings and relationships; instead it frequently constitutes one of the most appreciated aspects. It may be supposed that compared to the membership of other groups, i.e., those considered "strong" because they are founded on elements of politics, religion, or values, "tribes" are more vulnerable or perceived as being less important. However, they can play a significant role in the rediscovery of personal identity, since the "passions" that hold these groups together are chosen freely by the individual, while being shared effectively with others in the context of a group.

\subsection{Desire for Happiness}

According to the authoritative economist Layard (2005), the seven major factors that affect human happiness are: family and relationships, economic situation, work, community and friends, health, personal freedom, and personal values. Family and private life are therefore more important than any other factor that influences a person's happiness. In fact, research carried out in different parts of the world confirms that separation from one's partner is the most important cause of unhappinessmore than unemployment or health problems.

Economists point out that the relational sphere is fundamental to the happiness of human beings, which shows that the possession of material goods might give immediate satisfaction, yet provides limited satisfaction over time. Thus people tend to seek continuous and increasingly intense pleasures in order to maintain the same level of well-being, so that their "subjective" happiness (the self-assessment 
of one's own happiness) remains constant, even if and while their "objective" happiness is increasing.

Socio-cultural constraints cause people to focus their attention on consumerist elements, so a large amount of time is dedicated to the pursuit of monetary goals to the detriment of familial life and health; as a result, subjective well-being is low in comparison to the desired level. Obviously, a reorientation of time management in favor of family life and health would increase subjective well-being.

General research in the economic sector seems to confirm that the secret to happiness for men and women of our time lies in the ability to resist the attraction of consumption and aesthetics, and to prioritize relations and feelings. An individual who lives in harmony with himself and others is also able to enhance his abilities and to succeed in the professional field. Stress, anxiety, and depression, which are caused by an unsatisfactory private life, can reduce the potentialities of an individual, causing a dangerous regressive spiral.

In the last few centuries, philosophers, novelists, poets, and scholars have tried to describe the nature and form of happiness, taking inspiration from scientific disciplines and artistic intuition. The ancients were able to capture the essential aspects of happiness in a very lucid and clear way, and contemporary scholars have entered the debate, drawing on the contributions of human and social sciences. Virtue, knowledge, science, reason, friendship, and wisdom are some of the ways to achieve happiness, according to classical culture. From a sociological perspective, a lot of attention has been paid to the role of feelings in social dynamics, underlining the importance of factors that had not been included in the explanation of mass phenomena for far too long. Recently, many authors have dealt with happiness; for example, Bauman seems to have successfully identified the needs of individuals in a global and hyper-consumerist society, elucidating their ideas, using different methods and approaches.

In his analysis, Bauman (2002) identifies four different meanings of happiness:

1. Objective happiness: used when we are talking about the condition of another person. We tend to correlate the state of the world and the state of the soul (Good Luck)

2. Happiness as a subjective experience: the idea that happiness refers to feelings, emotions, sensations, and states of mind (Pleasure)

3. Happiness as balanced life: based on harmony and focused only on things worthy of being wished for, and which it would be convenient to try (Satisfaction)

4. Happiness as the whole of life, in its totality: characterized by moments of intense happiness, but also by moments of suffering and frustration (Good Life).

Bauman then relates his ideas to Seneca, who explains, in De Brevitate Vitae, the distinction between true happiness and presumed, false, or misleading happiness. True happiness brings pleasure to the happy man but not all pleasures make a man happy (wisdom). Seneca states that if a person wishes to obtain happiness, he cannot trust the advice of the average man on the street. The essential cause of human misery is the incurable transience of human existence, the imminence of the end. And what man evokes in his dream of happiness is Time standing still. Seneca 
emphasizes virtue and wisdom, stating that happiness corresponds to freedom from the fear of death.

According to Bauman, if we asked ourselves to explain people's actions, most of us would reply that they are driven by the search for happiness. In the past, this was not taken for granted: suffering and joy were the real and inevitable destiny of man, and the problem was not how to run from or eliminate suffering, but rather how to reconcile with it. More recently, the problem has become how to transform happiness from a state of rare privilege, a reward for the righteous man, to a universal right of mankind (such as is mentioned in the American Declaration of Independence). This means that individuals are entitled to complain if their need for happiness is ignored, and can rebel if it is not assured. We are involved, therefore, in a perpetual search for a better life than the one we are living a life preferable to that which we have already experienced.

Nowadays, the focus is not on the social relations of the network, but on the ease with which relationships can be demolished; they are as easy to break up as they are to establish. Similarly, it can be said that the economy of consumption is at its best when it is able to reduce the period between use and waste. According to Bauman, this also affects interpersonal relationships: the yearning for attraction consists of the yearning for the beginning of a new attraction. It is difficult to create and maintain an ideal life of happiness in an unstable and changing world, one that is so incurably uncertain. The ideal horizon of happiness is no longer the long term, and in concrete terms, relationships are based on doubtful and uncertain feelings. Thus they become a never-ending source of anxiety-the sort of anxiety that curbs zest and vitality. For this reason, nobody can feel safe, and everybody lives in fear (Bauman, 2002).

\subsection{From Consumer Society to Sustainability?}

According to Bauman, solidarity is different from tolerance: tolerance implies a feeling of superiority to our fellow man, to whom we decide to grant our patronizing acceptance. Solidarity, on the other hand, is what counteracts solitude and the feeling of abandonment; it is not having to rely on one's own strengths alone. It is the yearning to feel like a part of something bigger-to fight for a common cause. Bauman writes that solidarity, far from being a worthless yearning, is actually the driver of change: no one knows, though, if this change is feasible or can ever be achieved (Bauman, 2006).

Bauman wonders what the long-term consequences of a brand new social movement (the very one that is developing before our eyes) would be. We are witnessing an unequivocal alternative: either a new chapter in the history of our planet is beginning, or we are just looking at a big carnival. In fact, we know, says Bauman, what the meaning of carnival is: we need to gather all our forces to get rid of-however fleetingly - all the oppressive rules and routines that surround us, so that everything can simply go back to its previous condition (Bauman, 2007). 
The question we must pose, then, is how likely it is that solidarity will establish itself here and now in our society, and what we should do to ensure that solidarity is even possible. Bauman argues that the sociologist Richard Sennett tried to formulate a redefinition of Humanism to fit our century, and his response was threefold: he speaks about the necessity for a current-day humanist, of informal and open cooperation. Informal, because rules must spring out of the dialogue itself; open, because without predetermined expectations, it is open to whoever wants to partake. Finally, Sennett speaks of cooperation, because we must abandon the dream of seeing ourselves as winners facing a loser. Collaboration enriches everyone, and you can verify for yourself whether this collaboration works or does not (Bauman, 2011).

This is the hope and invitation of Bauman — not an insignificant one, given the importance of its implications. According to him, the situation is way worse than what is perceived by public opinion. The long-term future is being decided in our era, and will affect the next few decades, or even a lifetime (Bauman, 2008).

We are facing a pressing need to guide a process of change; to fulfill the arduous task of reconciling well-being, human progress, and the sustainability of our life on the planet. Will we be able to move from a society of consumption to a society of sustainability? Zygmunt Bauman replies that we need to do it, and that the problem is not whether this is possible, but that the starting point-the consumer society-is incapable of helping us reach this goal. Obviously, however, we do not have any other springboard from which to start. Bauman writes that although he would welcome the emergence of a solution to these problems, he does not anticipate this happening as yet. The society of consumption is hostile to sustainability: people are consuming too much, depleting natural resources, and the crisis of debt is precisely the consequence of the orgy of consumption. Avoiding spending more than we can afford is advice that every grandmother would give. Unfortunately, people seem to have forgotten every alternative system to the model of consumption for escaping this crisis. The only answer that we are offered is the need for growth of the gross domestic product (GDP), so that we can continue to consume more. According to Bauman, however, we must find the route to human happiness in ways that do not imply excessive consumption - the only thing we seem able to do. We should, instead, aim for mutual assistance, because it is the only thing that can make us feel safer (Bauman, 2007).

From a reading of the most important books of Zygmunt Bauman, it is clear that creativity and innovation were foremost in his thought and social activities. We believe that the Polish sociologist represents a fundamental reference for a new idea of sociology —one that could change its paradigms, languages, and methods, and (while respecting scientific discipline) address or engage with the problems of humanity. In particular, it is essential to realize that sustainability could transform lifestyles and consumer behavior. It is therefore eagerly hoped that there will be scholars who will take up pursuit of Bauman's sociological perspectives. 


\section{References}

Bauman, Z. (1989). Modernity and the holocaust. Oxford: Basil Blackwell.

Bauman, Z. (2000). Liquid modernity. Cambridge: Polity Press.

Bauman, Z. (2002). Society under siege. Cambridge: Polity Press.

Bauman, Z. (2005). Liquid life. Cambridge: Polity Press.

Bauman, Z. (2006). Liquid fear. Cambridge: Polity Press.

Bauman, Z. (2007). Consuming life. Cambridge: Polity Press.

Bauman, Z. (2008). The art of life. Cambridge: Polity Press.

Bauman, Z. (2011). Collateral damage. Social inequalities in a global age. Cambridge: Polity Press.

Beck, U. (1994). Riskante Freiheiten. Frankfurt: Suhrkamp.

Corvo, P. (2011). The pursuit of happiness and the globalized tourist. Social Indicators Research, $102,1$.

Layard, R. (2005). Happiness: Lessons for a new science. New York: Penguin Group.

Maffesoli, M. (1995). The time of the tribes: The decline of individualism in mass society. New York: Sage. 
Part II

Methodological Paths and Perspectives for a New Social Theory of Sustainable Development 


\title{
Chapter 5 \\ Sustainability and Sustainable \\ Development Goals (SDGs): From Moral \\ Imperatives to Indicators and Indexes. \\ A Methodology for Validating \\ and Assessing SDGs
}

\author{
Angela Delli Paoli, Felice Addeo, and Emiliana Mangone
}

\subsection{Introduction}

During the last two centuries, societies have become increasingly complex in terms of both relationships and processes. Secularization, rationalization, and, finally, individualization have resulted in transformations in social representations and in the beliefs through which subjects interpret the society in which they live as well as the values by which they orientate themselves. All these processes have led to a redefinition of the relationship between individuals and their environment, producing a sort of "break" (transformation) in rhythms and lifestyles, and affecting people's representation of life and their world. These changes in rhythms and lifestyles lead to a kind of "decline in daily life," a measure of human well-being that goes beyond economic parameters (Addeo \& Bottoni, 2016; Stiglitz, Sen, \& Fitoussi, 2009) and includes aspects relating to the ability of individuals to carry out an activity, their cultural identity and sociability as well as aspects related to their living environment. These changes lead us to reflect on human and social development.

When we talk about development, we usually make reference to economics. However, as is well known, the notion of development is not confined to economic paradigms at all: today when we speak about development, we mean sustainable development - a development process aimed at providing basic environmental, social, and economic services to all the members of a community, without impairing the environmental and social setting in which such services are provided.

This chapter is the result of active collaboration among the authors. In the final draft, Angela Delli Paoli wrote Sects. 5.2, 5.4, and 5.7; Felice Addeo wrote Sects. 5.3, 5.5, and 5.6, and Emiliana Mangone wrote Sect. 5.1.

A. Delli Paoli $(\bowtie) \cdot$ F. Addeo $\cdot$ E. Mangone

University of Salerno, Salerno, Italy

e-mail: adellipaoli@unisa.it 
The existence of effective systems of sustainable services is one of the determinants that ensures that all citizens can participate in social life and can express their individual skills in a civilized and democratic country. This condition is one of three identified by Sen $(1982,1992,2003)$ that is required, but not sufficient, to ensure that financial, social, or territorial barriers do not hinder citizens' essential rights in an ethical and moral logic. Changing contexts, and their greater complexity, have led to the need for consideration of modernizing innovation actions that can provide social responses to the needs of real citizens, to combine resources and maintain quality standards. An extension of rights is, however, accompanied by a decreasing capacity of public funding, thus shifting the attention to cost containment.

The issue of development is evolving today in the direction of sustainable development, commonly defined as the development process in which (despite the presence of many diversified interests) environmental, social, and economic needs are dealt with by matching and integrating three macro-objectives that can explained as follows (Mangone, 2007):

- Economic competitiveness: To reach this aim, the territory must emerge as a leader in certain specific economic activities. Interventions need to be planned to depend on the availability of a number of specific factors, such as specialized production, expertise, and human resources. In agreement with these principles, local governments must take action to enhance the assets of the territory and steer economic development towards activities that have gained a competitive edge on the market.

- Environmental sustainability: Since economic considerations do not constitute the only strengths and weaknesses (of a territory) to be taken into account when talking about local development, we also need to look at other aspects related to citizens' everyday life, such as accessibility and the physical and psychical livability of spaces. The territory must be interpreted not only as the space where productive activities are carried out, but also as a space endowed with a specific "cultural identity."

- Social cohesion and balance: As has been stressed above, a local development strategy must aim at raising the "feeling of belonging to a territory" by building and strengthening consensus and social balance. To this end, the majority of social groups, all of which carry different material interests, demands, and needs, must share values related to fundamental aspects of society in order to promote law and order, thus avoiding conflicts.

These three objectives must be seen as having equal value: the last two objectives should not be obstacles in the way of territorial development; instead, they may act as remarkable boosters thereof. Therefore, a development strategy must be based on an "integrated logic" that can embrace (in a non-contradictory way) the three objectives that determine territorial sustainable development. Because of resistance and overlapping, it is certainly difficult to attain an overall view of these objectives. Therefore local governments must act as political intermediaries, by involving all the stakeholders of territorial sustainable development. The process of sustainable development does not come without conflict between objectives and stakeholders. 
This should induce us to define and share standards suitable for managing and overcoming such conflicts.

The change in contexts has therefore established the need to initiate reflection on innovative actions that have the capacity to provide social responses to the real needs of citizens, and that are, above all, able to combine resources and quality for a sustainability perspective that has an ethical and moral approach to the promotion of social justice (Nussbaum, 2003), and which creates potential for human development (Nussbaum, 2011). It was, indeed, the latter that inspired the United Nations (2015) to build a program of objectives for sustainable development (SDGs) based on a set of indicators that suggest policies and actions that must be implemented by member countries.

The SDGs succeed the Millennium Development Goals (MDGs) as a reference and universal guidepost for transiting to sustainable development in the period 2015-2030. In contrast to the MDGs, these goals are supposed to be universal-applicable to all countries, both developed and developing. In 2014, after a year of intergovernmental work (of what was called the Open Working Group), and after the decision taken at the RIO + 20 Conference, a proposal was put forward in the form of 17 goals, with several targets under each goal, amounting to a total of 169 targets. The proposed goals and targets can be seen as a network in which links among goals exist through targets that refer to multiple goals (Le Blanc, 2015).

The SDGs are built on a three-pillar model of sustainable development that remains ambiguous, with sustainability split into environmental protection, and economic and social development. The SDG dashboard suffers from an insufficiently developed theoretical framework that exposes it to the risk of being too vague and meaningless. Without a conceptual and empirical definition of sustainable development, it risks plunging into meaninglessness at best, and becoming a catchphrase for demagogy at worst, being used to justify and legitimate a myriad of policies (from anti-capitalist reforms to capital-intensive market development). A more elaborate, holistic, and broader conception of sustainable development is therefore required - one that could form the hard core around which policies are built.

The aim of this chapter was to contribute to both sustainability research and policies by presenting an evidence-based theoretical framework of sustainable development based on moral imperatives, a methodology for assessing it, and a procedure for validating it.

Thus, by following an approach that puts human well-being at the center, we suggest a model based on a set of key sustainable development themes and moral imperatives that should guide policy making.

The aim of this study was threefold. Firstly, we aimed to clarify the conceptual and normative framework that underpins SDGs. Secondly, we aimed to suggest a methodology for assessing SDGs that is able to go beyond single indicators, without losing the information on individual moral imperatives and their compatibility with each other. Thirdly, we aimed to validate such a framework, and through it, to assess the performance of European Union (EU) Member States with regard to SDGs. 
This is done in four steps:

1. Starting from the insufficiently developed framework of SDGs, our aim was to investigate such a framework by aggregating indicators, using moral imperatives and key themes.

2. By content validation of the indicators for each thematic priority, we built indices by progressively selecting the more valid indicators by means of a two-stage factor analysis.

3. Indices of moral imperative were then developed, in order to evaluate their validity through a construct validation procedure.

4. A composite SDGs index is developed, and its performance as well as the performance of the moral imperatives and thematic indices in EU member states are evaluated.

Providing guidelines for actions by simultaneously viewing a plethora of indicators can be very challenging. The aggregation of indicators into indexes at different levels and in a single composite measure will facilitate the achievement of a comprehensive assessment of sustainability.

In this way, the study will contribute to clarify the normative context of the assessment procedures, so as to provide crucial tools for political action. The chapter is set out as follows: Sect. 5.2 deals with theoretical and methodological challenges in research on SDGs; Sect. 5.3 presents the research methodology (research design, data collection, and data analysis techniques); Sect. 5.4 presents a framework with three moral imperative or ultimate goals and 13 thematic layers of enabling goals, by content-validating them; in Sect. 5.5, the framework is construct validated, and an SDGs composite index is built, while Sect. 5.6 shows the performance of EU Member States on single and composite indices. Finally, implications and limitations of the study as well as directions for future research are discussed, and conclusions are drawn.

\subsection{Theoretical and Methodological Challenges in SDGs Research}

From a theoretical and methodological point of view, we can distinguish four main approaches in research on SDGs.

A first approach concentrates on the conceptual definition of sustainable development (Delli Paoli \& Addeo, 2019). According to the number of dimensions, or pillars, at the basis of sustainable development, we can distinguish four main approaches to the concept: a one-pillar model, a three-pillar model (Littig \& Grießler Griessler, 2005), a multi-pillar model, and an inter-pillar model (Murphy, 2012, p. 19). The one-pillar model prioritizes environmental and ecological dimensions. The three-pillar model defines sustainable development through an equal balance between ecological, economic, and social development (Diaz-Sarachaga, Jato- 
Espino, \& Castro-Fresno, 2018; Stevens \& Kanie, 2016; Wichaisri \& Sopadang, 2017). The multi-pillar model originates from a growing concern about the three-pillar model, which was considered to have overlooked other pillars of fundamental importance (Dahl, 2012; Littig \& Grießler Griessler, 2005). The inter-pillar model originates from a call for the clarification, conceptually and operationally, of linkages, trade-offs, and synergies among the three pillars, to make them compatible and coherent (Dahl, 2012; Diaz-Sarachaga et al., 2018; Dobson, 2003; Gough et al., 2008; Littig \& Grießler Griessler, 2005), and a need for reframing the threepillar model by considering them as interconnected instead of being isolated or discrete dimensions (Holden, Linnerud, \& Banister, 2016; Kemp \& Martens, 2007; Kemp, Parto, \& Gibson, 2005; Murphy, 2012).

A second approach sees a need to structure the SDG indicators into a coherent framework. Sometimes such frameworks are policy based, using policy documents and strategic goals as a frame of reference. Sometimes they are conceptual or theory-laden, independent of political priorities, and rooted in a model of sustainable development processes (Hák, Janousková, \& Moldan, 2016; Holden et al., 2016; Singh, Murty, Gupta, \& Dikshit, 2009).

A third approach calls for better, more relevant, and valid indicators, and concentrates on indicator quality, on the selection process of SDG indicators as well as their validity, legitimacy, and relevance, i.e., their linkage to indicated goals and targets. This line of research aims to provide a conceptual framework for goals and the setting of targets as well as their operationalization (Burford et al., 2013; Hák et al., 2016; Hák, Kovanda, \& Weinzettel, 2012; Hák, Moldan, \& Dahl, 2007; UNSD, 2015).

A fourth stream of research concentrates on building a composite SDGs index, by aggregating many (100-200) SDG indicators. There are several examples of this approach. In 2015, Bertelsmann Stiftung (BS) and the Sustainable Development Solutions Network (SDSN) devised the composite SDGs Index in order to benchmark the performance of countries on SDGs. The first edition of this study involved 77 indicators and 149 UN member nations, whereas the 2017 edition included 99 indicators and 157 nations (Sachs, Schmidt-Traub, Kroll, Durand-Delacre, \& Teksoz, 2016). This index uses readily available international indicators, giving them equal weight, which is an adequate reflection of the SDGs, since they do not suggest any hierarchy or preferences between the goals. In addition, other studies have provided alternative methodologies to assess SDGs in a composite index (Campagnolo, Carraro, Eboli, \& Farnia, 2015; Delli Paoli \& Addeo, 2019). The well-known problem with this approach, however, is how to weight the different indicators (Costanza et al., 2016).

Another line of research aims to explore the association between sustainable development and its ultimate goal, i.e., well-being. This empirical line of research correlates the dependency of human well-being to the health of ecosystems (Helne \& Hirvilammi, 2015). Operationally, it analyses the correlation between well-being (defined as the dependent variable in subjective life satisfaction scores) and SDGs indicators (as the independent variables) through a regression model (Helliwell, Layard, \& Sachs, 2016). The main methodological challenge here is the subjective 
assessment of well-being based on the individual's perception, which can be culturally biased, making international comparability difficult (Costanza et al., 2016).

Our paper aimed to cover all of the above-mentioned methodological challenges:

1. Starting from the insufficiently developed framework of SDGs, we aimed to group a set of valid indicators under moral imperatives and key themes (see Fig. 5.1). We suggested a framework based on three moral imperatives (human well-being, social justice, and ecological justice) and 13 themes: improving job opportunities; enhancing human capabilities; promoting health; poverty prevention; ensuring equality; promoting justice; fair distribution; intergenerational justice; better community life; mitigating pollution; mitigating climate change;

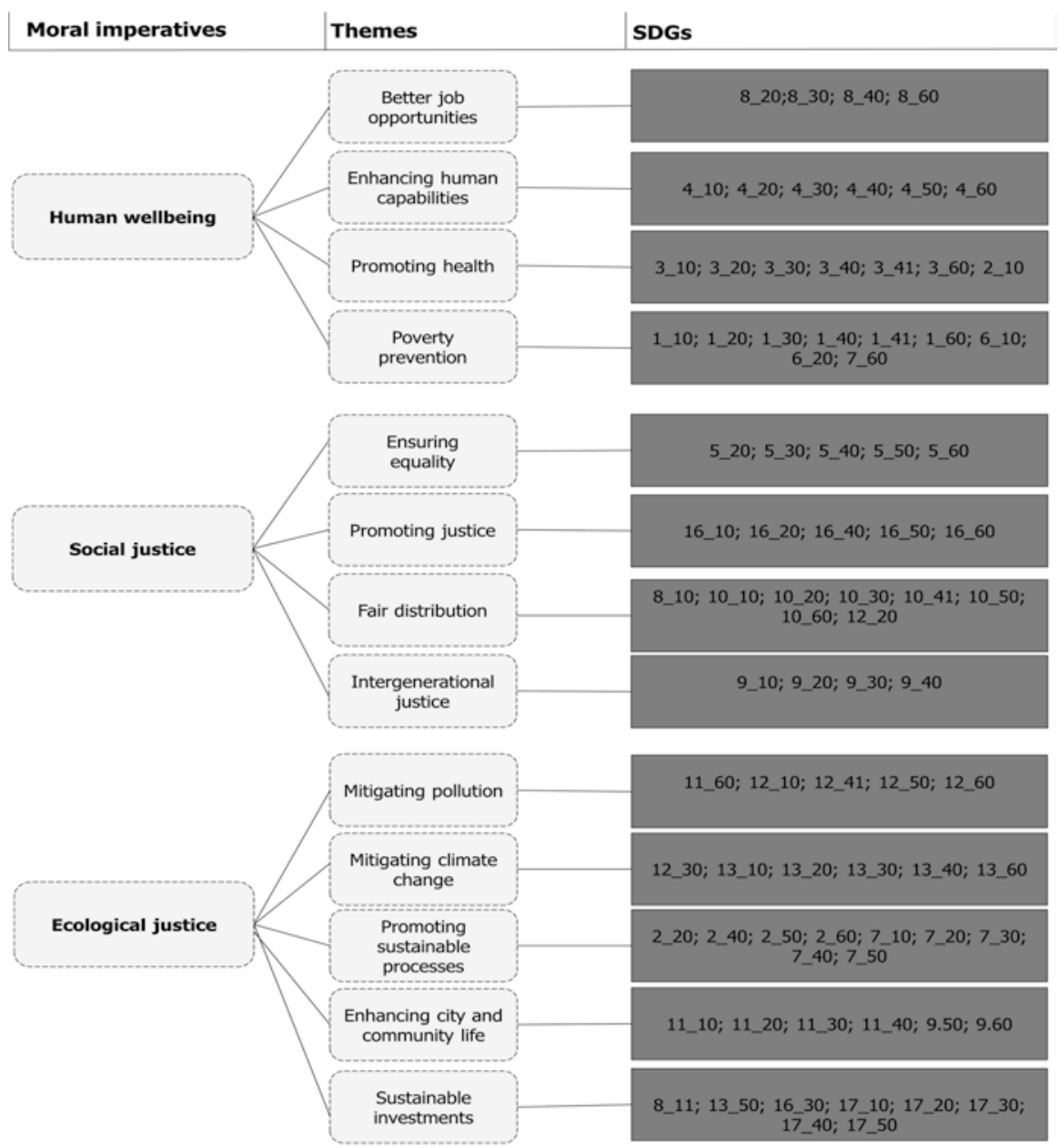

Fig. 5.1 The theoretical framework of SGDs (authors' own elaboration) 
promoting sustainable processes and sustainable investments. This provides a theoretical underpinning for the SDGs.

2. For each theme, we built indices by progressively selecting the more valid indicators through a content-validation procedure.

3. We then built moral imperative indices and evaluated their validity through a construct validation procedure.

4. Finally, after validating the moral imperatives, we built a composite SDGs index and evaluated its performance as well as that of the moral imperative indices of EU Member States.

\subsection{Methodology}

Data were collected from the official Eurostat 17 SDGs set, using the most recently updated source for each indicator. We selected those indicators offering data for at least $90 \%$ of Member States. This criterion led us to select 101 indicators, and to discard SDG6 and SDG14, because there were too many missing values for most of their indicators.

Data analysis consisted of four steps:

- Building a composite index for each theme.

- Building moral imperative indices.

- Construct validation of moral imperative indices.

- Building a composite SDGs index to assess general performance of EU members.

The creation of the composite indices followed a two-stage Principal Component Analysis approach (Di Franco \& Marradi, 2013). This procedure was applied in the building of valid, theme-based indices, moral imperative indices, as well as the overall SDGs index.

In the first stage, the whole set of indicators was analyzed in order to extract meaningful clusters of variables. In the second stage, a new principal component analysis was performed on variables showing the highest loadings. The procedure ended when only one component-which synthesized the greatest part of the total variance and the greatest number of variables with high loadings—was extracted.

The semantic polarity of some indexes was inverted to make them more intelligible; that is, when needed, indices were reverse-coded to sustain a common directionality of all indices. Then, for each country, an adjusted index score (that lay between 0 and 100) was created. This adjusted score marks the placement of the country between the worst (0) and best cases (100). 


\subsection{Building an Evidence-Based Theoretical Framework for SDGs}

Concealed trade-offs between pillars of sustainable development meant that it was necessary to first build a theoretical framework based on moral imperatives and themes that constitute the reference point for validating indicators and indices, before building an overall SDGs index. Indeed, we rejected the idea of using a composite SDGs index alone, and instead, we first built single moral imperatives indices in order to validate indicators and indices, before aggregating them.

Our framework adopts the broad interpretation of the capabilities approach that was originally developed by Amartya Sen in the 1980s and 1990s, and further elaborated by Martha Nussbaum $(2003,2011)$, as an analytical framework for SDGs.

In its original elaboration, the capabilities approach (Sen, 1982, 1992) was a reaction to the utilitarian and resource-based model of development. Whereas these models focus entirely on income growth, the capabilities model considers freedom and well-being as the definitive goals of development. The capabilities approach is grounded in a view of development that overcomes the basic-need approach, providing a more complex view of humanity (Sen, 2009, p. 250). Within such a perspective, human development includes elementary needs like nourishment and shelter as well as complex needs such as self-esteem and subjective well-being. Capabilities are combinations of functioning allowed to an individual that denote the various things a person may value doing or being: "A functioning is an achievement of a person: what he or she manages to do or to be, and any such functioning reflects, as it were, a part of the state of that person" (Sen, 2005, p. 5). We can say that functioning refers to achievements, whereas capabilities refer to the opportunity set (Gore, 1997).

The first moral imperative of sustainable development should therefore be human well-being. Well-being is concerned with objectives that a person values and the individual's freedom to choose those things he or she values. Thus, in an evaluation exercise, the focus should be on the processes - structural and personal conditions affecting an individual's ability to choose. These conditions are conversion factors, and include personal but also social and environmental characteristics (Frediani, 2010; Robeyns, 2006).

While the first imperative concerns the personal aspects of development, the second and third imperatives derive from the consideration of the above-mentioned conversion factors. Specifically, the second imperative derives from the concept of justice as it emerges from the capability approach, in conjunction with the social justice perspective, and particularly from the two principles of justice as elaborated by John Rawls (1999, p. 266). The first principle calls for a system of basic liberties for all—political liberty, liberty of conscience, freedom of association-and implies equal participation. The second principle is related to the fair distribution of income and wealth; that is, to the structure of distributive justice. Justice does not imply perfect social and economic equality. The fairness of justice implies that inequalities may be present as far as they are to the benefit of all; that is, as far as they 
contribute to a better functioning society (Rawls, 1999, p. 54). Therefore, the first principle is related to effective citizen participation in decision making as a central part of governance at the intersection of power, politics, and institutions, while the second concerns the fair distribution of opportunities in socio-economic relations among citizens (Maffettone, 2010).

The third moral imperative derives from the connection between the capability approach and the environmental justice approach (Ballet, Koffi, \& Pelenc, 2013), which recognizes that ecological problems are embedded in deep-seated human and social ones. According to Lord (2006), justice demands that environmental protection measures are not detrimental to human well-being. A situation that results in a reduction of the overall capabilities set is less just than one that improves the capabilities. Therefore, environmental justice can be considered as another moral imperative of sustainable development. The capabilities approach should be viewed as a participative approach, the aim of which is protection of natural resources in conjunction with, and for, the relevant local population. Ecological justice legitimates a perspective on environmental preservation which does not significantly reduce the capabilities space of local people (Ballet et al., 2013).

Within our framework, sustainable development constitutes a new paradigm that articulates human well-being and social justice in conjunction with environmental justice concerns (Fig. 5.1). Such a perspective legitimates a view of sustainable development as an equitable distribution of capabilities at the intragenerational and intergenerational levels, depending on the human-socioecological features of a given territory.

Therefore the framework is based on three moral imperatives representing the ultimate goals of sustainable development as well as 13 themes or strategic goals.

The first moral imperative-human well-being - aggregates themes related to job opportunities, education, health, and standard of living. The second moral imperative — social justice—aggregates equality, justice, and distribution indicators. The third moral imperative —environmental justice-aggregates pollution and climate change mitigation, biosphere integrity, sustainable production, and investments as well as sustainable communities indicators.

With reference to human well-being, the EU SDGs dashboard seems to adopt a narrow interpretation of capability. Indeed, the indicators focus on basic human development issues such as job, education, and health, without including indicators linked to quality in the labor market, of working conditions, of health policies, or promotion. No considerations related to fair wages and salaries, work time regulation, workplace health and safety, or the entitlement to social security are included. With reference to the social justice imperatives, there are no indicators related to the first principle. The dimension of liberty and participation in its governance and policy perspective is completely lacking in the EU SDGs indicator set. With reference to the ecological justice imperative, sustainable consumption indicators are under-represented.

We interconnected the indicators according to the three moral imperatives and themes, and, for each theme, implemented a two-stage Principal Component Analysis in order to content validate single indicators and build composite thematic 
indices. This double step improved the interpretation of the latent construct, by detecting those features strongly contributing to the factors, and deleting those that were unconnected. Therefore, content validation was based on unidimensionality, which involves establishing that a set of empirical indicators relates to one-and only one-construct.

Indeed, multidimensional measures (that comprise indicators related to more than one construct) hamper the interpretation of association between those measures and other variables, the construction of the overall SDGs index, and the overall findings (Bagozzi, Yi, \& Phillips, 1991). Through a two-stage Principal Component Analysis (Di Franco \& Marradi, 2013), we identified which indicators were strongly linked to a latent variable, which is the theme: the higher the size of the factor loading, the stronger the link would be.

Table 5.1 shows the indicators per theme as well as their content validity. As can be seen from Table 5.1, the highest number of invalid indicators is under the environmental justice imperative.

\subsection{Construct Validation of Moral Imperatives Indexes}

After creating single thematic indices, we interconnected them under the three moral imperatives indices through another round of two-stage Principal Component Analysis (Tables 5.2, 5.3, and 5.4). This second round emphasized some inconsistencies of the SDGs framework: some of the ecological justice imperative themes load in the opposite direction to the others. Particularly, this is the case with the climate change index, which suggests an inherent conflict in ecological justice. This index was dropped from the analysis, because it is unrelated to development.

Results showed that the extraction of one single factor, per moral imperative, was appropriate to represent the factorial solution.

The size of factor loadings is very high (always over 0.6 ), and this suggests that all the selected indices contribute to defining the moral imperatives. In order to test the construct validity of our framework, we used different measures of our moral imperatives by following the perspective of convergent validity (Campbell \& Fiske, 1959), which prescribes that different attempts to measure the same concept should agree. Thus two measures of the same construct should correlate highly if they are valid measures of the concept. In other words, construct validity is the extent to which an operational procedure can measure the concept it is supposed to measure (Cook \& Campbell, 1979).

Therefore, it represents the correspondence between the conceptual definition of a variable (the construct) and its operationalization (Schwab, 1980).

In order to construct validate the human well-being index, we used the human development index, which is a composite index developed annually, by the United Nations Development Programme (UNDP), since 1990. This index is rooted within an alternative approach to the traditional unidimensional measure of development (i.e., the gross domestic product). The three levels of development considered in 
Table 5.1 Indicators and content validity (authors' own elaboration, based on data from the EUROSTAT EU SDGs indicator set: https://ec.europa.eu/eurostat/estat-navtree-portlet-prod/Bulk downloads? code $=$ sdg)

\begin{tabular}{|c|c|c|}
\hline Code & Indicator name & $\begin{array}{l}\text { Content } \\
\text { validity }\end{array}$ \\
\hline \multicolumn{3}{|c|}{ Better job opportunities } \\
\hline 08_20 & Young people neither in employment nor in education and training & + \\
\hline 08_30 & Employment rate & + \\
\hline 08_40 & Long-term unemployment rate & + \\
\hline 08_60 & People killed in accidents at work & - \\
\hline \multicolumn{3}{|c|}{ Enhancing human capabilities } \\
\hline 04_10 & Early leavers from education and training & - \\
\hline 04_20 & Tertiary educational attainment & + \\
\hline 04_30 & Participation in early childhood education & + \\
\hline 04_40 & Underachievement in reading, mathematics and science & + \\
\hline 04_50 & Employment rate of recent graduates & + \\
\hline 04_60 & Adult participation in learning & + \\
\hline \multicolumn{3}{|c|}{ Promoting health } \\
\hline 02_10 & Obesity rate & + \\
\hline 03_10 & Life expectancy at birth & + \\
\hline 03_20 & Share of people with good or very good perceived health & + \\
\hline 03_30 & Smoking prevalence & + \\
\hline 03_40 & Death rate due to chronic diseases & + \\
\hline 03_41 & Death rate due to tuberculosis, HIV and hepatitis & + \\
\hline 03_60 & Self-reported unmet need for medical care & - \\
\hline
\end{tabular}

Poverty prevention

01_10 People at risk of poverty or social exclusion

01_20 People at risk of income poverty after social transfers

01_30 Severely materially deprived people

01_40 People living in households with very low work intensity

01_41 In work at-risk-of-poverty rate

01_60 Population living in a dwelling with a leaking roof, damp walls, floors or foundation, or rot in window frames or floor

06_10 Population having neither a bath, nor a shower, nor indoor flushing toilet + in their household

06_20 Population connected to at least secondary wastewater treatment

07_60 Population unable to keep home adequately warm

$+$

$+$

$-$

$-$

$+$

Ensuring equality

05_10 Physical and sexual violence to women experienced within 12 months prior to the interview

05_20 Gender pay gap in unadjusted form

05_30 Gender employment gap

05_40 Inactive population due to caring responsibilities

05_50 Seats held by women in national parliaments and governments

05_60 Positions held by women in senior management

\begin{tabular}{l}
- \\
+ \\
+ \\
+ \\
+ \\
- \\
\hline
\end{tabular}

(continued) 
Table 5.1 (continued)

\begin{tabular}{l|l|l}
\hline Code & Indicator name & $\begin{array}{l}\text { Content } \\
\text { validity }\end{array}$ \\
\hline Promoting justice & - \\
\hline $16 \_10$ & Death rate due to homicide & - \\
\hline $16 \_20$ & $\begin{array}{l}\text { Population reporting occurrence of crime, violence or vandalism in their } \\
\text { area }\end{array}$ & + \\
\hline $16 \_30$ & General government total expenditure on law courts & + \\
\hline $16 \_40$ & Perceived independence of the justice system & + \\
\hline $16 \_50$ & Corruption Perceptions Index & + \\
\hline $16 \_60$ & Population with confidence in EU institutions & \\
\hline
\end{tabular}

\section{Fair distribution}

\begin{tabular}{l|l|l}
\hline $08 \_10$ & Real GDP per capita & + \\
\hline $10 \_10$ & Purchasing power adjusted GDP per capita & + \\
\hline $10 \_20$ & Adjusted gross disposable income of households per capita & + \\
\hline $10 \_30$ & Relative median at-risk-of-poverty gap & + \\
\hline $10 \_41$ & Income distribution & + \\
\hline $10 \_50$ & Income share of the bottom 40\% of the population & + \\
\hline $10 \_60$ & Asylum applications & - \\
\hline $12 \_20$ & Resource productivity and domestic material consumption (DMC) & - \\
\hline Intergenerational justice & + \\
\hline $09 \_10$ & Gross domestic expenditure on R\&D & + \\
\hline $09 \_20$ & $\begin{array}{l}\text { Employment in high- and medium-high technology manufacturing sectors } \\
\text { and knowledge-intensive service sectors }\end{array}$ & + \\
\hline $09 \_30$ & R\&D personnel & + \\
\hline $09 \_40$ & Patent applications to the European Patent Office (EPO) &
\end{tabular}

Better community life

\begin{tabular}{l|l|l}
\hline $11 \_10$ & Overcrowding rate & + \\
\hline $11 \_20$ & $\begin{array}{l}\text { Population living in households who consider that they experience noise } \\
\text { pollution }\end{array}$ & - \\
\hline $11 \_30$ & Difficulty in accessing public transport & - \\
\hline $11 \_40$ & People killed in road accidents & + \\
\hline $09 \_50$ & Share of busses and trains in total passenger transport & + \\
\hline $09 \_60$ & Share of rail and inland waterways activity in total freight transport & + \\
\hline $11 \_50$ & Exposure to air pollution by particulate matter & + \\
\hline Mitigating pollution & \\
\hline $12 \_10$ & Consumption of toxic chemicals & + \\
\hline $11 \_60$ & Recycling rate of municipal waste & + \\
\hline $12 \_41$ & Circular material use rate & + \\
\hline $12 \_50$ & Generation of waste excluding major mineral wastes & - \\
\hline $12 \_60$ & Recycling rate of waste excluding major mineral wastes & + \\
\hline Mitigating climate change & + \\
\hline $12 \_30$ & Average $\mathrm{CO}_{2}$ emissions per km from new passenger cars & + \\
\hline $13 \_10$ & Greenhouse gas emissions & \\
\hline
\end{tabular}


Table 5.1 (continued)

\begin{tabular}{l|l|l}
\hline Code & Indicator name & $\begin{array}{l}\text { Content } \\
\text { validity }\end{array}$ \\
\hline $13 \_20$ & Greenhouse gas emissions intensity of energy consumption & + \\
\hline $13 \_30$ & Mean near surface temperature deviation & + \\
\hline $13 \_40$ & Climate-related economic losses & - \\
\hline $13 \_50$ & $\begin{array}{l}\text { Contribution to the international 100bn USD commitment on climate- } \\
\text { related expending }\end{array}$ & - \\
\hline $13 \_60$ & $\begin{array}{l}\text { Population covered by the Covenant of Mayors for Climate and Energy } \\
\text { signatories }\end{array}$ & + \\
\hline Promoting sustainable processes & + \\
\hline $02 \_20$ & Agricultural factor income per annual work unit (AWU) & + \\
\hline $02 \_30$ & Government support to agricultural research and development & + \\
\hline $02 \_40$ & Area under organic farming & + \\
\hline $02 \_50$ & Gross nutrient balance on agricultural land & + \\
\hline $02 \_60$ & Ammonia emissions from agriculture & - \\
\hline $07 \_10$ & Primary \& final energy consumption & - \\
\hline $07 \_20$ & Final energy consumption in households per capita & - \\
\hline $07 \_30$ & Energy productivity & + \\
\hline $07 \_40$ & Share of renewable energy in gross final energy consumption & + \\
\hline $07 \_50$ & Energy dependence & + \\
\hline Sustainable investments & + \\
\hline $17 \_10$ & Official development assistance as share of gross national income & + \\
\hline $17 \_20$ & EU financing to developing countries & + \\
\hline $17 \_30$ & EU imports from developing countries & \\
\hline $17 \_40$ & General government gross debt & \\
\hline $17 \_50$ & Shares of environmental and labor taxes in total tax revenues & \\
\hline $08 \_11$ & Investment share of GDP & + \\
\hline & & + \\
\hline
\end{tabular}

Table 5.2 Factor loadings of the thematic indices of the human well-being imperative (authors' own elaboration, based on data from the EUROSTAT EU SDGs indicator set, https:// ec.europa.eu/eurostat/ estat-navtree-portlet-prod/ Bulkdownloads? code $=$ sdg)

\begin{tabular}{l|l}
\hline & $\begin{array}{l}\text { Factor } \\
\text { loadings }\end{array}$ \\
\hline Better job opportunities & 0.764 \\
\hline Enhancing human capabilities & 0.912 \\
\hline Promoting health & 0.623 \\
\hline Ending poverty & 0.864 \\
\hline
\end{tabular}

the index are: the opportunity for people to lead a long and healthy life, to access education and acquire knowledge, and to have the opportunity to afford a decent standard of living.

In order to construct validate the social equity moral imperative, we used the Social Inclusion Monitor, designed to measure the progress made and the ground lost on issues of social justice in each EU Member State, based on the data collected by the Bertelsmann Stiftung within the Sustainable Governance Indicators (SGI) project. 
Table 5.3 Factor loadings of the thematic indices of the social justice imperative (authors' own elaboration, based on data from the EUROSTAT EU SDGs indicator set, https:// ec.europa.eu/eurostat/ estat-navtree-portlet-prod/ Bulkdownloads?code $=$ sdg)

Table 5.4 Factor loadings of the thematic indices of the ecological justice imperative (authors' own elaboration, based on data from the EUROSTAT EU SDGs indicator set, https:// ec.europa.eu/eurostat/ estat-navtree-portlet-prod/ Bulkdownloads? code $=$ sdg)

Table 5.5 Factor loadings of the SDGs index (authors' own elaboration, based on data from the EUROSTAT EU SDGs indicator set, https:// ec.europa.eu/eurostat/ estat-navtree-portlet-prod/ Bulkdownloads?code $=$ sdg)

\begin{tabular}{l|l}
\hline & $\begin{array}{l}\text { Factor } \\
\text { loadings }\end{array}$ \\
\hline Ensuring equality & 0.735 \\
\hline Fostering innovation & 0.967 \\
\hline Fair distribution & 0.845 \\
\hline Promoting justice & 0.920 \\
\hline
\end{tabular}

\begin{tabular}{l|l}
\hline & $\begin{array}{l}\text { Factor } \\
\text { loadings }\end{array}$ \\
\hline Better community life & 0.845 \\
\hline Promoting sustainable processes & 0.866 \\
\hline Sustainable investment & 0.848 \\
\hline Mitigating pollution & 0.721 \\
\hline
\end{tabular}

In order to construct validate the environmental equity imperative, we used the Environmental Performance Index (EPI), produced jointly by Yale University and Columbia University, in collaboration with the World Economic Forum (Wendling et al., 2018). It provides a measurement of environmental progress covering two dimensions of environmental performance, namely environmental health (air quality, water and sanitation, heavy metals) and ecosystem vitality (agriculture, water resources, air pollution, climate and energy, fisheries, forest biodiversity, and habitat).

Both the correlations between the human well-being imperative and the human development index and that between the social justice imperative and the Social Inclusion Monitor were very high (0.847), and significant at the 0.01 level. The correlation between the ecological justice imperative and the environmental performance index was also high, although lower than the two previous correlations (0.647 and significant at the 0.01 level).

Having validated our SDGs construct, the last step of the process was to combine the three moral imperatives of SDGs in a composite SDGs index (Table 5.5). 


\subsection{The Performance of EU Countries with Regard to SDGs}

In order to represent the performance of the European Member States on the three moral imperatives, we built thematic cartographies for each of them (Figs. 5.2 and 5.3).

The cartographies show:

- The overall score on the moral imperatives in five classes indicated by the intensity of color of the countries: the darkest band is bounded by the maximum scoring (top performers), whereas the lightest band describes cases where major challenges must be overcome to achieve the SDGs (worst performers).

- The score on each theme that composed the specific moral imperative. These scores are indicated by the bar charts.

The Northern countries generally show better performance on the three imperatives and on the overall SDGs index (Fig. 5.4).

Starting with the human well-being imperative, the social democratic countries are the best performers, with Sweden having the highest score. However, as can be seen from Fig. 5.2, this does not mean that highly ranked countries have achieved the human well-being imperative. Indeed, as can be seen from the bar charts, some of the best performers also scored low in relation to some themes. It is the case of poverty that seems to represent a major problem, both for the richest and the poorest countries. Yet some of the worst performers, such as Bulgaria and Romania, performed better in relation to job opportunities. These findings are also confirmed by looking at the social justice imperative, which is higher in the same countries, but with lower scores in fair distribution. Also, among the best performers, some social gaps are yet to be filled. With reference to ecological justice (Fig. 5.3), most countries face significant challenges with regard to environmental issues, especially in mitigating climate change and pollution. This demonstrates that neither the richest nor the poorest countries are completely ready for SDGs. Even the relative top performers have their work cut out for them. For instance, preventing poverty, ensuring a fair distribution, and fighting climate change remain an issue, both for rich and for poor countries.

\subsection{Implications, Discussion, and Conclusion}

The study discusses a theoretical framework and a methodology for assessing SDGs. The research and policy implications of applying this approach to the synthesis of SDGs indicators are relevant for academics, policymakers, and practitioners.

The research implications are linked to the importance of research design and the selection of indicators, to facilitate the harmonization and alignment of the indicators and dimensions, using value judgements. From this perspective, this paper can stimulate the discussion about the need for relevant indicators for monitoring SDGs (Dahl, 2012; Hák et al., 2016; Morse, 2013; Riley, 2001). 


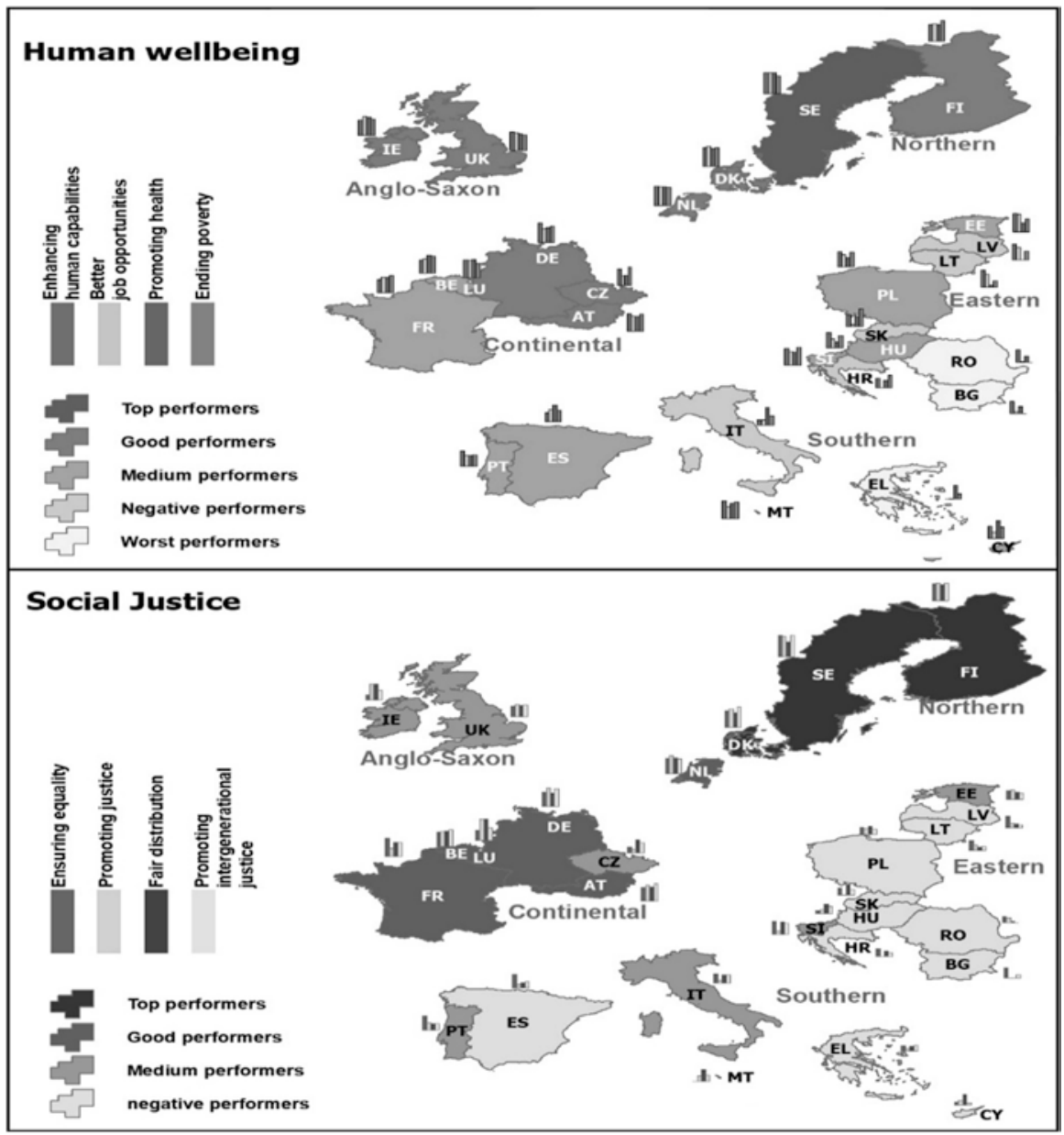

Fig. 5.2 Cartographies of the human well-being and social justice indices and their components (authors' own elaboration, based on data from the EUROSTAT EU SDGs indicator set, https:// ec.europa.eu/eurostat/estat-navtree-portlet-prod/Bulkdownloads?code $=$ sdg)

This study provides a starting point for what can be done to strengthen the scientific underpinning of sustainability indicators. Our analysis demonstrates that SDGs are not fully consistent with sustainability. In order to avoid the serious risk of misallocating development investments, some shifts are required in the SDGs agenda.

The first shift should be around principles and norms. The relevance of human, social, and economic issues in SDGs prevails over other sustainability aspects, such as the environment. Due to the trade-offs among factors of sustainability, global composite indices may be biased toward some of the sustainability pillars, so they are not an accurate measure to use in the appraisal of the fulfillment of SDGs. 


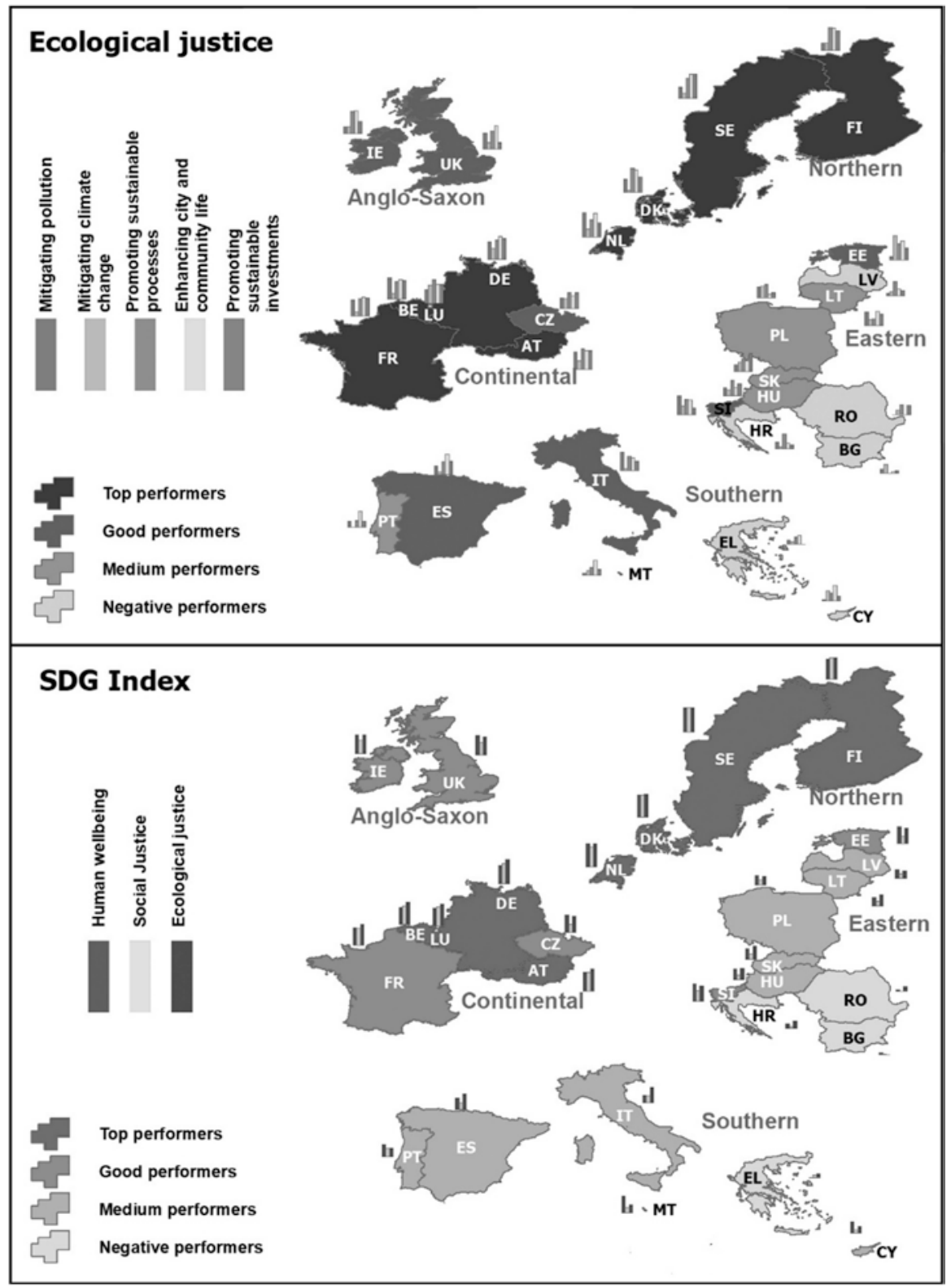

Fig. 5.3 Cartographies of the ecological justice and the SDG indices and their components (authors' own elaboration, based on data from the EUROSTAT EU SDGs indicator set, https:// ec.europa.eu/eurostat/estat-navtree-portlet-prod/Bulkdownloads?code $=$ sdg) 


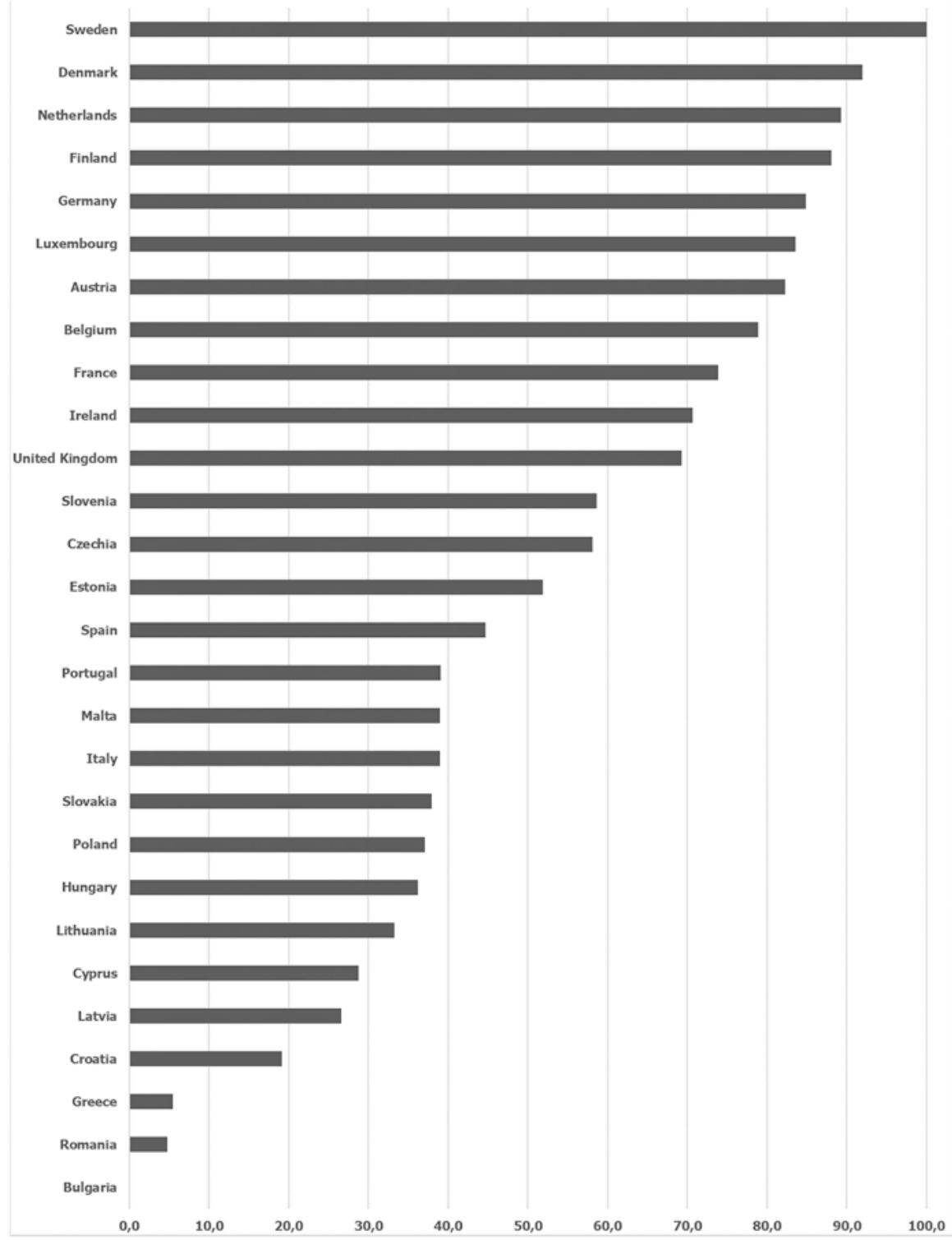

Fig. 5.4 The performance of EU Member States on the SDG index (authors' own elaboration, based on data from the EUROSTAT EU SDGs indicator set, https://ec.europa.eu/eurostat/estatnavtree-portlet-prod/Bulkdownloads? code $=$ sdg) 
The second shift should be around policy agenda. The analysis of indicators demonstrates that SDGs are ultimately affirmative — rather than transformative - of the current economic, social, and ecological status quo. They do not revise the organization of economic development, which adopts a full capitalist and profit-based rationale that is affirmative of the current social, economic, and environmental system.

Although SDGs seem to adopt the abstract principles of social, economic, and ecological justice, they do not integrate substantive development issues such as a consideration of work conditions and quality, of service provision (care for children, for the elderly, for persons with special needs, for migrants and refugees), of governance and institutions, of alternative production and consumption processes or of systematic environmental injustice. Using the capability approach, we can say that the current conceptualization of SDGs evaluates sustainable development based on functioning (achievements), and not within the space of capabilities and opportunities (Sen, 1992). In so doing, it remains conservative and lacks a compelling account of well-being. It is based on quite orthodox indicators that miss the opportunity to transform our understanding of well-being in the direction of positive health and health promotion in all its dimensions. The indicators are more focused on preventing death, illness and risks than on promoting positive well-being, by improving healthy human, political, social, and economic environments.

Moreover, as has already been underlined (Dahl, 2012, p. 15), the present indicators address the "hardware" of national sustainability, as they measure the status of environmental, social, and economic parameters, but they do not assess the "software"- the processes of decision making - that supports progress toward a sustainable system.

By assessing single themes, aggregating them into moral imperatives and presenting an overall SDG index, the study demonstrates that SDGs are an action agenda, both for high-income and low-income countries. Generally, the ecological justice imperative seems to be the weakest pillar of sustainable development. This may indicate a misalignment between socio-economic and environmental policies that needs further investigation. Moreover, this may indicate that some trade-offs may occur across SDGs. Progress on one pillar, such as the economic or social goals, cannot fully offset lack of progress on another (e.g., improving environmental degradation). Obviously this may have some implications for the general framework, implying a reframing of the UN paradigm of three pillars of sustainable development as independent of each other, and requiring them to be conceptualized as a nested system, both conceptually and operationally.

This misalignment can also be explained by referring to the level of analysis of sustainability: part of the problem is that sustainability cannot be measured solely at the national level, as it is a nested system affected by complex interactions among political and governmental levels.

Our study contributes to the identification of a methodology for monitoring SDGs over time. A longitudinal analysis of the performance of SDGs over time, updated and reported regularly, can provide clear signals regarding the success or failure of national policy initiatives and actions. This could be helpful in identifying priorities for early action, understanding implementation challenges, and detecting gaps that must be closed in order to achieve the SDGs. 
The study also has some limitations. Firstly, it used the most recent available data for each indicator, and did not consider historical data, since the availability of such time series was too limited for some variables. As a result, the thematic indexes, the imperatives indexes, and the overall SDGs tell us where a country currently stands on each indicator, but this information cannot be used to infer how rapidly countries have been progressing towards achieving the SDGs.

Secondly, the study leverages on data of different quality for the different countries. Some countries have missing data on some of the indicators as well as misclassification and out-of-date assessment. Filling these gaps will require improved metrics that would imply investment in the strengthening of data collection and statistical capacity in all countries. Moreover, data on environment are incomplete and of poor quality. This alone may create an imbalance and bias for all analysis involving these data.

Thirdly, the study ranks countries relative to other countries in the EU, and does not rank them in relation to the thresholds consistent with SDGs achievement. Thus it can help countries benchmark their progress against that of their peers, but not against the goal thresholds for the achievement of the SDGs, to be met by 2030 . This could be a direction for future research.

\section{References}

Addeo, F., \& Bottoni, G. (2016). Coesione Sociale e regimi di welfare. Un'indagine empirica sugli Stati dell'Unione Europea. In M. Del Forno (Ed.), Nel complesso mondo del welfare. Idee, metodi e pratiche (pp. 137-167). Milano: FrancoAngeli.

Bagozzi, R. P., Yi, Y., \& Phillips, L. W. (1991). Assessing construct validity in organizational research. Administrative Science Quarterly, 36(3), 421-424.

Ballet, J., Koffi, J. M., \& Pelenc, J. (2013). Environment, justice and the capability approach. Ecological Economics, 85, 28-34.

Burford, G., Hoover, E., Velasco, I., Janou`sková, S., Jimenez, A., Piggot, G., et al. (2013). Bringing the "missing pillar" into sustainable development goals: Towards intersubjective values-based indicators. Sustainability, 5(7), 3035-3059.

Campagnolo, L., Carraro, C., Eboli, F. and Farnia, L. (2015). Assessing SDGs: a new methodology to measure sustainability. Paper presented at the UN Summit on Sustainable Development Goals, New York, September 25.

Campbell, D. T., \& Fiske, D. W. (1959). Convergent and discriminant validation by the multi traitmultimethod matrix. Psychological Bulletin, 58, 81-105.

Cook, T. D., \& Campbell, D. T. (1979). Quasi-experimentation: Design and analysis issues in field settings. Boston: Houghton Mifflin.

Costanza, R., Daly, L., Fioramonti, L., Giovannini, E., Kubiszewski, I., Mortensen, L. F., et al. (2016). Modelling and measuring sustainable well-being in connection with the UN sustainable development goals. Ecological Economics, 130, 350-355.

Dahl, A. L. (2012). Achievements and gaps in indicators for sustainability. Ecological Indicators, $17,14-19$.

Delli Paoli, A., \& Addeo, F. (2019). Assessing SDGs: A methodology to measure sustainability. Athens Journal of Social Sciences, 6(3), 229-250.

Di Franco, G., \& Marradi, A. (2013). Factor analysis and principal component analysis. Milano: FrancoAngeli. 
Diaz-Sarachaga, J. M., Jato-Espino, D., \& Castro-Fresno, D. (2018). Is the sustainable development goals (SDGs) index an adequate framework to measure the progress of the 2030 agenda? Sustainable Development, 26, 663-671.

Dobson, A. (2003). Citizenship and the environment. New York: Oxford University Press.

Frediani, A. A. (2010). Sen's capability approach as a framework to the practice of development. Development in Practice, 20(2), 173-187.

Gore, C. (1997). Irreducible social goods and the informational basis of Amartya Sen's capability approach. Journal of International Development, 9(2), 235-250.

Gough, I., Meadowcroft, J., Dryzek, J., Gerhards, J., Lengfeld, H., Marandya, A., et al. (2008). JESP symposium: Climate change and social policy. Journal of European Social Policy, 18(4), 325-344.

Hák, T., Janousková, S., \& Moldan, B. (2016). Sustainable development goals: A need for relevant indicators. Ecological Indicators, 60, 565-573.

Hák, T., Kovanda, J., \& Weinzettel, J. (2012). A method to assess the relevance of sustainability indicators: Application to the indicator set of the Czech Republic's sustainable development strategy. Ecological Indicators, 17, 46-57.

Hák, T., Moldan, B., \& Dahl, A. (Eds.). (2007). Sustainability indicators: A scientific assessment. SCOPE 67. Washington, Covelo, London: Island Press.

Helliwell, J., Layard, R., \& Sachs, J. (2016). World Happiness Report 2016, Update (Vol. 1). New York: Sustainable Development Solutions Network. Retrieved from https://s3.amazonaws. com/happiness-report/2016/HR-V1_web.pdf

Helne, T., \& Hirvilammi, T. (2015). Wellbeing and sustainability: A relational approach. Sustainable Development, 23, 167-175.

Holden, E., Linnerud, K., \& Banister, D. (2016). The imperatives of sustainable development. Sustainable Development, 25(3), 213-226.

Kemp, R., \& Martens, P. (2007). Sustainable development: How to manage something that is subjective and never can be achieved? Sustainability: Science, Practice and Policy, 3(2), 5-14.

Kemp, R., Parto, S., \& Gibson, R. B. (2005). Governance for sustainable development: Moving from theory to practice. International Journal of Sustainable Development, 8(1/2), 13-30.

Le Blanc, D. (2015). Towards integration at last? The sustainable development goals as a network of targets. Sustainable Development, 23, 176-187.

Littig, B., \& Grießler Griessler, E. (2005). Social sustainability: A catchword between political pragmatism and social theory. International Journal of Sustainable Development, 8, 65-79.

Lord, E. (2006). Environmental policy and political justice: A Rawlsian perspective. The Triple Helix, 3(1), 75-78.

Maffettone, S. (2010). Rawls. An introduction. Cambridge: Polity.

Mangone, E. (2007). Territorial development and governance: Third sector organizations. In Girardot, J. J. \& Miedes, B. (Ed.) International Conference of Territorial Intelligence: Huelva, 2007. Papers on Territorial Intelligence and Governance Partecipative Action-Research and Territorial Development (pp. 537-555). Huelva, Spain: Observatorio Local de Empleo.

Morse, S. (2013). Indices and indicators in development: An unhealthy obsession with numbers. London: Routledge.

Murphy, K. (2012). The social pillar of sustainable development: A literature review and framework for policy analysis. Sustainability. Science, Practice and Policy, 8(1), 15-29.

Nussbaum, M. C. (2003). Capabilities as a fundamental entitlements: Sen and social justice. Feminist Economics, 9(2-3), 33-59.

Nussbaum, M. C. (2011). Creating capabilities. The human development approach. Cambridge, MA, London: The Belknap Press of Harvard University Press.

Rawls, J. (1999). A theory of justice (Revised ed.). Cambridge: Belknap.

Riley, J. (2001). The indicator explosion: Local needs and international challenges. Agriculture, Ecosystems \& Environment, 87, 119-120.

Robeyns, I. (2006). The capability approach in practice. The Journal of Political Philosophy, 14(3), 351-376. 
Sachs, J., Schmidt-Traub, G., Kroll, C., Durand-Delacre, D., \& Teksoz, K. (2016). SDGs Index and Dashboards Global Report. New York: Bertelsmann Stiftung and Sustainable Development Solutions Network (SDSN).

Schwab, D. P. (1980). Construct validity in organizational behavior. Research in Organizational Behavior, 2, 3-43.

Sen, A. (1982). Choice, welfare and measurement. Oxford: Blackwell.

Sen, A. (1992). Inequality re-examined. Oxford: Clarendon Press.

Sen, A. (2003). Development as capability expansion. In S. Fukuda-Parr \& A. K. Shiva Kum (Eds.), Readings in human development. Concepts, measures, and policies for a development approach (pp. 3-16). New Delhi, NY: Oxford University Press.

Sen, A. (2005). Human rights and capabilities. Journal of Human Development and Capabilities, 6(2), 151-166.

Sen, A. (2009). The idea of justice. London: Penguin.

Singh, R. K., Murty, H. R., Gupta, S. K., \& Dikshit, A. K. (2009). An overview of sustainability assessment methodologies. Ecological Indicators, 9(2), 189-212.

Stevens, C., \& Kanie, N. (2016). The transformative potential of the sustainable development goals (SDGs). International Environmental Agreements, 16, 393-396.

Stiglitz, J. E., Sen, A., \& Fitoussi, J. P. (2009). Report by the commission on the measurement of economic performance and social progress, Commission on the Measurement of Economic Performance and Social Progress.

UN. (2015). Transforming Our World: the 2030 Agenda for Sustainable Development. New York, NY: UN General Assembly. Retrieved April 25, 2019, from https://sustainabledevelopment.un.org/content/documents/21252030\%20Agenda\%20for\%20Sustainable\%20 Development\%20web.pdf.

UNSD. (2015). Discussion paper on principles of using quantification to operationalize the SDGs and criteria for Indicator selection. ESA/STAT/441/2/58A/14. New York, NY: UNStatistical Division.

Wendling, Z. A., Emerson, J. W., Esty, D. C., Levy, M. A., de Sherbinin, A., et al. (2018). 2018 environmental performance index. New Haven, CT: Yale Center for Environmental Law \& Policy.

Wichaisri, S., \& Sopadang, A. (2017). Trends and future directions in sustainable development. Sustainable Development, 26, 1-17. 


\title{
Chapter 6 \\ Sustainability as a Key Imperative \\ in Project Cycle Management: Sociological \\ Considerations
}

\author{
Maurizio Esposito
}

\subsection{Introduction}

An analysis of the contexts of individual and social well-being cannot be extricated from vital concepts such as sustainability and social cohesion. Subsequent to the economic crisis of 2008, social spending by local authorities fell drastically on an international level, and was accompanied by a constant reduction in personnel due to standstills of turnover and employment; this situation has also had very strong effects on the Third Sector (i.e. non-profit organisations with different structures and purposes, such as the voluntary sector, non-governmental organisations, belonging neither to the public sector nor to the private sector), which was forced to gradually reduce its work spaces. The concept of welfare itself has undergone reconsideration, increasingly being connected to models of sustainable development, social innovation, and generativity.

The latter can also be defined in a micro sense in terms of "social generativity," an action in the economic, political, social, or cultural sphere that creates something new, or regenerates something that already exists. Social generativity is a response to external stimulation, with the objective of promoting the self-determination of the human person, directly, through empowerment, or indirectly, through improvement in the environmental context.

Social project design and intervention against marginalization have been enriched by new terms such as sustainability, co-development, concertation, bottom-up approach, participation, and subsidiarity. These terms are often used, however, as buzzwords, or empty words without any particular meaning. The objective of this chapter was to try to systematize the concepts, deconstructing the common sense, and attempting to reconstruct the reference paradigms.

\footnotetext{
M. Esposito $(\square)$

University of Cassino, Cassino, Italy

e-mail:m.esposito@unicas.it
} 


\subsection{Sociology and Social Vulnerability: Sustainability in Project Design}

The concept of sustainability is used in within the frame of various meanings, so much so that Ehrenfeld lists approximately 300 different denotations (2008, p. 2), and includes it in the definition of an "essentially controversial notion.". Its etymology suggests metaphors of "sustaining" and "supporting," leading us to think in terms of eco-systems and the duration of a state. Born in an ecological context (United Nations-World Commission on Environment and Development 1987), today it cannot be left out of paradigms of a broader sociological, economic-financial, political, or cultural context.

Its definition conveys an increasingly "prescriptive" meaning, to do with the future, with the legacy that we plan to-and that we are obliged to-leave to new generations. The final objective of sustainability is projected into a moment in time that is not immediate (even if it is firmly and deeply rooted in the present): hic et nunc leaves room for Tomorrow and the Kingdom of Possibilities. The future, in reality, always has something to do with the category of intangibility and uncertainty: the present and the past are subject to observation and memory, while the future is only subject to forecasts or prescriptions (Valera, 2012, p. 48).

The term "co-project" is also connected with the future, from the Latin projacere - pushing forward, or predicting. It does not only mean participating together; it also means "Governance of joint resources" (see Ostrom, 2006), or a synergy that becomes a real partnership in which dichotomy between he who produces services and he who receives them is overcome. It goes beyond the logic of assistance, considering the beneficiaries of the intervention as the authors of change, and seeing the Third Sector as an active agent of the phase of programing, organization, and management of the integrated system of social services. In this regard, for example, in Italy, Article 1, Paragraph 4 of Law 328 of the 2000 "Law for execution of the integrated system of intervention and social services" clearly speaks of coordinated project design and execution of intervention, while Article 6, Paragraph 2 speaks of coordination of human and financial resources.

The real and regenerative meaning of these new paradigms of sustainability is that there is no longer just a customer relationship, but co-responsibility and a real partnership between the individuals involved in co-project design. In this way, responsibilities are shared and take on an important value. As already suggested by Jankélévitch (1967), it should be understood not only as a responsibility "a posteriori" for intervention already implemented, but also, and most of all, as a responsibility "a priori," just like the legacy that we decide to leave to new generations in terms of equal, universal, and truly sustainable welfare. While the first responsibility is based on the act, the second is based on being. The legacy should therefore be considered as a common asset; so much so, that Jonas (1979) speaks of "the imperative of responsibility." The coherence of our actions should not be sought for in ourselves, but should be assessed according to the effects and impacts that they generate. 
When sociology is confronted with the topic of social project design, the fields that are immediately interesting are social marginality and vulnerability. While pure research starts from a point of interest that can be connected with general and epistemic curiosity, applied research, research-action, and research-intervention always begin from a heuristic and idiographic need, providing a concrete problem to work on. In social policies, as Alessandro Bruschi (2007) clearly points out, the scenarios that can be imagined should not and cannot be the result of aesthetic and formal choices; as applied research and social action, new scenarios should, on the contrary, derive from - and be inextricably connected to-needs to be solved, that is, specific problems of the beneficiary group.

Social vulnerability is a pervasive problem of our modern society, which is faced with loss of the present and fear of the future. This concept is therefore closely connected with the one that is much more well known and recognizable in social sciences, namely poverty. Being a rather complex topic, a correct analysis of this phenomenon states that its definition should not be considered as an individual situation, but rather as a special social process, part of the network of relations that supports complex social relations, originating and demonstrating its effects in the general social dynamic (Sarpellon, 1983, p. 23). The definitions of absolute and relative poverty, together with the most modern definitions of unidimensional $/ \mathrm{mul}$ tidimensional, qualitative/quantitative, objective/subjective, static/dynamic poverty, as well as the emerging ones connected with the widespread concept of "new poverties," such as health poverty, inactive poverty, industrious poverty, and so on (Maturo, 2007, p. 41) make the phenomenon difficult to interpret, sometimes having indecipherable plots. What occurs on an epistemic level is also reproduced on the heuristic and operative front: intervention against poverty and social exclusion are often connected with improvised and partial experience related to logics that Bruschi would not hesitate to define as "handmade" (Bruschi, 2007, p. 21).

For this reason, we will try to get to grips with the topics of social project design and a sense of sustainability, starting from recognized European guidelines on project management techniques, and specifically, the so-called "Project Cycle Management" model (hereinafter referred to as PCM).

In this toolkit, sustainability is a key imperative. PCM includes the following five criteria used by the European Community (EC) to evaluate the success of projects or programs: (1) relevance, (2) efficiency, (3) effectiveness, (4) impact, and (5) sustainability. In this sense, sustainability evaluation is understood as an assessment of the likelihood that benefits produced by the project will continue to flow after external funding has ended, and with particular reference to factors relating to ownership by beneficiaries, policy support, economic and financial factors, socio-cultural aspects, gender equality, appropriate technology, environmental aspects, and institutional and management capacity (PCM: 23).

An analysis of sustainability would therefore focus on specific issues such as (1) ownership by beneficiaries, (2) policy support/consistency, (3) appropriate technology, (4) environment, (5) socio-cultural issues, (6) gender equity, (7) institutional management capacity, and (8) economic and financial viability. In particular, "sociocultural factors" are fundamental, because they focus on the following: whether the 
project is in tune with local perceptions of needs and of ways of producing and sharing benefits; whether local power-structures, status systems, and beliefs are respected, and if the project seeks to change any of those, how well accepted the changes will be, both by the target group and by others; how effectively it was based on an analysis of such factors, including target group/beneficiary participation in design and implementation, as well as the quality of relations between the external project staff and local communities (PCM: 133).

More specifically, in "Sigma Papers" n. 57, SIGMA (a joint initiative of the OECD and the EU, principally financed by the EU), at the request of the EC, the Principles of Public Administration (the Principles) were developed to define the requirements for a well-functioning public administration, as advocated in both the enlargement and ENP (European Neighbourhood Policy). These Principles operationalize the universal principles of good governance, including those advocated by the Sustainable Development Goals (SDGs), especially Goal 16: "Peace, Justice and Strong Institutions." One of the evaluation criteria is just "Sustainability," which responds to the following questions: Will the benefits continue after the implementation of the strategy? Are the impacts likely to be long-lasting? What can be done to ensure that they remain sustainable? Which institutional arrangements allow for maintaining the benefits achieved? (Vági \& Rimkute, 2018, p. 98).

\subsection{Project Cycle Management (PCM): Sustainability on Track}

PCM is a project design and management tool based on the Logical Framework Approach. The guideline has been implemented as a support instrument to improve project techniques; the quality of project design is intimately connected with concepts of feasibility and the efficiency of programs, projects, and their organizational, financial, environmental, and social sustainability. PCM is a complex and creative process that involves the decision making and negotiation skills of the stakeholders; therefore teamwork, negotiation techniques, and communication remain the central pivots of all of the activities.

A project must:

1. Clearly define stakeholders, including the target group and the final beneficiaries

2. Have well-defined coordination, management, as well as a financial system

3. Have a monitoring and evaluation system

4. Have an adequate level of economic and financial analysis, stating that the project benefits exceed costs.

PCM scans the various phases of a project. As this is a cyclic procedure, it allows for submission of the project to continuous controls, from its initial expression and 
in itinere activities, bringing about changes and/or improvements. The Project Cycle consists of five phases, namely:

1. Programming: The territorial and sector-based context is analyzed, and the problems, obligations, and opportunities on which the action is focused are identified. It identifies the main objectives and the sector-based priorities.

2. Identification: It represents the result of selection between the possible ideas, which undergo a prefeasibility study.

3. Formulation: The selected strategy is subjected to an in-depth study, and the work plan is created.

4. Implementation: The project becomes action.

5. Evaluation: This is done in order to check the short- and long-term effects, and to acquire experience for the future in terms of sustainability.

Furthermore, PCM specifies that the duration of every phase of the cycle depends on the project according to its entity, its objective, and the operative methods used. Furthermore, it also guarantees:

1. That the projects support public and social policies.

2. That the projects are important; they must engage with the actual needs of the group of beneficiaries.

3. That the projects are feasible, that is, the objectives can actually be achieved.

4. That the benefits achieved are sustainable; they can persist once the project has been completed.

To support the achievement of these objectives, PCM includes active participation of the key actors, the stakeholders, and uses the Logical Framework Approach to identify the steps of project development.

The Logical Framework Approach, hereinafter referred to as LFA, is an analytic and organizational instrument of project design: it should not be considered as a replacement for personal and professional experience, but complementary to other project management techniques. LFA allows for the achievement of a specific objective through a sequence of logical actions, all of which are clearly interconnected.

This approach was born in the 1960s in the USA to support the US Agency of International Development in its planning and evaluation phases. Its main objective was to fill the gaps left by three kinds of project-management deficiencies, essentially due to:

1. Unclear planning, and, consequently, an ambiguous definition of the objectives.

2. Organizational responsibilities that are not always clear and scheduled.

3. Consequent difficulties in clearly understanding the objectives of final evaluation, thus operating towards sustainability.

LFA was therefore designed as an instrument that provides aid to thinking, and it produces information that should be analyzed and organized in a structured manner, so that important topics can be resolved, project weaknesses can be identified, and decision makers can make rational decisions. This approach consists of two phases, 
the first of which is called the Analysis Phase and the second the Planning Phase. By overlapping this layout with that of the PCM project cycle, the analytic phase is carried out in the "identification" period, while the planning phase is classified in the "formulation" period.

The analysis phase is carried out through a relational learning process, thinking in terms of a bottom-up approach, in order to follow the direction of efficiency and effectiveness.

Four levels of this phase are:

1. Stakeholder Analysis, where the potential stakeholders are identified, and their skills and added value are assessed.

2. Problem Analysis, where the main problems are identified, and the causes and relations are established.

3. Objective Analysis, which facilitates the imagination of a better situation in the future, due to the project being implemented.

4. Strategy Analysis, where different strategies for reaching the solutions are identified, and the one considered to be the most appropriate is chosen.

In this phase, a whole range of questions must be answered: What intervention can be activated in order to achieve the desired results and produce sustainability for the relevant beneficiaries? What intervention is the most efficient and involves the lowest costs? Which strategies can have a greater impact on the target group? How can potentially negative impacts be mitigated?

Subsequently, during the planning phase, coinciding with the formulation step of PCM, three levels can be identified:

1. Developing a Logical Framework Matrix (LFM), where the entire project structure is defined, its internal logic and its risks are tested, and measurable indicators of the success of the intervention are expressed.

2. Activity Scheduling, where the sequence and dependence of the activities are established, together with their duration and relative responsibilities.

3. Resource Scheduling, where a form is prepared, indicating human, instrumental, structural, and infrastructural resources, and the budget is defined.

The entire intervention plan can be read in a synoptic form in the LFM. The LFM plays a dual role: structuring of the formulation process and supporting activity management, as well as communication of the key information related to the initiative itself. It takes the form of a planning table with four lines and four columns.

The four lines describe the essential conditions of the project — the general objectives, the project purpose, the results, and activities.

The general objectives deal with social sustainability, as they refer to the economic and social impact, with the project itself contributing to its achievement. General objectives normally act as a correlation between the project and the reference program. The project purpose consists of the actual objective, what achievement the team aims at, and what advantages the beneficiaries can enjoy by the end of the project. The results are identified as goods and services created by virtue of project activities, the achievement of which is therefore a direct consequence of 
planning management. Finally, the activities are the operations that the project team must carry out to reach the predefined results.

The four columns provide information regarding the details indicated in the lines. The first column provides a narrative description of the event indicated; the second indicates one or more "Objectively Verifiable Indicator(s)" (OVIs)—-temporal, qualitative, and quantitative parameters of evaluation of the objectives, of the results, and of input of the project; the third column identifies the sources of verification from which information regarding the OVIs is acquired, and finally, the fourth highlights the assumptions and basic preconditions of the project.

The OVIs and the relative sources to be defined with regard to the activities have a distinct nature compared with other fields of the matrix. Activity indicators are the means available for their implementation, and the sources of verification are replaced by the definition of costs necessary for their achievement. The indicators, defined by Marradi as an empirical trace of a concept (1987), should be objectively verifiable, as their value must necessarily measure the same variable, regardless of the subjectivity of the individual in charge of measuring it. PCM indicates that a good indicator should be "SMART": Specific, Measurable, Available, Relevant, and Time-bound.

In "Project Cycle Management," one of the key multi-agency issues is "environmental sustainability," which refers to the need to protect biological and physical systems that support life (e.g., ecosystems, the hydrological cycle, and climatic systems). Environmental sustainability is a principle that needs to be integrated across all areas of decision making. This requires development planners to assess the environmental impact of all proposed policies, programs, and projects, to take action to minimize the adverse environmental impacts, as well as take advantage of opportunities for environmental improvement (PCM: 6). In a more general sense, "sustainable development" is thus defined as development that meets the needs of current generations without compromising the ability of future generations to meet their own needs. In this context, environmental and natural resources are capital that must be maintained in order to support sustained economic activity. Protecting the environment thus preserves the very basis of development.

\subsection{Conclusions}

The objective of this chapter was to deconstruct fragmentation and improvisation of the project-design methods, in order to create the preconditions for an epistemic reasoning, acting as a rational model for sustainable project management. Sustainability generally refers to conservation of a state (Osorio, Lobato, \& Del Castillo, 2005); this means that the main concern in social intervention must not only be the achievement of a specific objective, but of sustainable impacts in terms of general objectives. The added value created by a social action must be maintained over time; only this kind of learning can create social cohesion, which is understood as trust, culture, and economic/social well-being. 
This definition conveys a problem that is not only lexical but also semantic: in terms of conservation of a state, sustainability could be seen as a static, immobile term; yet it has a vital, dynamic meaning of change, of growth, and of cohesion, without inequalities. The words "Sustainable Development Goals" themselves may at first appear to be an oxymoron: should the goals refer to a system to be maintained or to a development to be reached? In the author's view, sustainability cannot exist without development or growth.

In more specific and operative terms, "new programming," promoted by the European Union (EU) and undertaken as the main reference of new national development policies, is inspired by strong and innovative concepts such as partnership, concertation, and a bottom-up approach. An essential characteristic of the instruments of new planning for development can be found in the complexity of "program governance" (denotative of the PCM model described in this chapter), due to the intervention of various individuals, institutional and private, that must converge towards a common objective of development. The Europe 2020 strategy is the EU's agenda for growth and employment during the current decade. It emphasizes smart, sustainable, and inclusive growth to overcome the structural weaknesses in Europe's economy, improve its competitiveness and productivity, and underpin a sustainable social market economy.

In the new programming strategies, we must rediscover the central position of the "person" as a member of a network of relations. Therefore, a system must be stimulated in which everyone can develop positive relations with other individuals or communities, to improve personal well-being, and, at the same time, to build an environment capable of offering support to all in everyday life. Finally, it is important to create a "generative" vision of welfare services-not only a redistributive one; to try to create a new sustainable welfare in which all individuals have the right - and the duty - to contribute, not only to their own personal well-being, but to that of the entire community.

Basing local development on the real needs of the territory, and assigning an active role to several territorial individuals in the identification, selection of requirements, as well as their transformation into qualified intervention projects - that must be effective and sustainable at the same time-becomes vital in the system of rules upon which new planning for development is based. Sustainability, social context, and responsible participation must become not only a fashionable slogan, but should be real key imperatives.

\footnotetext{
${ }^{1}$ The 2030 "Agenda for Sustainable Development," adopted by all United Nations Member States in 2015, provides a shared blueprint for peace and prosperity for people and the planet, now and into the future. At its heart are the 17 Sustainable Development Goals (SDGs), which are an urgent call for action by all countries-developed and developing - in a global partnership. They recognize that ending poverty and other deprivations must go together with strategies that improve health and education, reduce inequality, and spur economic growth.
} 


\section{References}

Bruschi, A. (2007). L'intervento sociale. Dalla progettazione alla realizzazione. Roma: Carocci.

Ehrenfeld, J. R. (2008). Sustainability needs to be attained, not managed. Sustainability: Science, Practice and Policy, 4(2), 1-3.

Jankélévitch, V. (1967). Le pardon. Paris: Aubier-Montaigne.

Jonas, H. (1979). Das Prinzip Verantwortung. Versuch einer Ethik für die technologische Zivilisation. Frankfurt: Suhrkamp.

Marradi, A. (1987). Concetti e metodo per la ricerca sociale. Firenze: Giuntina.

Maturo, A. (2007). Sociologia della malattia. Un'introduzione. Milano: FrancoAngeli.

Osorio, L. A. R., Lobato, M. O., \& Del Castillo, X. A. (2005). Debates on sustainable development: Towards a holistic view of reality. Environment, Development and Sustainability, 7, 501-518.

Ostrom, E. (2006). Governare i beni collettivi. Venezia: Marsilio.

Sarpellon, G. (1983). Rapporto sulla povertà in Italia. Milano: FrancoAngeli.

United Nations-World Commission on Environment and Development. (1987). Our common future. Oxford: Oxford University Press.

Vági, P., \& Rimkute, E. (2018). Toolkit for the preparation, implementation, monitoring, reporting and evaluation of public administration reform and sector strategies: Guidance for SIGMA partners. SIGMA Papers, No. 57, OECD Publishing, Paris. https://doi.org/10.1787/37e212e6-en

Valera, L. (2012). La sostenibilità: un concetto da chiarire. Economia and Diritto agroalimentare, $17,39-53$. 


\title{
Chapter 7 \\ Toward an Understanding of Psychopathological Syndromes Related to Social Environments
}

\author{
Paolo Cianconi, Federica Tomasi, Manuela Morello, and Luigi Janiri
}

\subsection{Introduction}

In general, we mean, as well as aberrant or unacceptable ones, are communities that emerged at the end of World War II, with the analysis of Nazi-fascism, and the concomitant practices of eugenics and extermination. These themes have become more and more complex to analyze, as they moved from modernity to post-modern societies. The ushering in of the second millennium meant that reality and cause-andeffect relationships were questioned more, yet were more difficult to follow, even though it was expected that culture would be able to define fewer confusing parameters about what is acceptable and what is not. And yet acceptability depends on discussion, whether it concerns man, animal species, technology, ecosystems, the biosphere, or the future.

Human mind is generated by a biological fabric. It uses socialization and culture to produce useful technologies to allow our species better fit to survive. Mind develops theories about environment, using different types of intelligence. The aim is to adapt all the time and economically to the contexts that are placed within the limits of our perception. The mind is a highly integrated, coherent, sentient, and proactive repository of information. Coherence and proactivity are essential for the health of individuals, groups, and communities. In this regard, we have tried to link the concept of mind to sustainability. According to Scheffer, sustainability of an ecosystem has to do with a relatively fluid balance of the heterogeneous biomass contained in it; this balance guarantees stability, survival, distance from crises, and a shift in

P. Cianconi $(\bowtie) \cdot$ L. Janiri

Cattolica University “A. Gemelli” Hospital, Rome, Italy

F. Tomasi

A.T. Beck Cognitive Behavior Therapy Institute, Rome, Italy

M. Morello

Palermo, Italy 
regime (Scheffer, 2009). Sustainability of thought also implies the well-being of the mind that participates therein. Well-being includes beneficial feedback from neurotransmitters, communication skills, and the positive effects of the selected technological support. The aim of sustainability of the mind is to maintain an information process capable of implementing aspirations for a better adaptation to life, integrating awareness - or participating biomass - with a successful context trade-off.

For man, this includes the cognitive, emotional, behavioral, and biological domains. Biological reactivity to psychological stressors is made up of a complex integrated system of central and peripheral neural-endocrine responses, designed to prepare the organism for challenge or threat. Developmental experience plays a role, as does genetic variation. This is evident when calibrating the dynamic response of this system (Ellis \& Boyce, 2008). The evolutionary model sees human neurobiological mechanisms as shaped-by natural selection-to detect threats, and to respond with adaptive benefits. Success leads to evolutionary fitness that facilitates adaptation to different environments (Ellis et al., 2012). Individual, group and collective minds realize sustainability if able to avoid threats, disinformation (infotrauma), loss of technological complexity and cultural decadence, gap of power and drop of the possibility to access to resources.

This stream of equilibrium is presumably achievable thanks to a combination of the relational modalities, the interdisciplinary/intercultural thought structures, and the methodological intervention practices that consider socio-economic profile and political structure, feeding, regulating, and maintaining an evolutionary process of psychological well-being for all. A very refined version of this may be the tension that leads to ecosystem democracy. However, sustainability can have unexpected costs. Physicians try to clarify sustainability and the psychopathological consequences thereof. A consequence of environmental conditions in communities that are affected by change is that they struggle to cope with the concomitant increased psychopathology. While society produces culture in order to deal with and avoid negative environmental effects, the relationship between culture and psychopathology has not yet been clarified. Indeed, the conflict between culture and psychopathology lacks a solid empirical foundation (Maj, 2011). A number of specialists assume that culture is the source of mistakes that occur when one makes certain distinctions. On the other hand, culture will become a key piece in the building of concepts used for classification (World Health Organization, 2011). Neuroscience defines the brain as an organ that is bio-socially structured and culturally sensitive. Complexity in the understanding of the mechanisms and etiology of pathophysiology are at the core of discussions that involve medical and humanistic scholars. Cellular mechanisms that facilitate the assessment of individuals in terms of the chronic stressors encountered in the world are currently unknown (Meaney, Szyf, \& Seckl, 2007). Likewise, neuroscience recently has had to revise its principles in order to take into consideration the social and cultural aspects of psychopathology that are affecting the inner and outer worlds, disturbing homeostatic and behavioral responses. This includes the multilevel involvement of cognitive and emotional systems that profoundly impact behavior, influenced by cultural expectations on a social level, as well as the development of a culturally sanctioned idiom of distress 
that can also be interpreted in a predictive coding framework (Sallin et al., 2016). The Diagnostic and Statistical Manual of Mental Disorders (DSM-5) has adopted the term "culturally influenced": therefore, syndromes related to culture are expressions and idioms of distress as well as pathways for seeking help (American Psychiatric Association, 2013).

Cultural syndromes (one of the three main types of Cultural Concepts of Distress) are a cluster of symptoms and attributions that tend to co-occur among individuals in specific cultural groups, communities, or contexts, and that are recognized as coherent patterns of experience (American Psychiatric Association, 2013). Psychiatric diagnostic categories tend to have a one-on-one relationship with underlying biological and neurological mechanisms, and ignore problems that are best understood at a historical, psychological, and sociological level (Karter, Sarah, \& Kamens, 2018). A variety of perspectives can try to go further than the classic psychiatric taxonomy, in order to reach an ecological approach to mental health. For medical anthropology Cultural Syndrome is the bio-cultural result of ethnicity, where "ethnos" is understood as: geographical belonging or affiliation (topos), specific language (logos), social and sacred laws (ethos), population (genos) and its lineage (epos) (Altan, 1995).

It can be said that neither ethnos - the producer of these syndromes, which should ensure "relatively stable conditions" so that a syndrome can be identifiednor its product, the culture (cultural syndromes) from which the syndrome emerges as a part of the entire picture, can be solidly defined as static elements (Clifford, 1988). The number of cultural syndromes is potentially infinite; just like any cultural product, they are born, grow, change, and disappear in space and time by following their communities and groups. Some scholars report an increase of some cultural syndromes (Sumathipala, Siribaddana, \& Bhugra, 2004). This increase could be explained by the fact that certain cultural syndromes are spread across the globe because they are related to some invariants of the biopsychosocial paradigm of our species, although that is changing. It was suggested that the "boundedness" feature of syndromes was weakened by migrations and the subsequent broadening of geodemographic areas (Alarcón, 2014). Cultural syndromes may show an increase in incidence, and simultaneously lessen their cultural characteristics, in contact with post-modern societies (Kar, 2015). Therefore, various issues emerge, and simplification may not be the most useful method to facilitate understanding of how culture is related to the genesis of syndromes. A syndrome is an enduring cluster of observed symptoms or behavioral patterns that indicate a disorder (Kleinman, 1988). We should keep in mind that syndromes, in themselves, much like distress, do not exist, and that they are simple abstractions.

In this chapter, we propose a model to explain the possible cybernetics of syndromes. We consider cultural tradition as well as the transformation processes that link the effects of migration to the process of globalization. We try to figure out how psychiatric syndromes are linked to social context and the ecosystem in which they are embedded. Syndromes indirectly highlight choices made when certain conditions spread into the social body. It is possible to see consequence expression in the psychopathology of the general population, especially among vulnerable groups. 
Speculation in this regard can be a useful indicator for the maintenance of mental health as well as facilitate reflection on choices made - and the consequences thereof-for societies. In this regard, the World Health Organization (WHO) has recognized increasing psychopathology trends in our societies, which indicate worrying levels of future mental health impairment by 2020 (Fassari, 2018).

\subsection{Foundations}

This chapter deals with the fact that certain clusters of symptoms in classic syndromes, which initially appear to be specific to certain cultures, change in their appearance. Initially, this phenomenon was noted in migrating populations. However, it also occurs in the absence of any migration, when surrounding conditions in a native context change drastically. It is well accepted that, for some reason, the interaction between our biology, culture, and ecosystems can potentially lead to the development of mental disorders.

Considering the environmental impact on humans, syndromes are localized, individual, or group reactions to the flow of different types of complex communication. Syndromes arise, for a variety of reasons, as an emerging process that is affected by different dimensions (including biology, psychology, context, technology, and climate). Syndromes have both a surface structure and an inner structure or "core." Social changes affect the core before they affect the surface. Signs and symptoms (surface) arise as a communication. They can have more than a meaning and carry more than a warning. We speculate that there is always an active environmental role in syndromes. This argument may not apply equally to different syndromes (Bell, 2017) such as autism spectrum disorder, psychosis, and post-traumatic stress disorder (PTSD), or even personality disorders. Social factors (such as communication and feedback) are sometimes like physical forces. Changes can occur if people move, or if new things enter into their environment. In physics, motion is the change of position of a point in relation to time, with reference to a specific observer who measures what happens in a determined reference system. To explain the effects of variance on the phenomenology of syndromes, we consider two cases. In the first case, the observer is a migrant who moves from one background to another (i.e., two cultures). Secondly, we discuss what happens when the scenery and background moves (culture), while the subject (the observer) stays still geographically.

\subsection{The Study of Movement: Subjects on the Move}

The first part of this chapter focuses on social variables of migration (Bhugra \& Jones, 2001). The influence of mental health and possible disorders in immigrants and migrants is discussed. Migrants and refugees are a concrete example of a social variable of human crisis. They cross borders and take in experiences from various 
areas. In the 1960s, European francophone and anglophone psychiatrists realized that (White) psychiatric clinics faced real challenges in interpreting, diagnosing, and managing the mental health of the first generation of individuals from this initial post-colonial exodus.

They also expected, as a corollary to this situation, that the original culture would be able to recognize and "cure" the culture-bound syndromes of these migrants. However, those new immigrants to Europe showed a low positive response, even to traditional therapy (Beneduce, 2007; Nathan, 2001) that had generally been used in their homeland. These patients stated that although the symptoms were like other times in which they had felt ill, this time the healer was unable to help them. Healers were able to recognize the symptoms, and confirm that the sickness appeared the same, yet it was different; "it is changed." In the case of migrants and different kinds of refugees, we suggest that there is a new, specific, heterogeneous social insecurity that is filling, or perhaps replacing, the traditional meaning of their cultural syndromes. These new distresses might somehow be absorbed in a traditional cultural interpretation. In this regard, problems of migrating populations could have socialhistorical variances.

WHO recognizes that refugees and migrants are vulnerable groups exposed to many different forms of distress. DSM-5 recognizes that racial ideology, discrimination, and social exclusion have a profoundly negative effect on mental health (American Psychiatric Association, 2013). This effect includes the threat of death, torture, and being overcome by the surrounding chaos, both during the migratory journey and in residence in Western countries. An immigrant in the West might feel confused and isolated, have language difficulties, not be able to find job, harbor traumas, and have few opportunities for cultural exchange. All these problems can lead to distress and psychiatric disorders. The experience of illness could be the same as it is in classic cultural syndrome. However, it is not, and the possible proof is that the disorder will resist conventional therapy.

While externally showing a familiar phenomenology, the syndrome has accumulated enough variance to imply a phase of change. If the population moves, variance comes into play and syndromes begin their mutation. The psychopathology of migration groups often encounters these changes (adaptations) (Ahmed \& Bhugra, 2007; Kirmayer \& Young, 1998). Considering the elusive phenomenology (Risso \& Böker, 2000) and resistance to clinical intervention, we can label them as mutating syndromes.

\subsection{The Study of Movement: Scenarios on the Move}

The development of societies is not perfectly homogenous. There are some organizations that are slowly changing their laws and customs, while others are not. From the Industrial Society to postmodern societies, cultural complexity and information have greatly accelerated. This is an example of movement in which the cultural 
scenario in which people live shifts, rather than the point of reference, which remains more static.

Mind and psychic phenomenology have experienced similar accelerations. Mutation and transformation — in their complexity — are not linear, and they appear to have a direction beyond a single dimension. Societies absorb manner, ideas, products, and behaviors; these spread through the social body, either as epidemics or contagious phenomena, or not at all (Gladwell, 2000). This is evident from an analysis of current techno-psychosocial experiments. We can consequently see how aesthetics, certain forms of art, architecture, some TV-shows, fiction in the communication networks, as well as the market of identity influence us. Although these inputs are sometimes quite far from our direct perception, syndromes can register them. Rapidity and instability of social phenomena can easily be applied to our world, and be internalized, especially by young people (Kato \& Kanba, 2016). In this post-modern scenario, traditional healers, psychotherapists, and psychiatrists are increasingly faced with changes in the syndromes.

Psychiatric syndromes are confused, being an accumulation of ethnic contaminations and spirituality, holistic visions, elements of psychology, use of substances and drugs, phytotherapy, traditional medicine, and so on. Therapists are also confused. In these syndromic phenomena, symptoms can replicate those in manuals. However, the syndromes are often quite ambiguous. People have undergone change and transformation, and the syndromes defy precise identification with alreadyknown ones. As has already been mentioned, these are some of the conditions afflicting migrants.

Interestingly enough, Western patients, despite their more secure social systems, are also prone to these syndromes. It would be easy to argue that Western people have migrated from their home country, and are therefore not associated with such syndromes and pathologies. This could not be further from the truth. Let us go back to the concept of the scenario of movement. Migration is not limited to the individual moving within a geographic territory. If it is the social territory that moves under our feet, like a sliding platform, the objective situation is that of being elsewhere, despite the fact that we have not moved geographically.

This is, in effect, the essence of the post-modern change caused by global instruction: we move without necessarily moving. Staying still (in the same place), we nevertheless undergo external and heterogeneous ideational flow (glocal). Social and cultural processes are connected. Recent acceleration of these conditions has allowed for the scenario to move around us, changing what we have and see, revolutionizing the rules that govern the economy of groups (including families), changing people's dynamics, aims, goals, and cognitive maps. Rapid transition in societies produces a quantity of spurious social variables that influence the coping skills of groups and individuals, generating material changes and resulting in stress. The structure of globalization is responsible for a great deal of exogenous psychopathology related to "flow and flux" (Cianconi et al., 2015). At this point, even Western people have migrated from an original place, because variance reaches them, even at home. 


\subsection{Panorama of Mutating Syndromes (Cybernetics of the Syndromes)}

The emergence of new syndromes indicates mutation of the general social order. Syndromes often mirror this change, just as happens with certain types of artistic work. McLuhan argued about art: "art empowers us to discover social and psychic targets in lots of time to prepare to cope with them" (McLuhan 1964) and social sensibility. Some syndromes are indicators of society's entropy. Being part of a social process, they might play more than a role, operating via a distinct socially mediated mechanism.

It is clear that we will therefore find specific syndromes that reflect the conditions that society is currently facing. New syndromes arise in threatened societies, as seen in the phenomena of millenarianism (Puech, 1970), salvific self-suppression syndrome, social paranoia syndromes, decadence/decline syndromes (Diamond, 2005), or death connected to despair (Shanahan et al., 2019), and, more recently, climate change syndromes (Clayton, Whitmore, Christie Manning, Krygsman, \& Speiser, 2017; Fernandez et al., 2015). Collapsing societies, or those hit by natural disasters or calamities, seem to create their own syndromes (Diamond, 2005), the development and increased presence of which will be evident in strange new symptoms, such as: specific fears, a feeling of annihilation, expiation rituals, search for sacrifice or scapegoats, charismatic mass-enthusiasm, suicide induced by loss of honor, as well as messianic callings (Roux, 1977).

Subsequent to colonialism, syndromes have been noted in native populations (aborigines, first-world nations) (Cianconi, Lesmana, Ventriglio, \& Janiri, 2019). Syndromes have been described for those societies that use certain production systems, for example temporary reversal of roles in agricultural societies, mass-trance, ghost possession syndrome of ancestors, and industrial disease. Societies that are experiencing rapid economic crises or decline have a higher level of distress in their populations, which has led to an increase in suicide rates (Christodoulou et al., 2017; Mattei, Pistoresi, \& Vogli, 2019), depression, alcohol abuse, and gambling.

Syndromes in societies characterized by well-being or rapid expansion have generated, made compulsive consumers who have lost their trans-generational moderation bonds, and select groups experience a loss of customs and morality, as well as high narcissistic trends. Syndromes that resulted from migratory stress-the result of painful diasporas-have led to vagabondage on the streets of Western towns (Hacking, 1998). Mutant syndromes are evidence that society is developing longterm variables that trigger adaptation and change processes - a hysteresis of a new stable state, distant enough to be beyond the conscious perception of individuals. Cultural and social psychiatry describes many of these conditions (Pilgrim \& Rogers, 2005). Finally, we suggest that syndromes can be likened to an "early warning system." They are sensitive and able to absorb social change, reacting in a pliable way. In some ways, these mutant syndromes shed light on our future. Syndromes could enable us to carry out parabolic cultural calculation. 
While the general awareness of the danger, of the dyscrasia, (the threats that result from miscalculations or impending intrusions) could be blocked, some other sensitizing phenomena, such as syndromes, could emerge to signal what is happening. Therapists should learn to identify this process as a warning of the existence of a syndrome in their patients. Psychotherapists and healers must try and change both the setting as well as their therapeutic tools. The minds of individuals, groups, and communities have an ability to absorb a certain quota of variance, and possibly to express it in the form of behaviors and symptoms.

Such new syndromes might be unwanted, as they are-in effect-mental disorders. They could bring fear and anxiety, and lead to impulsive acts in people and/or the collective, as is evident in all types of witch hunts. Changes in the format of the diseases of these early patients is already being realized in the future. At the end of this process, syndromes come to us as messengers. Therefore, mutant syndromes are heralds. At this point, we need to discuss how syndromes undergo a process of reshuffling and contamination when they clash with new socio-economic systems or encounter changes in medical treatment. There are two possibilities: either a syndrome suddenly forms, or it uses the more ambiguous mechanism of mimesis. This subdivision is quite symbolic; a syndrome can use a vast array of possibilities-from rapid emersion to mimetic mechanisms.

\section{Rapidly Mutant Syndromes}

At one end of this dynamic spectrum, we find the "bubble-up" phenomenon: a clinical entity may suddenly undergo transformation, with a clear-cut and entirely new organization. When this happens, the new syndrome it highlights quickly emerges in society.

The group (ethnos) affected by this new disease shows classic fear, surprise, perplexity, and disorientation — at least initially. If a syndrome appears like a simulacrum (Baudrillard, 1968), it is usually the signal of a sudden and drastic break from social development and growth. A pertinent example of this is post-traumatic stress disorder (PTSD), a syndrome that emerged at the end of the Vietnam War and after a series of widespread conflicts that happened in quick succession. Exposure to violence and destruction gave rise to cognitive and emotional disorders. American veterans became ill from the stress of war, but also from cultural conflicts in America during a period of pacifism, with the emergence of post-colonialism and, finally, new forms of war on the media. Avenger shooter terrorists, such as Anders Behring Breivik, James Holmes, and Brenton Tarrant, could be categorized within this group of syndromes.

This syndrome, which interests forensic and social psychiatry in particular, highlights some characteristics that are part of generic groups, presenting specific modalities (symptoms and cause) on which the psychiatrist may base his or her ideas, yet not leading to a diagnosis (Siersbæk, 2015). This syndrome was nonexistent until recently, and the people who embody it appear very similar to others who 
do not commit these horrible actions (Kleinfield, Buttner, Chen, \& Stewart, 2015). The weapons' industry is surely responsible for this situation, as the market and energy sources are the reasons behind climate change and relative syndromes.

The authors of these violent acts are usually adolescents or young adults, presently mostly males, intelligent, generally well-off, often exhibiting social problems, selective withdrawal, rarely sociable, and having little intimate life. These individuals are in some way connected to the concept of immediate payback for their pain and suffering, blaming others for their frustrations; they are reluctant to accept change and adapt to reality (Furia, Torchia, \& Corvo, 2016). They create a personal "story," adopting a stance of White supremacy, hate phobias, millenarian cults, and attitudes of "taking the law into your own hands." They train using books, websites, and videogames, and form superficial connections with other terrorists, whom they appear to idolize. Many shooters imagine that they belong to mediaeval groups or are descendants of Columbine, for example. At some point, these people decide to take justice into their own hands. Although we do not have a diagnosis for this yet, we do have a contagion on our hands. Today, we find ourselves confronted by a complex, heterogeneous group of vulnerable young people. Their problems range from social withdrawal and refusal to enter society, to an extreme sensitivity to globalization and its consequences.

We could be faced with a sort of counterinsurgency against globalization, where the ideas and tools of globalization are used. In the twenty-first century, we are experiencing behavior and reactions generated by products and images-individuals grouped together by a constant crisis, and consumed by social fears in the context of post-modern times. Some syndromes are so rapid that they exist and seem irresistible for a group or collectivity, but then disappear after a season. Internet self-harm and suicide-site syndromes are examples of this (terminus syndrome).

\section{Slow Mimetic Mutant Syndromes}

At the other end of the spectrum, we find those syndromes that are based on mimesis. Such syndromes do not form suddenly, or in a concentrated manner, ex novo. If a variance slowly penetrates a society, its onset as a syndrome is rather a devious process. Variance will mean that all of society will struggle in certain interrelated domains, to a certain extent, and this, in turn, will affect social stability. These effects on social stability give shape to clinical interactions. In the case of mimetic mutant syndromes, variance is ambiguous.

The following is a list of problematic issues that act as triggers to these syndromes: poor access to resources, dysregulation of social functions, misery and fatigue, years of democracy/dictatorships, racism and oppression, political disparities (Hansen, Braslow, \& Rohrbaugh, 2018), economic inequality (Johnson, Wibbels, \& Wilkinson, 2015), crises of classic family bonds and stochastic parental behavior, erratic neighborhood conditions and helplessness, perception of threat, loss of freedom and civil rights, technological gaps, lack of proper information, lack 
of cultural and conflict mediation, hyper-bureaucracy, the availability of new drugs, contact with pollutants, self-harm drives, addiction, hostility without a specific reason, stagnation and despair, change in ecological conditions, living at starvation level, migration under horrendous conditions, and so on.

Finally, exposure to environmental unpredictability, chaos, and danger (in the absence of solutions) can lead to ongoing exposure to morbidity, i.e., mortality. More and more studies report a strong relationship between psychosis and such cultural, psychological, and sociological factors. These distress elements are not immediate, but they can be factors of a critical shifting. They can be tolerated and become chronic a long time before a syndrome is detected. Meanwhile, patients will still present with the recognized signs and symptoms.

Practitioners, for their part, might interpret the complaints and symptoms as a variant of an already-known disorder. A new syndrome might not be immediately evident to healers, and so collectively too. We might even find that the new syndrome fits into a current one, with common symptomatology.

Professionals tend to interpret complaints and symptoms as disorders they already know. These slowly developing yet dynamic syndromes are manifested using foundations and features that are already present and understood within the culture. For this reason, it is often not easy to understand the new situation, initially. Only later does it become clear that there is a new syndrome in the society. The disease mutates, not from the surface (i.e., from the clinical picture of syndromes, it appears the same), but rather from the inner core of the syndrome. There are plenty of examples of these mimetic mutant syndromes. Change occurs within the syndrome, and for some time it may manifest itself with symptoms we know and understand. Hysteria is the most obvious example. In the 1800s, hysteria manifested with certain characteristics (body-dance and physicality) similar to the possession syndromes of the late 1600s, from which it was directly derived. With the secularization of the Western world, syndromes have not lost their tendency to be contagious and mysterious. "Possession" epidemics of convents and towns were common well into the 1800 s.

The Central European bourgeoisie experienced a lot of variance and penetration in urban society. This syndrome (like early dementia) was an embarrassing-yet transient - mental illness. The mythological paradigm of a "cure" had to find a new foundation. A century was needed to adapt the concept of hysteria to the new modern bourgeoisie. In the 1950s, with different ingredients but similar methods, from the dust of heterogeneous social stimuli, symptoms started intertwining to form a new psychopathological construct: borderline personality disorder.

\section{The Syndrome's Life}

Syndromes also experience changes that require long-term trade-offs with opposing factors. Firstly, syndromes must deal with the technologies of medicine. If the therapy undergoes an evolution in this regard, the syndrome is involved in this mutation. Therapy and treatment are also subject to these events. Illness is also influenced as 
treatment improves. Medical culture contributes to the shaping and smoothing of dysfunctional forms of the syndrome with time.

Another important factor is social change. Society can try to adapt to disturbing variations through acceptance, reduction of stigma, change in customs, and migration, in this way facilitating social absorption of disturbing elements. In these situations, the syndromes have been weakened and their activity has been resolved or has been controlled. In large cultural changes, there is a percentage of syndromes that are catastrophic. Some neo-syndromes are usually the most destructive, as they linger for a long time. They have a strong symbolic impact on those first individuals who experience them. Interestingly, we can eventually observe that these new syndromes become more common but cause less damage and disorder in patients. These syndromes can mutate, increase in frequency, yet simultaneously dissipate. Their seriousness tends to dissipate over time as society assimilates and also impairs them. As they wane, they undergo a mechanism that is analogous to the way in which a living organism defends itself from pathogens.

\section{Heralds}

When society faces changes, the biopsychosocial structure of our minds and culture groups might interact with the variance and absorb it. Therefore, if there is no organization and coherence, a new conflicting model of being might be produced.

A herald has thus been generated. This messenger has a new, extemporary and phenomenological shape. The path the herald may choose to manifest itself in will depend on the type of variance that it is required to embody. If this development is forceful and violent, it will suddenly produce an original core that is covered with groupings of symptoms (a symptomatic shell) that has never been seen before. If the variance is ambiguous, or has more time to be metabolized, it could penetrate a ready-made shell of symptoms (as long as there is another syndrome that can incorporate it). In fact, in the case of mimesis, the variance that has accumulated inside is not sufficient to break the walls of the symptoms, which are still able to hold onto the original characteristics of the disorder.

\subsection{Conclusions}

In this study we have discussed an aspect of complexity of social systems, using syndromes as a mirror. From an evolutionary point of view, we speculate that syndromes are social surveillance signals. They increase or decrease as their changing form gives feedback on the choices that communities are making in the ecosystem into which they are inserted.

Syndromes are dynamic functions. Their symptoms are expressions of clear malfunctioning of the biological, cognitive, emotional, and social systems (the syndrome 
core), influenced by a context or cultural condition. When a social system (whether globalization, migration, or any other social crisis) changes, the dynamic balance needed for survival is compromised, which is evidenced in certain psychopathologic phenomenology. Today's therapists must have a solid grasp on the evolution of our world in order to study mutations that occur in communication. Biological entities often struggle to achieve homeostasis even in desirable environments.

We do not know enough about the extent to which culture, biology, and sensitivity mold themselves within a specific context. The flow of symptoms in cultural syndromes seems to accompany ecosystems in their relative balance, or inside crises. Humans are machines that need to be understood, but the process of comprehension is not simple.

The parameters of complete sustainability depend on: the analysis of the environment in which the crises take place, the equitable distribution of resources, the maintenance of functionality, the selection of technology and its use, analysis of signs of dysfunction, the protection of minds, and resilient models.

\section{References}

Ahmed, K., \& Bhugra, D. (2007). Depression across ethnic minority cultures: Diagnostic issues. World Cultural Psychiatry Research Review, 2(2/3), 47-56.

Alarcón, R. D. (2014). Cultural inroads in DSM-5. World Psychiatry, 13(3), 310-313.

Altan, T. C. (1995). Ethnos e Civiltà. Identità etniche e valori democratici. Milano: Feltrinelli.

American Psychiatric Association. (2013). Diagnostic and statistical manual of mental disorders (5th ed.). Washington, DC: American Psychiatric Association.

Baudrillard, J. (1968). Le système des objets. Paris: Gallimard.

Bell, V. (2017, September 19). Why we need to get better at critiquing psychiatric diagnosis. Mind Hacks. Neuroscience and psychology news and views. Retrieved from https://mindhacks. com/2017/09/19/why-we-need-to-get-better-at-critiquing-diagnosis/

Beneduce, R. (2007). Entopsichiatria: Sofferenza mentale e alterità fra storia, dominio e cultura. Roma: Carocci.

Bhugra, D., \& Jones, P. (2001). Migration and mental illness. Advances in Psychiatric Treatment, 7, 216-223.

Christodoulou, C., Efstathiou, V., Michopoulos, I., Ferentinos, P., Korkoliakou, P., Gkerekou, M., et al. (2017). A case-control study of hopelessness and suicidal behavior in the city of Athens, Greece. The role of the financial crisis. Psychology Health and Medicine, 22(7), 772-777. https://doi.org/10.1080/13548506.2016.1164872

Cianconi, P., Lesmana, C. B. Y., Ventriglio, A., \& Janiri, L. (2019). Mental health issues among indigenous communities and the role of traditional medicine. International Journal of Social Psychiatry, 65(4), 289-299. https://doi.org/10.1177/0020764019840060

Cianconi, P., Tarricone, I., Ventriglio, A., De Rosa, C., Fiorillo, A., Saito, T., et al. (2015). Psychopathology in post-modern societies. Journal of Psychopathology, 4, 430-439.

Clayton, S., Whitmore, W., Christie Manning, C., Krygsman, K., \& Speiser, M. (2017). Mental health and our changing climate: Impacts, implications, and guidance. Washington, DC: American Psychological Association and ecoAmerica.

Clifford, J. (1988). The predicament of culture. London: Harvard University Press.

Diamond, J. (2005). How societies choose to fail or succeed. New York: Viking Press.

Ellis, B. J., \& Boyce, W. T. (2008). Biological sensitivity to context. Association for Psychological Science, 17(3), 183. https://doi.org/10.1111/j.1467-8721.2008.00571.x 
Ellis, B. J., Del Giudice, M., Dishion, T. J., Figueredo, A. J., Gray, P., Griskevicius, V., et al. (2012). The evolutionary basis of risky adolescent behavior: Implications for science, policy, and practice. Developmental Psychology, 48, 598-623. https://doi.org/10.1037/a0026220

Fassari, C. (2018, February 22). Società di Psicopatologia. Disturbi mentali in aumento entro il 2020, primi fra tutti ansia e depressione. Quotidiano sanità. Retrieved from https://www.quotidianosanita.it/scienza-e-farmaci/articolo.php?articolo_id=59256

Fernandez, A., Black, J., Jones, M., Wilson, L., Carulla, L. S., Burt, T. A., et al. (2015). Flooding and mental health: A systematic mapping review. PLoS One, 10, e0119929. https://doi. org/10.1371/journal.pone.0119929

Furia, A., Torchia, F., \& Corvo, S. (2016). Flight german wings 9525 EU and EASA post-accident actions. Italian Journal of Aerospace Medicine, 94-106.

Gladwell, M. (2000). Tipping point: How little things can make a big difference. Boston, MA: Little, Brown and Company.

Hacking, I. (1998). Mad travelers. Reflections on the reality of transient mental illnesses. Charlottesville, VA: First Harvard University Press.

Hansen, H., Braslow, J., \& Rohrbaugh, R. M. (2018). From cultural to structural competencytraining psychiatry residents to act on social determinants of health and institutional racism. JAMA Psychiatry, 75(2), 117-118. https://doi.org/10.1001/jamapsychiatry.2017.3894

Johnson, S. L., Wibbels, E., \& Wilkinson, R. (2015). Economic inequality is related to crossnational prevalence of psychotic symptoms. Social Psychiatry and Psychiatric Epidemiology, 50(12), 1799-1807. https://doi.org/10.1007/s00127-015-1112-4

Kar, S. K. (2015). Dhat syndrome: Will it reach a height or die soon? Journal of Human Reproductive Sciences, 8(4), 246. https://doi.org/10.4103/0974-1208.170421

Karter, J. M., Sarah R., \& Kamens, S. R. (2018). Toward conceptual competence in psychiatric diagnosis: an ecological model for critiques of the DSM. In Critical psychiatry (pp 17-69). https://doi.org/10.1007/978-3-030-02732-2_2

Kato, T., \& Kanba, S. (2016). Boundless syndromes in modern society: An interconnected world producing novel psychopathology in the 21st century. Psychiatry and Clinical Neurosciences, 70, 1-2. https://doi.org/10.1111/pcn.12368

Kirmayer, L. J., \& Young, A. (1998). Culture and somatization: Clinical, epidemiological and ethnographic perspectives. Psychosomatic Medicine, 60(4), 420-430.

Kleinfield, N. R., Buttner, R., Chen, D. W., \& Stewart, N. (2015, October 3). Mass murders fit profile, as do many others who don't kill. New York, NY: New York Times.

Kleinman, A. (1988). The illness narratives: Suffering, healing, and the human condition. New York: Basic Books.

Maj, M. (2011). Psychiatric diagnosis: Pros e cons of prototypes vs. operational criteria. World Psychiatry, 10(2), 81-82.

Mattei, G., Pistoresi, B., \& De Vogli, R. (2019). Impact of the economic crises on suicide in Italy: The moderating role of active labor market programs. Social Psychiatry and Psychiatric Epidemiology, 54(2), 201-208. https://doi.org/10.1007/s00127-018-1625-8

McLuhan, M. (1964). Understanding Media: The Extensions of Man. New York: McGraw-Hill.

Meaney, M. J., Szyf, M., \& Seckl, J. R. (2007). Epigenetic mechanisms of perinatal programming of hypothalamic-pituitary-adrenal function and health. Trends in Molecular Medicine, 13, 269-277. https://doi.org/10.1016/j.molmed.2007.05.003

Nathan, T. (2001). Nous ne sommespas seuls au monde. Le seuil paris.

Pilgrim, D., \& Rogers, A. (2005). Social psychiatry and sociology. Journal of Mental Health, 14(4), 317-320. https://doi.org/10.1080/09638230500194992

Puech, H. C. (1970). Histoire des religions. Paris: Gallimard.

Risso, M., \& Böker, W. (2000). Sortilegio e delirio. Napoli: Liguori.

Roux, J. P. (1977). H.-Ch. Puech, (Dir.), Histoire des religions. Revue de l'histoire des religions vol. 3, 1977, 191-92, (pp. 197-202). Paris: Gallimard.

Sallin, K., Lagercrantz, H., Evers, K., Engström, I., Hjern, A., \& Petrovic, P. (2016). Resignation syndrome: Catatonia? Culture-bound? Frontiers in Behavioral Neuroscience, 10, 7. https://doi. org/10.3389/fnbeh.2016.00007 
Scheffer, M. (2009). Critical transitions in nature and society. Princeton: Princeton University Press.

Shanahan, L., Hill, S. N., Gaydosh, L. M., Steinhoff, A., Costello, E. J., Dodge, K. A., et al. (2019). Does despair really kill? A roadmap for an evidence-based answer. American Journal Public Health, 109(6), 854-858. https://doi.org/10.2105/AJPH.2019.305016

Siersbæk, N. L. (2015). Limits of psychiatric diagnoses are revealed by mass shooters. Medscape Psychiatry. Retrieved from https://www.medscape.com/viewarticle/854876

Sumathipala, A., Siribaddana, S. H., \& Bhugra, D. (2004). Culture-bound syndromes: The story of Dhatu syndrome. The British Journal of Psychiatry, 184, 200-209. https://doi.org/10.1192/ bjp. 184.3 .200

World Health Organization. (2011). A conceptual framework for the revision of the ICD-10 classification of mental and behavioral disorders. World Psychiatry, 10(2), 86-92. 
Part III

Which Social Science About the Sustainability? 


\title{
Chapter 8 \\ Social Research: On Participation and Critical Detachment
}

\author{
Franco Ferrarotti
}

\subsection{Theory and Model}

The well-known Talcott Parsons, celebrated author of The Social System, considers himself an "incurable theorist," as he states in his own writings. Perhaps "incurable model-builder" would be a more accurate label.

A model is an intellectual construction where the parts are congruent, but it remains an essentially arbitrary, fictio mentis (abstract) construct that cannot be considered historically grounded. It can, however, perform a useful function as a heuristic device, especially in the hands of a careful researcher, capable of distinguishing between the purely logical level and the actual specific historical context. In contrast, theory is a "glance" (theorein = looking) at a definite phenomenon within a specific historical context.

For the ancient Greeks, there was the joy of "seeing." In Phaedrus, Plato dwells on the satisfaction of the pupil who sees himself in the friend's pupil. In the instructions to his Metaphysics, Aristotle exalts the power of oráo — "looking," "seeing"and speaks about the relationship between the past tense video, and "idea" or vision. Theory, therefore, is a "glance," but not simply "theatrum." The original "vision" is not only physical, but also has a spiritual or religious undertone. The very term "theory" could be interpreted as theós and oráo, that is to say: "I see god," to the

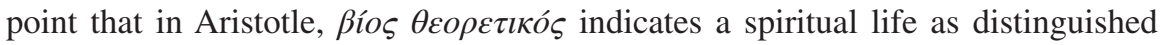
from other kinds of life. Theory, then, is a glance, but not used in its abstract or generic meaning. While "model" is an abstract construction, essentially arbitrary, yet formally logical, theory is historically grounded in the sense that it presupposes a "standpoint" — what Max Weber calls a Standpunkt - that allows the researcher to focus on a specific research object, and enables him to distinguish between what is relevant and what is not important. The confusion between the terms "theory" and

\footnotetext{
F. Ferrarotti ( $\square)$

Sapienza University of Rome, Rome, Italy
} 
"model" inevitably tends to make the research process a-historical, and, therefore, arbitrary and thus irrelevant.

\subsection{The Personal Equation}

Max Weber's historical importance lies in the fact that he went beyond Emile Durkheim's static and naturalistic chosisme, or preoccupation with "things," and postulated as the object of sociological analysis not a social fact treated as a thing, but social action in a dynamic sense, and values as they are lived.

For this reason, despite its occasional obscurity and omissions-some of them serious-Max Weber's methodology constitutes an important advance towards the construction of a science of man. His themes are presently still central to scientific discussions. More acutely, perhaps, than any other sociologist, Weber was aware of the difficulty inherent in the scientific study of human reality; the difficulty of being value-free when faced with events that cannot be understood without recourse to a value-judgement. The illusion implicit in Durkheim's methodological rules is that, just like the facts of nature, social facts will speak for themselves when they are stripped down to their nature as "things" that can be objectively perceived. In this sense, and seen from this viewpoint, psychology and history may seem superfluous. All that matters, however, is that the social scientist, like the physicist, the chemist, and so on, should perceive them clearly. The sociologist is expected to adjust his own personal equation, just like the physicist and the chemist, so that he/she can perceive them clearly. Like the scientist, the sociologist is expected to adjust his own personal equation in relation to his observations. But what does this mean? Will eliminating the barriers between the natural and the social sciences hide the fact that they are individual and essentially irreducible to each other? For decades, the social sciences have suffered from a serious "inferiority complex" vis-à-vis the natural sciences, envying their exactness and objectivity. But since Heisenberg and Einstein, when natural scientists themselves recognized that crucial elements in their theoretical constructions were "ideological" in nature, is this still a valid attitude?

The social sciences have the same claim to scientific validity as the natural sciences have traditionally enjoyed. But this does not mean that elements should be identified without caution. The personal equation of the natural scientist (who is usually considered the scientist par excellence, but whom I prefer to call the "traditional scientist") consists, for the most part, of a distortion of the senses that can be measured quantitatively. A scientist who is aware of his personal equation is thus in a position to eliminate and correct errors of observation. But, what does the personal equation of the social scientist consist of? One thing is certain: whether he is discerning or myopic, whether he is slow or fast in reading off the findings of a given instrument, is almost irrelevant with regard to the way he goes about his work and to the type of inquiry in which he engages. The sociologist's personal equation is different. As has rightly been pointed out, considerable confusion has been caused 
by the instructions into the social sciences of a method that was thought to be identical to that successfully applied in the natural sciences, when there was, in fact, only a limited similarity between the two fields (Kaufman, 1949, p. 145).

The sociologist's personal equation is qualitative, not quantitative. This is not the place to go into the long argument that opposed Dilthey, with his concept of Erleben and "understanding," and Windelband and Rickert, which laid the basis for Weber's doctrine of the "ideal type." It is enough to point out that the sociologist's personal equation involves his own social being, his specific existential experience, his cultural background, his political behavior, his family ties, his prevailing mental attitudes and stereotypes, as well as his "values." An important achievement of contemporary sociology is recognition of the fact that not only must sociologists introduce certain guiding assumptions into their research, but that, in addition, definite and necessarily evaluative assumptions are inevitable in any sociological research project if it is not to be reduced to the mere random accumulation of elementary data (Ferrarotti 1989). If this is true, if the personal equation of the sociologist involves the sociologist himself as a social fact, and embodies his ultimate essence as a human being, as a person, what does its solution imply for him? It implies revealing himself to himself, not only through an ideal projection resulting from a process of introspection, but also, and more importantly, by situating himself in society, by finding the precise position that he occupies. The formulation of a criterion of selection, which is, in essence, the fundamental requirement of science, is directly related to this social position. Just as society cannot be studied in general, so it can only be observed from specific intellectual standpoints-those of each individual social scientist. In this sense it is correct to say that sociology is simply "the proposal (...) to give a new meaning to facts which have already been studied by other sciences" (Monnerot, 1946, p. 63). However, it must be added that this new meaning, this new dimension that enables us to grasp, at a single glance, a total view of the human sciences, and to compare their results, implies that the social scientist's approach is radically different from that of the traditional scientist. This approach consists of two elements: (a) a constant process of self-analysis and of making explicit the sociologists' subjective values and the assumptions underlying their systems of preferences; and (b) systematic research whose motivation takes the form of a relation, communication and interchange with the other, of a dialogue with the object of research.

This perspective reveals the confusions underlying current discussions of methodology. It is confusion that considerably reduces its heuristic value, and which often risks making a research project, with the dissolution of the object of the inquiry, amount to no more than the mere production of formalistic and fundamentally gratuitous jargon.

The scientist, it is observed, whether a mathematician, a physicist, or a chemist, does not bring his own person into the field of action and observation. Why cannot the same rule be applied to the sociologist? Various attempts at a systematic elaboration of a sociological method share this pipe dream. They are dominated by a conviction that, despite the acknowledged peculiarity of their object, the human sciences 
should learn from the achievements of nineteenth-century physics and natural science.

There is a tendency to overlook the crucial fact that the natural scientist has no need to bring his own person into the work he is carrying out, into the material he handles and analyses. Such an intrusion would be of no assistance to him in analysis, and besides, even if he should wish to intervene personally, there would be no opportunity to do so, because the kind of reality with which he is working is impervious to such interference. Once he has established the limits of validity and the necessary corrections to allow for distortions of sensory organs and of the instruments of observation and measurement, the data he obtains are subjected directly to the rules of inductive and deductive reasoning. In other words, the type of observation to which the scientist is dedicated cannot involve his social being. The object of his inquiry does not require this, since it is incapable of meaningful reactions. In this case, the strictest enforced neutrality separates the research worker from the object of his research.

\subsection{Critical Distance and Inevitable Involvement}

The situation of the sociologist is quite different. As Robert Redfield pointed out, despite the requirements of the scientific method that they are supposed to be following, it seems that sociologists cannot escape from the fact that they must concern themselves fundamentally with states of mind. The specific object of the sociologist's research, the field in which he moves as a scientist, is the same as that in which he moves as a person. Between what is being understood and he who understands, there comes into being a kind of complicity, a relationship that may take on the meaning of a determining emotional experience affecting the whole life of a man, or even a whole period of history. It is possible to illustrate this.

"The birth of the proletariat as it could be observed in England between 1844 and 1848 - it has been noted - seems to have become for Marx an emotional experience in the same way as the breaking off of his engagement with Regina Olsen was a real experience for Kierkegaard." Hence, from Marx's point of view, the phenomenon (the birth of the proletariat observed in England between 1844 and 1848) has a double value; it is essential and existential at one and the same time (in terms of the opposite of essence and existence, as postulated by scholastic philosophy). Seen from without by another sociologist, we have the following picture: everything occurs as if the consciousness of the proletariat, then being born as a class in England, were outside the proletariat—as if it were in the personal consciousness of Marx that the destiny of the proletariat revealed itself as a "lived" situation, and, in Hegelian terms, achieved consciousness of itself. Thus, Marx and the newly born proletariat may appear, in the eyes of the sociologist, in their profound contemporaneity, as one and the same phenomenon, from which neither the history of Marx nor the history of the proletariat can be obtained, except by abstraction. We have here "a kind of basic complicity between what is being understood (the proletariat) and he 
who understands (Marx)" (Monnerot, 1946, pp. 97-98). Other examples are available, possibly less suggestive, but no less real. The case of Thorstein Veblen, who had, as John Dos Passos picturesquely put it, for years been "subtly paying out the logical inescapable rope of matter-of-fact for a society to hang itself by," is in this sense instructive. The economic and social situation and price-system, which Veblen had consistently denounced for over 30 years, entered the depths of their crisis with the slump of the second half of 1929, while Veblen was dying in bitter solitude in Palo Alto. On a level that is only ostensibly more modest, every social scientist can produce plausible confirmation, from his own experiences of field research, both with regard to the object of the inquiry and its sponsors. Anyone with direct experience of fieldwork knows, in fact, that there always comes a moment when you become involved or engaged in the process of research; a moment when you have to decide whether to take on your own role consciously, and to face the responsibilities and risks involved, or to beat a strategic retreat into the rarefied jargon of pseudoscientific neutrality.

This is a scientific, not a moral, decision: the meaning of the whole research project depends on it. These experiences confirm that for the sociologist, data cannot simply be observed, extracted - as it were - from reality, by means of physical organs: they do not pass straight from the eye to the brain but enter into his consciousness, becoming a living part of his experience, arousing affinities and resistances, and becoming part of his way of being a human. The observer and the observed are still face to face, but the two realities are not in this case extraneous or incompatible: they are homogeneous-they influence each other reciprocally, they attract and repel each other, and are part of the same living tissue (Ferrarotti, 2003b).

This means that the sociologist's most indispensable and irreplaceable instrument of research is his own experience as a social being, as a man who is totally involved with the reality he is investigating. The knowledge and information that he obtains are grafted onto this experience. For this reason, while the scientist can, within certain limits, afford to ignore his own personal history, the sociologist can never do this. Even when he is sitting at his desk, arranging his data, and therefore not directly engaged in field research, he can only understand it based on his own experience, within his "personal equation."

Outside it, he runs the risk of using a framework that is purely abstract or formal. In other words, it appears to be clear that sociological research is never research pure and simple, or the systematic collection and methodical elaboration of data. It is also a social operation. This means that it goes beyond naturalistic scientific research. It is inevitably accompanied by repercussions of varying types and incidences affecting the object of the inquiry. It has its own dynamic of development; it requires the guarantee of a certain number of methodological assumptions, and cannot, therefore, be reduced to the mechanical application of particular research techniques. More specifically, if it is not to become entirely gratuitous, it requires-on the part of the research worker-a certain degree of participation.

As has been pointed out elsewhere, no analytical report, no statistical analysis or inventory of empirical data is a valid substitute for this conscious participation, this 
putting of oneself on the same wavelength as the human condition that is to be analyzed.

\subsection{The Researcher is Himself "Researched"}

It is a fact of considerable importance that the role and situation of the social scientist has become the subject of discussion in the USA, particularly with regard to industrial research. This is especially remarkable when we consider that, until recently, the USA represented a cultural universe dominated by the fetishism of facts-as-facts; a culture where it was considered superfluous to attempt an interpretation of the facts in terms of relatively comprehensive conceptual frameworks.

This is certainly a sign of maturity, and indicates that sociological research, at least in certain fields, has progressed beyond the purely academic stage. The social scientist knows that he cannot take cover and keep discretely to one side. The process of research demands fieldwork, in direct contact with the human reality that is under examination; it is based on the exchange of information; it is essentially a dialogue that cannot take place without leaving traces.

The notion that the social scientist is not setting out to do anything, but is only trying to understand and to analyze, can no longer be regarded as acceptable. The questions that the investigation asks his interlocutor-subjects are not lost in the empty air; they become part of a situation of change, and are to some extent decisive in determining its course and further development.

After a long period of undirected research, based essentially on the mere statistical accumulation of fragments of human experience, and on attempts to quantify phenomena that are qualitative and not susceptible to straightforward measurement, American social scientists now seem to show a growing awareness of the need to adopt selection criteria, making explicit the values and preliminary choices that justify these criteria, and at the same time noting the repercussions of research itself on the social reality being analyzed.

Together with Leonard Sayles and other disciples, William Foote Whyte, among contemporary American sociologists, appears to be clearly aware of the limitations imposed by rigidly structured questionnaires and by the exclusive reliance on statistical methods (Ferrarotti 2003a).

Ever since the publication of his first book, Street Corner Society (which consists of a series of observations regarding the behavior and structure of some spontaneous groups and their dynamics in the context of a working-class city neighborhood), Whyte has been conspicuously consistent in the use he has made of what I have called "the sympathetic method." It is an approach reminiscent of the descriptive methods of ethnography, but it leads, through the method of participant observation, to the formulation of significant working hypotheses, based on wide background research, which can be subjected to quantitative empirical verification.

The main feature of this approach is the fundamental importance it accords to participation in the course of the research process, and hence the attention it pays to 
the preliminary problem of the acceptance of the inquiry by those who are its object. This necessarily implies an agreement between the parties regarding the meaning of the research-regarding its ultimate goals. For this reason, even more than a simple interpersonal, or-more generally - a social relationship, sociological research implies a relationship in terms of its aims, i.e., a relationship between persons who accept, within certain limits, a common aim.

It is important to note that the problem of acceptance cannot be considered as really, or substantively, solved by establishing contact and reaching an agreement with only one of the parties in question. For example, in the field of industrial sociology, the most directly exposed to friction and conflict between institutionally organized competitive forces, it is necessary to explicitly acknowledge all the official and unofficial centers of authority and power (Ferrarotti 1985).

In this sense, it is necessary to adopt what North American sociologists have called "multiple entry." The first phase of the research, the phase that consists of "background research," takes on a decisive importance for the entire subsequent progress of the work, involving the accumulation of data, the elaboration of working hypotheses, and their verification (Ferrarotti, 2003b, 2007).

It is in this early stage of an investigation that the mechanical application of abstractly conceived methods and techniques of enquiry are likely to produce extremely negative results that inhibit progress in the research, since they give rise to abstractions and generalizations based on a human reality whose specific dimensions have not yet even been glimpsed. Is it then surprising that this human reality takes its revenge by silence, reticence, or drawing a red herring across the track? If it is true that the interview is the basic instrument of this dialogue, the object of which is research, then should it not be a common activity of the research worker and the object of his research?

\section{References}

Ferrarotti, F. (1985). The myth of inevitable progress. Westport: Greenwood Press.

Ferrarotti, F. (1989). The present state of sociology in Italy. In Current sociology (Vol. 37, p. 2). London: Sage.

Ferrarotti, F. (2003a). An invitation to classical sociology: Meditations on some great social thinkers. Lanham: Lexington Books.

Ferrarotti, F. (2003b). On the science of uncertainty: The biographic method in scientific research. Lanham: Lexington Books.

Ferrarotti, F. (2007). Social theory for old and new modernities: Essays on society and culture, 1976-2005. Lanham: Lexington Books.

Kaufman, F. (1949). Methodology of the social sciences. New York: Routledge.

Monnerot, J. (1946). Les faits sociaux ne soint pas des choses. Paris: Gallimard. 


\title{
Chapter 9 \\ Sustainability Through Unsustainability? \\ Unintended Consequences \\ and Emancipatory Catastrophism
}

\author{
Carmelo Lombardo and Lorenzo Sabetta
}

\subsection{Introduction. Social Change and Unintended Effects: A Classic Combination}

Since the pioneering work of Robert K. Merton in the 1930s, the topic of the unwanted and unanticipated outcomes of human actions has established itself as a central issue in sociological thought. The very notion of unforeseen consequences of purposive social action has a long-standing and relevant tradition in sociology. It stems from Weber's "Sociology of the Paradox of Consequences" (Cherkaoui, 2007, p. 1). In Popper's opinion, "the characteristic problems of the social sciences arise only out of our wish to know the unintended consequences of human actions"which means that "the real task of social sciences is to explain those things which nobody wants" (Popper, 1962, pp. 123-124).

As has been noted, such unintended repercussions of social action are present "everywhere in social life," thus representing one of the "fundamental causes of social imbalances and of social change" (Boudon, 1982, p. 1). The latter, in fact, often proceeds by tortuous paths and counterintuitive connections, neither plotted nor designed:

- The enhanced cultivation of modern science was inadvertently triggered by Pietistic values and religious sentiments (see Cohen, 1990; Merton, 1970), in such a manner that "secularization was the unintended outcome of the religiously motivated science of the Seventeenth century" (Shapin, 1988, p. 601).

\footnotetext{
the author of Sects. 9.1 and 9.2, and Lorenzo Sabetta of Sects. 9.3 and 9.4.

C. Lombardo $(\triangle)$

Sapienza University of Rome, Rome, Italy

e-mail: Carmelo.Lombardo@uniroma1.it

L. Sabetta $(\bowtie)$

Institute for Analytical Sociology, Linköping University, Linköping, Sweden

Although this contribution is the result of collaborative work by the authors, Carmelo Lombardo is 
- In liberal industrial societies, a decrease in inequality of educational opportunities could ironically cause worsening inequality in terms of social opportunities and social mobility (see Boudon, 1974).

- The 1986 Immigration Control Act, a US act designed to control and reduce immigration, eventually increased it substantially in the following decade (Portes, 2000, pp. 5-6).

- The current female population deficit in China has been an unintended (even though easily anticipated) consequence of the one-child policy, introduced by the Chinese government to curb population growth (de Zwart, 2015, pp. 291-292).

This selected list of random examples can easily be extended-possibly even endlessly (in this regard, see Mica, 2018). However, we must observe that the importance of the unintended by-products of social transformations, emphasized as they were by many social scientists, had served as a focal point, especially for the sociological project of Ulrich Beck. According to him, the history of modernity (actually, its very definition) is deeply marked by the impact of unintended changes and accidental alterations. "Reflexive modernization conceptualizes the motive power of social change in categories of the side-effect" (Beck, 1997, p. 38), to the extent that "the motor of social transformation is no longer considered to be instrumental rationality, but rather the side-effect" (Beck, 1997, p. 23). This implies that the age in which we live should be sociologically theorized, first and foremost, as "the age of side-effects" (Beck, 1994). ${ }^{1}$

Needless to say, a fully detailed examination of Ulrich Beck's approach would be far beyond the scope of our analysis. Based on Beck's sociological theory, the goal of this chapter is to point out a specific implication of the role of unintended dynamics in social change: what Albert O. Hirschman called "blessings in disguise" - the concept of emancipatory catastrophism. This concept refers to the hidden emancipatory side effects of global risk. Beck's argument is that modern environmental catastrophes may ironically have the potential to bring about major, constructive changes in the way social actors organize their lives and societies. In other words, extreme "bad" harbors the potential to create normative horizons of common "good," stimulating reflection on questions of justice. "This process of "social

\footnotetext{
${ }^{1}$ It is difficult to overestimate the significance of side effects and unintended consequences in Beck's sociology. As he has stated many times over the years, "society is changed not only by that which is seen and desired but also by that which is not seen and not desired" (Beck, 1997, p. 32). Modernity cannot be "conceived of only in instrumentally rational and linear terms, but as refracted, as the rule of side-effects" (Beck, 1997, p. 3). The very notion of "risk society," possibly Beck's most successful contribution, "epitomizes an era of modern society that no longer merely casts off traditional ways of life, but rather wrestles with the side effects of successful modernization" (Beck, 2009, p. 8).

${ }^{2}$ As social scientists are well aware, it is wildly misleading to conflate effects which were unwanted at the beginning of a course of action with those effects that are not wanted at all: "unforeseen consequences should not be identified with consequences which are necessarily undesirable (...). For though these results are unintended, they are not upon their occurrence always deemed axiologically negative. In short, undesired effects are not always undesirable effects" (Merton, 1936, p. 895).
} 
catharsis' can facilitate the development of new normative horizons and has the potential to reconfigure cultural practices" (Mythen, 2017, p. 25). Before tackling and discussing the issue of emancipatory catastrophism in detail, it might be useful to take a step back, and briefly examine the relationship between individual aims, aggregate outcome, and compositional mechanisms, which provide the logical foundation of Beck's point of view.

\subsection{Individual Intentions, Latent Functions, and Transformational Mechanisms}

At the core of the concept of unforeseen effects lies a clear-cut dichotomy: on the one hand, there is the perception of the social actors regarding their own actions (i.e., the "subjective side" of their behavior: beliefs, reasons, aims, conscious elements-what the actors think their actions are); on the other hand, there are the actions themselves - their actual ramifications (i.e., the objective meaning of the actors' behaviors). In fact, the classic distinction between "manifest" and "latent" functions was devised "to preclude the inadvertent confusion between conscious motivations for social behavior and its objective consequences" (Merton, 1968, p. 114).

Thus, emphasizing the importance of what is unintended and unforeseen means "interpreting data by establishing their consequences for larger structures in which they are implicated" (Merton, 1968, p. 101), so the functionalistic focus is on the manifold impact that individual behavior has on the broader social, cultural, and political context. As a direct result of discriminating between the purposive and planned outcomes and the unexpected and unplanned outcomes of social activities, the relationship between the social and the individual levels, between the whole and its parts, becomes more complicated, and so does the road from past to future. Firstly, from the perspective of social change, the pervasive role of latent functions entails the impracticability of transposing micro-sociological data on a macrosociological level and vice versa, i.e., the infeasibility of assuming that a given phenomenon "occurs because individuals behave in such a way as to bring it about" (Boudon, 1986, p. 59). And since small changes in the structure of social interaction can have "a profound impact on the social outcomes that emerge, (...) aggregate social patterns typically say very little about the micro-level processes that brought them about" (Hedström, 2005, p. 149). It happens, therefore, that local problems are globalized, and-conversely_-global problems are localized; seemingly irrelevant small-scale things influence larger-scale things and back again; axiologically negative phenomena engender an axiologically positive state of things, and the other way around. The original scope of social phenomena (what they are initially intended to be) matters little for their effective consequences (what they actually turn out to be), since mass effect implies processes and transformations "which deny or contradict pristine motives and intentions" on which they are based (Turner, 
1996, p. 178). Moreover, unlike personal reasons, "functions are never intrinsic" because "they are assigned relative to the interests of users and observers" (Searle, 1997, p. 19).

As is clear, all these are variations on the central theme variously called "accumulation," "emergence," "composition," or "aggregation"- - all concepts that articulate the indirect, oblique, tortuous (that is, unintended) way through which social results shape individual behavior. Although it is not as widely acknowledged as it should be, the need (and maybe the necessity) to deploy such concepts is due precisely to the impossibility of investigating social phenomena by trying to identify who wanted them or who endeavored to make them happen: that is, the impossibility of giving an intentional explanation of social outcomes. ${ }^{3}$ If notions of "emergence" or "composition" are ubiquitous in sociological literature, it is because they are indispensable for explaining the undeniable presence of things which nobody looked for within social reality. Ultimately, as has already been stated, late modernity itself "is not an intentional process. It is a process of cumulative unintended side effects that eventually produce a change in fundamental social principles. These are often effects that were originally intended to be narrower in scope than they turned out to be" (Beck \& Willms, 2004, p. 29. See also Perelman, 2015). ${ }^{4}$

In this respect, the aim of "conceiving the action in a way that makes it rational from the point of view of the actor" (Coleman, 1990, p. 18) seems to be of little help for analyzing unintended macro-effects, since rationality is a category that pertains mainly to individual actors, and, as such, it cannot properly account for those opaque cause-effect chains in which aims and effects are unrelated or unassociated. As Coleman (1990, p. 6) himself observed, after all, "the major problem for explanations of system behavior based on actions at a level below that of the system is that of moving from the lower level to the system level". Indeed, it is precisely at this point-the point where "transformational mechanisms" become operative and effective (Hedström \& Swedberg, 1998, p. 23; Ylikoski, 2017, p. 403)-that the importance of unintended consequences displays itself. Transformational means nothing more than a change of some sort that arises in the "black box" type shift from the individual/past/purposive to the collective/future/unplanned level. As argued by John Goldthorpe (2007, p. 129), however, the "analytic primacy in sociology lies with the consequences of individual action": if sociologists confine themselves to highlighting intentional causal relations, they would not be able, by definition, to develop sound theories that explore the emergence of unplanned

\footnotetext{
${ }^{3}$ Speaking of a specific mechanism that he named "invisible elbow," Charles Tilly argued that "if actors could actually anticipate consequences of their chosen actions and then produce the actions without error, we would indeed only need to sort intentions and preferences" (1996, p. 596).

${ }^{4}$ In this sense, instead of conceiving modern society as the result of a voluntarist project from the outset, made by collective actors fully aware of their own choices' significance (as in Coleman's conception: 1990 , pp. $650-651 ; 1992$, pp. 117-118), it appears more realistically appropriate to firmly separate out subjective intents and objective consequences, since they can be of quite different magnitudes. Again, the necessary theoretical starting point is a "systematic distinction between such subjective categories as intent, purpose, motive, or plan and objective categories of varying kinds of actual consequence" (Merton, 1989, p. 316).
} 
macro-social phenomena, thus betraying one of sociology's most distinctive (even though sometimes underrated: see Mica, 2017) missions.

Based on the above, this chapter underscores the point that social actions that are more influential in producing positive global consequences or desirable macroeffects are neither made for this purpose nor felt as such-in fact, often the contrary. Phenomena that initially seemed narrowly and blindly local, without any well-defined project and with no regard for their future consequences, are often those that later end up having the greatest impacts and the most enduring effects.

\subsection{Learning the Hard Way. The Circuitous Ways of Sustainability, or How Devastating Events Might Save Modernity}

A mechanism that contributes much to the dynamic of cultural and social change is that by which "activities oriented toward certain values release processes which so react as to change the very scale of values which precipitated them" (Merton, 1936, p. 903). Merton believes that this is "the essential paradox of social action," already recognized in Goethe's Faust, with the reference to the power which eternally wants evil and eternally does good. For example, it might well happen that "micropathologies" (i.e., an overstressing of individuals' adaptive capacities) could lead to "macro-normality" (i.e., an increase of society's adaptive capabilities), and vice versa (Hondrich, 1987) - a process completely unrelated to those purposes, projects, and designs that initially moved and oriented social actors.

It is in this respect that Ulrich Beck has recently written about "emancipatory catastrophism," the "positive" reformation of modes of thought, of lifestyles and consumer habits, of law, economy, science, and politics (thus essentially a reformation of society as a whole) triggered by such a negative thing as global climate change, a counterintuitive dynamic that highlights "the dramatic power of the unintended, unseen emancipatory side effects of global risk" (Beck, 2015a, p. 79). The underlying idea is that global warming has the power to change social actors, and for the better. The continuous increase of temperature, the Polar ice melting, the cumulation of extreme weather events, the decrease in freshwater availability, the high rates of biodiversity loss - all of this could be viewed as a unique opportunity to profoundly transform people's way of being in the world. The full realization of certain (objectionable and dangerous) values, exacerbating their contradictions, may eventually lead to their (beneficial) renunciation. In this light, common "good" is conceived of as a by-product of "bad" premises: "Haven't climate scientists set in train a transformation of capitalism that is destructive of nature, a transformation that was long overdue, but seemed impossible before?" (Beck, 2016, p. 117). It is not necessary to completely endorse the claim that "global climate risk could usher in a rebirth of modernity" (Beck, 2016, p. 117) in order to see that certain undoubtedly constructive and definitely unprecedented social phenomena (e.g., 
environmentalism, sustainability, ethical activism, degrowth movements, etc.) have been brought about as a direct consequence of some destructive developments, initially as mere reactive responses, then like entirely autonomous phenomena. Bitter pills may indeed have blessed effects.

The global climate risk to humanity has (despite all the pessimism in the face of the failure of adequate political answers and actions) already invested the postmodern "everything-goes" philosophy with a new-if not utopian, then dystopianmeaning. Paradoxically, global climate risks have given us new orientations, new compasses for the world of the 21 st century. It does not mean that the side effects of the "bad" create a better world with no need for political action. Rather, it means that we have a different way of looking at climate change, thus creating an alternative for new forms of action (Beck, 2015b, p. 123).

Further reinforcing the topic of the "involuntary and unintended enlightening function" of disasters and social crises, Beck has observed that, nowadays, it is possible to see the very horrors and the terrifying ordeal of World War II as a historical change that marked a new era of cosmopolitism as well as the birth of many cosmopolitan institutions (Beck, 2016, p. 115). As Beck himself affirms, this last one is just an ex-post statement, that nevertheless indicates (in a paradoxical but telling manner) the relevant role of the unexpected in modern-age development, the winding road from past to future. Controversial as it may appear, the socio-political idea that a positive destiny could emerge and be induced by negative phenomena such as global environmental crises (that is, the sustainability-through-unsustainability dynamic) seems to have some theoretical and practical value. In order to better understand the rationale of emancipatory catastrophism, it could be useful to itemize its main characteristics:

- A Change-or-Die Situation. Just like any other disaster, calamity, or tragedy, "climate change is pure ambivalence" (Beck, 2010, p. 258). Catastrophes are intrinsically Janus-like: the real threat of ending also creates opportunities of new beginnings; being backed into a corner, in a "change-or-die" situation, could be the most powerful trigger for action. Faced with catastrophes, people can actually change: "risk arrives as a threat, but it brings hope." The palpable peril of witnessing a final global cataclysm is able to "create transnational public concerns, public awareness, and situations that demand immediate public action" (Beck, 2014, pp. 170-171). Moreover, sometimes it is easier to be reborn or rebuilt after some total ruin than to be gradually remodeled. A rising-from-theashes feeling can facilitate a fresh start. ${ }^{5}$

\footnotetext{
${ }^{5}$ This dynamic is not as paradoxical as it might first appear. After all, the same rising-from-theashes process seems to be at work in most successful stories of recovery from addiction, psychological disorders, or terminal illnesses. The point here is that people, quite often, must hit rock bottom (reaching the point where they are so hopeless that they could not feel worse) before they seek help and make vital changes. In this light, it is not weird that sober alcoholics usually define themselves as "grateful alcoholics" (Taylor, 1977, p. 175): being a recovering addict can bring exceptionally good consequences in its wake, maybe even more success in life than could have been achieved otherwise (i.e., without the struggle with the disease).
} 
- Reaction Is Easier Than Action. Usually, the consequences of social actions are not limited to the area in which they were initially performed, since they also occur in interrelated fields originally ignored; "yet it is because these fields are in fact interrelated that the further consequences in adjacent areas tend to react upon the fundamental value-system. It is this usually unlooked-for reaction which constitutes a most important element in the process" (Merton, 1936, p. 903 , italics added). In general, these reactions are not only important but also easier to come up with than autonomous projects planned from scratch: emancipatory catastrophism has an external driving force, an impulse from the outside represented by global environmental issues themselves, that can paradoxically benefit it in gaining momentum.

- Collective Effervescence and Social Fatum. The final stage of global environmental crises implies that some sort of "anthropological shock" (Beck, 1987)_ which could generate general emotional arousal and a stirring up of "collective effervescence"-might ensue (Durkheim, 1965, pp. 230-232). This might lead the community to come together and participate in the same action. Furthermore, as Beck argued, "the shared nature of the challenges posed by the threat of environmental crises could provide the glue to hold the West together" (2009, p. 65). The common will to cooperate can become part of each actor's self-interest: "globally shared risk scenarios, we argue, give rise to the emergence of new cosmopolitan affiliations of risk" (Beck \& Levy, 2013, p. 7), so that "a common interest in survival beyond borders can be constructed" (Beck, 2014, p. 176).

- A Real Factuality. The reality of human-caused climate change is no longer a subject of debate, now appearing rather as a bona fide reality: the facts speak for themselves. This evidence-based and data-supported phenomenon of environmental crisis promises to have a strength that "no social movement, no political party, and certainly no sociological analysis, no matter how brilliant and wellfounded, could ever have achieved" (Beck \& Sznaider, 2010, p. 647), given that "even sociological theories do not permit human actors to anticipate their fate" (Turner, 1996, p. 178). ${ }^{6}$ It is a sort of "naturally occurring" awareness-raising campaign, far stronger than usual ones, that might find its best advocate in its own enemy. The longer unsustainable practices continue, the greater will be the strength of constructive reactions.

- A Self-Defeating Mechanism. "Risk is not catastrophe, but rather, the anticipation of future catastrophe in the present, as a horizon of the present future. The obsession with risk is to avoid catastrophe; the logic of global risk is one of selfdestroying prophecies" (Beck, 2014, p. 170, italics added). To put it differently, the anticipation of catastrophes prompts changes in discourse and policy that could indeed prevent those catastrophes, meaning that "a successful dystopia aims at making itself obsolete: once the world it depicts is identified as a possible future, it seems to empower its readers again, restoring a 'sense of possibilities'

\footnotetext{
${ }^{6}$ However, the claim that "Beck conflates discourse with material practices and that he blurs the difference between the experience of a disaster and scientific predictions of climate change disasters distant in space and time" (Murphy, 2016, p. 342) is at least partly accurate.
} 
that eventually makes alternative pathways thinkable" (Claisse \& Delvennee, 2015, p. 2). A self-destroying prediction always involves voluntariness and deliberation: prediction's "suicide" is a consequence of the renewed intentions of social actors, who modify some aspects of their behavior in response to the new awareness, preventing the prediction from happening. This new awareness, of course, is caused by the prediction itself-if social actors had not known about the forecasting of imminent crisis, the predicted scenario would not have been modified (Sabetta, 2019, pp. 55-56).

- Sustainability and Beyond. "Ever since it has ceased to be disputed that the ongoing climate change is man-made and has catastrophic consequences for nature and society, the cards in society and politics have been dealt anew-worldwide. [Climate change] affords the opportunity of overcoming the nation-state narrowness of politics and of developing a cosmopolitan realpolitik" (Beck, 2010, p. 258, italics added). Hence, emancipatory catastrophism could go further than merely promoting a new politics of global sustainability, and might even lead to the point of questioning and reforming the entire society. It is not just a targeted therapy, since "the transformation of the unseen side effects of industrial production into global ecological flashpoints is not strictly a problem of the "environing' world, it is not a so-called environmental problem, but instead a radical institutional crisis of the first (national) phase of industrial modernity" (Beck, 2009, p. 92). And this is perhaps emancipatory catastrophism's greatest promise.

\subsection{An Open-Ended Conclusion}

Linking emancipatory catastrophism to unintended consequences, this chapter has provided some sociological motivations for defending the former. Our goal was to highlight the logical strength of Beck's idea, whereby a quantity of remarkably desirable social phenomena may be triggered by the apotheosis of previous destructive developments. To quote again from his words: "When a qualitatively new social dynamic is produced by side effects, it is because several sets of unintended side effects, emanating from several different spheres of society, have all coalesced to produce a result none of them was aiming at, and which they might well have tried to stop if they'd had any inkling" (Beck \& Willms, 2004, p. 194). The very notion of sustainability implies the existence of previous unsustainable human developments, overconsumption and environmental degradation, just as much as a transformative idea such as "degrowth" necessarily presupposes some unwise expansion and unreasonable rise that has gone before. For this reason, instead of just trying to avoid the "bad", it is a matter of exploring and developing its constructive and paradoxical potential, its positive side-effects. The current unsustainability of our ecosystem could be working for future global sustainability. This perspective could mark "the beginning of a civilization that seeks to make the unforeseeable consequences of its own decisions foreseeable, and to subdue their unwanted side effects 
through conscious preventative action and institutional arrangements" (Id. 2004, p. 111).

However, even if climate change by no means leads directly and inevitably to the apocalypse, it might as well do so. Here's the open-ended question: "between apocalyptic catastrophism and emancipatory catastrophism, which pathway to the future climate will humanity take?" (Asayama, 2015, p. 92). In fact, the devastating and fatal consequences of a final disaster cannot be underemphasized, since it surely has the potential to yield a series of accidents resulting in the extinction of human life (Mythen, 2004, pp. 19-20). Attempting to tackle this dilemma between apocalyptic and emancipatory (or cosmopolitanizing: see Levy, 2016) catastrophism is an extremely serious matter that deserves careful consideration. However, Beck's concepts of "risk society" and "emancipatory catastrophism" do not mean that we are more at risk today than we were yesterday, but that unintended and unforeseen consequences are attached to social phenomena in a way that is more unpredictable than ever before. Hence, the shift from certainty about the production of risk-free objects to uncertainty about the dynamics, whose unintended effects threaten to disrupt all orderings and all plans (see Latour, 2004, p. 25). In this sense, it is even more serious (at least, from an analytical point of view) to place the concept of unintended consequences tout-court back at the center of sociological theory. In a real sense, the feasibility of this operation constitutes another open-ended issue.

\section{References}

Asayama, S. (2015). Catastrophism toward 'opening up' or 'closing down'? Going beyond the apocalyptic future and geoengineering. Current Sociology, 63(1), 98-93.

Beck, U. (1987). The anthropological shock: Chernobyl and the contours of the risk society. Berkeley Journal of Sociology, 32, 153-165.

Beck, U. (1994). The age of side effects: On the politicization of modernity. In U. Beck, A. Giddens, \& S. Lash (Eds.), Reflexive modernization. Politics, tradition and aesthetics in the modern social order. Cambridge: Polity Press.

Beck, U. (1997). The reinvention of politics. Rethinking modernity in the global social order. Cambridge: Polity Press.

Beck, U. (2009). World at risk. Cambridge: Polity Press.

Beck, U. (2010). Climate for change, or how to create a green modernity? Theory, Culture \& Society, 27(2-3), 254-266.

Beck, U. (2014). How climate change might save the world. Development and Society, 43(2), $169-183$.

Beck, U. (2015a). Emancipatory catastrophism: What does it mean to climate change and risk society? Current Sociology, 63(1), 75-88.

Beck, U. (2015b). Author's reply. Current Sociology, 63(1), 121-125.

Beck, U. (2016). The metamorphosis of the world. Cambridge: Polity Press.

Beck, U., \& Levy, D. (2013). Cosmopolitanized nations: Re-imagining collectivity in world risk society. Theory, Culture \& Society, 30(2), 3-31.

Beck, U., \& Sznaider, N. (2010). New cosmopolitanism in the social sciences. In B. S. Turner (Ed.), The Routledge international handbook of globalization studies. London: Routledge.

Beck, U., \& Willms, J. (2004). Conversations with Ulrich Beck. Cambridge: Polity. 
Boudon, R. (1974). Education, opportunity, and social inequality: Changing prospects in Western society. New York: Wiley.

Boudon, R. (1982). The unintended consequences of social action. London: Macmillan Press.

Boudon, R. (1986). Theories of social change: A critical appraisal. Berkeley: University of California Press.

Cherkaoui, M. (2007). Good intentions: Max Weber and the paradox of unintended consequences. Oxford: Bardwell Press.

Claisse, F., \& Delvennee, P. (2015). Building on anticipation: Dystopia as empowerment. Current Sociology, 63(2), 155-169.

Cohen, I. B. (1990). Puritanism and the rise of modern science: The Merton thesis. New Brunswick: Rutgers University Press.

Coleman, J. S. (1990). Foundations of social theory. Cambridge: Harvard University Press.

Coleman, J. S. (1992). The vision of foundations of social theory. Analyse \& Kritik, 14(2), 117-128.

de Zwart, F. (2015). Unintended but not unanticipated consequences. Theory and Society, 44(3), 283-297.

Durkheim, E. (1965). The elementary forms of the religious life. New York: The Free Press.

Goldthorpe, J. (2007). On sociology (2nd ed.). Stanford: Stanford University Press.

Hedström, P. (2005). Dissecting the social. On the principles of analytical sociology. Cambridge: Cambridge University Press.

Hedström, P., \& Swedberg, R. (1998). Social mechanisms: An introductory essay. In P. Hedström \& R. Swedberg (Eds.), Social mechanisms: An analytical approach to social theory. Cambridge: Cambridge University Press.

Hondrich, K. O. (1987). Micropathology and macronormality. In J. C. Alexander, B. Giesen, R. Münch, \& N. J. Smelser (Eds.), The micro-macro link. Berkeley: University of California Press.

Latour, B. (2004). Politics of nature. How to bring the sciences into democracy. Cambridge: Harvard University Press.

Levy, D. (2016). Cosmopolitanizing catastrophism: Remembering the future. Theory, Culture and Society, 33(7-8), 291-299.

Merton, R. K. (1936). The unanticipated consequences of purposive social action. American Sociological Review, 1(VI), 894-904.

Merton, R. K. (1968). Social theory and social structure. New York: The Free Press.

Merton, R. K. (1970). Science, technology and society in seventeenth-century England. New York: Harper \& Row.

Merton, R. K. (1989). Unanticipated consequences and kindred sociological ideas: A personal gloss. In C. Mongardini \& S. Tabboni (Eds.), L'opera di R.K. Merton e la sociologia contemporanea. Genova: ECIG.

Mica, A. (2017). The unintended consequences in new economic sociology: Why still not taken seriously? Social Science Information, 56(4), 544-566.

Mica, A. (2018). Sociology as analysis of the unintended: From the problem of ignorance to the discovery of the possible. London: Routledge.

Murphy, R. (2016). Conceptual lenses to bring into focus the blurred and unpack the entangled. Environmental Sociology, 2(4), 333-345.

Mythen, G. (2004). Ulrich Beck. A critical introduction to the risk society. London: Pluto.

Mythen, G. (2017). Thinking with Ulrich Beck: Security, terrorism and transformation. Journal of Risk Research, 21(1), 17-28.

Perelman, M. (2015). The anarchy of globalization. Local and global, intended and unintended consequences. World Review of Political Economy, 6(3), 352-374.

Popper, K. R. (1962). Conjectures and refutations. The growth of scientific knowledge. New York, London: Basic Books.

Portes, A. (2000). The hidden abode: Sociology as analysis of the unexpected. American Sociological Review, 65, 1-18. 
Sabetta, L. (2019). Self-defeating prophecies: When sociology really matters. In R. Poli \& M. Valerio (Eds.), Anticipation, agency and complexity. Berlin: Springer.

Searle, J. R. (1997). The construction of social reality. New York: The Free Press.

Shapin, S. (1988). Understanding the Merton thesis. Isis, LXXIX(4), 594-605.

Taylor, M. C. (1977). Alcoholics anonymous: How it works; recovery processes in a self-help group. San Francisco: University of California.

Tilly, C. (1996). Invisible elbow. Sociological Forum, 11(4), 589-601.

Turner, B. S. (1996). For Weber: Essays on the sociology of fate. London: Sage.

Ylikoski, P. (2017). Social mechanisms. In S. Glennan \& P. Illari (Eds.), The Routledge handbook of mechanisms and mechanical philosophy. London: Routledge. 


\title{
Chapter 10 \\ Sociology and Sustainable Development: The Paradigm Is Going to Change
}

\author{
Alessandra Sannella
}

\subsection{Some Introductory Reflections}

The multi-faceted aspects that relate individuals to issues of sustainable development draw attention to the changes and effects that the implementation of the urgent UN 2030 Agenda (signed by countries throughout the world in September 2015) will bring to post-digital societies and social action. With its multiple variables that often resist complete identification, the possibility of simplifying such a complex analysis is a daunting task. Moreover, we lack adequate tools to describe a possible vision of a future society.

However, we can describe the controversial contexts within which societies must make the necessary changes in order to survive. A paradigmatic approach, anchored to sustainability and development - that does not deplete available resourcescould result in an important social shift. Furthermore, the transformation brought about by the fourth industrial revolution will have a structural impact on the planet's socio-economic policies, and hence on people's lives. In addition to these multiple elements, there are the effects that climate change will bring-desertification, floods, environmental disasters — which will inevitably have devastating effects on social groups, including structural inequalities, extreme poverty, and hunger.

If the goal of sociology is to study individuals in their interactions with social groups, in the necessary crasis between Geisteswissenschaften (human science) and Naturwissenschaften (natural science), the complex systems of a world with marked inequalities will challenge not only the economic sciences, but also, and above all, the social sciences, which will have to confront the pernicious effects of artificial intelligence. In this sense it is fundamental to define, as Shaker (2015, p. 305) posited, that sustainability "should be viewed as humanity's target goal of humane

\footnotetext{
A. Sannella $(\bowtie)$

Department of Human, Social and Health Sciences, University of Cassino, Cassino, Italy

e-mail: alessandra.sannella@unicas.it; http://www.eng.unicas.it/
} 
ecosystem equilibrium (homeostasis), while 'sustainable development' refers to the holistic approach and temporal processes that lead us to the end point of sustainability."

While sustainable development goals (SDGs) affirm that the UN member states have identified the need for an assessment on a global scale, as well as parameters through which sustainability and development can be combined, we now need to identify both the predictive and descriptive connections that sociology can activate. As scholars of the empirical sciences, we must demarcate the criteria required for the production of functional systems that facilitate sustainable development, in order to measure benefits, costs, risks, and vulnerabilities (Spence, 2019). The transformation of labor that has taken place through robotization and digital technologies, the changes in production costs, the accelerated pace of social life, the digitalization of daily life, and the impact of climate change must also include a cultural transition. This nuanced panorama must therefore also involve the humanities, in terms of the admonition to "leave no one behind."

\subsection{Development: A Concept in Decline}

Much of the literature shows the urgency of the global economic crisis and the difficulty in identifying a growth model that is sustainable and that reduces inequalities. The Global Report on Food Crises 2019 highlights that, in 53 countries, there are 113 million ( 9 million less than last year) acutely undernourished people in urgent need of food and livelihood assistance. Hence, what emerged from the World Humanitarian Summit in 2016 was the dire imperative to promote humanitarian development (HD); i.e., to move from delivering aid to ending need (Global Report, 2019 , p. 5), and to find innovative approaches for achieving the SDGs.

Of the EU countries, seven of 27 are registered in the top ten in the Global SDGs Index, and European countries have the highest score for the first goal (defeat of poverty), as well as the third (health and well-being). The lowest (even negative) trend is recorded for goal 12 (protection of sustainable production and consumption models), and goal 14 (enduring, sustainable preservation of the seas and oceans). Inequalities between and within states-goal 10-remain significant. The recent Oxfam Report, Oneness vs. the 1\%: Shattering Illusions, Seeding Freedom, highlights the necessity of strong standardization of a monopolistic world economy, where eight people, in 2018, possessed assets equal to those of the poorest half of the planet. This would obviously involve profound external control over the financial, health, and food sectors, to the point of even controlling human relationships. In the 19th century, a socio-economic model of development was proposed that differed from the evolutionary concept of "survival of the fittest." This classical approach in the historical process of the late 19th century "implies the unfolding of potentials that are in origin inherent, by its nature, in the social structure, a deployment that follows a stage of structural growth and maturity and one of decline, crisis and possible dissolution (...)". Development was therefore consid- 
ered as inherent in Marx's definition of economic and social formation. This notion, also present in the sociology of Hobhouse, embodied the natural and symbolic genesis of social development. A methodology of historical change came about from the transformation of the concept of development, which, in addition to being social, becomes sustainable, or rather tends not only towards an organization that is able to "resist" (survive), but must, above all, be able to grow. If signs of change are identified in the cultural impulses derived from the combination of innovation, change, and growth, sustainable development is the important change of paradigm that involves the future of societies in different fields.

In order to adequately reflect on growth and development in the sciences, we must obviously combine the multiplicity of variables that intervene in the social context, using a transdisciplinary approach (Sannella, 2019). In this framework, which might appear to be linear, important questions relating to the globalized world are posed, and require serious consideration. It is clear that the link between the environment and neo-liberalism (Magatti, 2017, p. 117) has effectively castrated subjective development, cancelling the recognition of differences and leading to changes of "value" in the production of a post-digital society. A consequence of this has been an increase in inequality.

\subsection{Translational Sociology?}

In a recent article published in "Nature" entitled "The missing ingredient for a better world: Data", Jessica Espey (2019), citing her experience with the Ministry of Finance and Development Planning in Liberia, highlights an important event in which damage to the electrical grid short-circuited the computers of the statistics office where she worked, resulting in a loss of all the data. This resulted in further research losses that were being carried forward: "Survey data typed in from paper reports were lost, along with tens of other data sets about educational outcomes, poverty rates and access to services" (Espey, 2019, p. 299).

This fact highlighted the absence of solid infrastructures for data collection, with the consequent inability of producing a picture of the country's socio-economic situation. Such conditions, the author points out, make it difficult to pursue the SDGs. This obstacle caused the most recent data, for example on poverty, to be updated only to 2015, and so, as Espey noted, to be obsolete, as is the case in 35\% of sub-Saharan countries. This makes it difficult to measure and create research networks useful for contrasting the disruptive effects of environmental impact on individuals. Although local profit does not reflect the expansion of the global economy, a meta-analysis must be carried out that also considers reduced staff training and fewer resources available in research. Improved data collection could lead to a less disaggregated and more up-to-date statistical situation, and would reinforce research, but this is still not enough. The question is whether the developed societies, anchored as they are to linear capitalist economies that exploit resources, will be able to move towards the circular economy and the Cradle to Cradle $(\mathrm{C} 2 \mathrm{C})$ 
approach, making the process interconnected and sustainable. In this framework, the social sciences aim, as Boudon (1997, p. 25) says, at the "production of unprecedented knowledge." This is the disciplinary controversy of the present-day challenge for the transition from closed to open systems (open science). The debate on sociological reflection needs renewed "experiential magnifying glasses" to analyze a finite section of meaningless infinity that makes it possible to delineate functional analyses in the entropy of the digital society. A perspective is therefore needed that utilizes an irreplaceable research tool: the experience of the social human being who participates in the very reality that is being investigated (Ferrarotti, 1968, p. 295). This reality is full of complexity, and changes in the context of the climatic, economic, and social changes that are rapidly overtaking the planet. The ecosystem paradigm (Bateson, 1972; Luhmann, 1992; Morin, 1983) could be an advantageous analytical observation point, even if one accepts the distinction made by Luhmannthat the system/environment should detect the transformation that has occurred in the digital society, where everything flows between environment/environments and relationship systems, in a line of continuity. It is in this regard that our reflection is focused on a disciplinary framework within which, by trans-disciplinary means, a social transferability of the research results could be pursued in order to carry out analyses that are not detached from social reality. In order to analyze questo 'social fact', it is therefore important to start from the data (see Sect. 10.1) deriving from the progress of the various disciplines, so that the categories of traditional analyses can be re-elaborated. The future will be full of new opportunities for sociology. One proposal concerns the need for policies that reduce the disparities connected both to the phenomenon of industrial transition and to the possibility of identifying solutions through common and shared strategies in the international scenario. The urgency of change that needs to be put in place also reflects the real need for training of researchers at multiple levels of interpretation.

To do this, we need to work on a multilevel plan that can combine theories from different disciplinary approaches with sociological analyses, and, through mixedmethod research, address systemic translational ${ }^{1}$ and transdisciplinary sociological research. This could facilitate a better interpretation of social structures, in order to transfer scientific knowledge "from basic research to hyper-connection.". The objectives of such a proposal lie in an effort connected to a scientific policy that knows how to pursue SDGs through a solid knowledge of qualitative and quantifiable bases in all disciplinary sectors (Nativi, Santoro, Giuliani, \& Mazzetti, 2019; Rockström et al., 2009; Steffen et al., 2015) and with possible social repercussions (OECD, 2019).

By means of the sophisticated technologies used in the various environments of the hard sciences, digital transformation, and hyper-connections, they can be obtained from the data useful for providing the explanation on the society. It could also outline a renewed structural-functionalist system (see Sect. 10.2) to be inte-

\footnotetext{
${ }^{1}$ Obviously, this acceptation has changed from the "translational research" proposed in 1830 by Dr. William Hait, as the interphase between basic research and its application in a clinical setting for the diagnosis, treatment or prevention of disease.
} 
grated to make it relevant in the contemporary era. In this sense, combining sociological reflection with sustainable development (Sannella, 2018, p. 11), and (more than ever) sociological research, is a necessity: sustainability needs to be approached as itself a problem, one that societies of the present day must tackle and for which they will require solutions (Neckel, 2017).

\subsection{Interpreting the Novocene Society}

Since 1998, Eve Passerini has been stressing the need for social sciences to consider the problems raised by the World Commission on Environment and Development: Our Common Future (WCED, 1987), which asserts that sociology has the theoretical and methodological means to contribute scientifically to understanding. In those years, American sociology was taking the big step of thinking in terms of rational choice theories, applied to both individual and collective action, in which the individual is formed through the environment. The challenge that has arisen over the 20 years since the emergence of this vision, leads us to envisage new areas of investigation, owing to collective representations in which the Anthropocene era is surpassed, as Lovelock announces (2019), and humanity has sprung towards the era of the Novocene. The revenge of Gaia (Lovelock \& Appleyard, 2006) speaks of an urgent need to be resolved through multiple responses.

Hence solutions proposed by individual disciplinary fields, or even by individual algorithms, will not suffice. The research will have to take into account the inference of human beings in the different contexts that are contaminated by the extremisms set in motion during the last century (Stinchcombe, 1994), and which today face the challenges of the digital society. In other words, do the explanatory claims lead us to question how to retrieve our guiding concepts, and use them as interpretative tools in the era of hyperintelligence? The epistemological roots that could support a sociological approach—in keeping with sustainable development—will have to take into consideration the threats of such a complex society, exposed as it is to scarcity of natural resources, environmental catastrophes, food shortages, and the accelerated introduction of robotic machines in everyday life. "If only because of this multiplicity of meanings, for sociologists there can be no question of regarding sustainability as the long-sought solution to every environmental and societal problem.

On the contrary, sustainability needs to be approached as itself a problem, one that societies of the present day must tackle and for which they will require solutions" (Neckel, 2017, p. 47). By drawing on Talcott Parsons's AGIL model theory, and imagining the functional organization of social systems, we could redesign a model that helps us to pursue SDGs, and appeal to common ideals, and thus ensure the stability of the social structure in the Agenda 2030 transition.

The goal 17 partnership was the main topic of consideration in the Global University Network for Innovation (GUNI, 2018, p. 21) document, highlighting the need to generate methodologies that can be replicated in a multidisciplinary way, to 
strengthen research networks, education in disseminating results, and sustainable development. Such a nuanced approach is already present in some countries, for example in Sweden, where civil engineering skills for sustainable development are intertwined with those of the human sciences through a general impact on the ethics of sustainability. "It appears the art of 'social engineering' is occupied by its opposite, according to which it is the civil engineer who enters areas where social science traditionally holds a prominent position and addresses social and political issues" (Bergström, 2018).

To develop an interpretive model, a systemic approach to sustainable development must be adopted, requiring the creation of research hubs and a quest for models, tools, and functional techniques for human development and for combating inequalities. We will have to improve the living quality of populations through policy strategies that enhance social cohesion and circular economic growth on a global scale. Sustainable development might be a crucial contribution to the development of such disciplines (Cohen, 1983). The achievement of SDGs offers an opportunity to attain results, in terms of both scientific research and social responsibility.

\subsection{Conclusions}

As is evident, we are still searching for a possible change in the reference paradigm that could "work" in connection with the UN Agenda, and form a mosaic of scientific reflection on sustainable development and on education concerning necessary change (Rethinking education: towards a global common good? UNESCO, 2015). The debate on the possibility of halting the decline of our planet is a clear emergency, even with regard to international policies. The contrast of extreme inequalities reveals itself in another look at the data: drinking water is lacking for almost 1 billion people, and another 2 billion drink contaminated water (WHO, 2019); at the same time, we can produce drones for shipping companies to deliver packages anywhere in the world. Unlike in the case of the previous study (Schrank, 2010), we should also complement rather than substitute for studies, with the aid of artificial intelligence, by focusing on more "sociological" explananda, including-but by no means limited to — social change, climate change, anomie, and inequality.

In the light of these considerations, it is incumbent on us to outline an interpretive framework capable of analyzing the structural changes that have taken place within the different contexts, starting from the reduction of the workforce and the increase in inequalities, and culminating in research for an inclusive social structure capable of countering dystopias, amplifying utopias (Giovannini, 2018), and applying sustainable development. In an age of intense power and big data that contaminate the media and political debate with fake news, manipulation, and control, scientific knowledge is crucial for human development and a reversal of the course toward Earth Overshoot Day, which is the day when, according to the Global 
Footprint Network, it is calculated that consumption will exceed the natural resources produced by Planet Earth.

Therefore, scientific forecasting cannot ignore a future without the core innovative input of sustainability through the analysis of a translational systemic sociology. As posited by Jeffrey Sachs, we should therefore consider "two specific tools that will be important for SDGs translation. The first is 'back casting': instead of predicting the future, a goal is set for a certain date in future and analyze how to get from present to target. The second is 'street technology-mapping'. Often used in sophisticated high-tech industries, road-mapping calls for deep questions about the path from today to achieving the future goal in order to identify the policy or technological barriers to overcome" (Sachs, 2015). Although we can consider the development of society (so-called advances societies), some tools from the points of view of technical, industrial, and economic policies, which could guide research, need to be used. Only a synergy between disciplines will be able to propose an integrated methodology where sociology can act as an interpretive hub. Therefore, scientific forecasting cannot hope to build a future based on assistance without making sustainability an absolute priority. In agreement with Horowitz (1993, p. 197), social science is unique in part because as well as examining the structural consequences of human behavior and prediction, they have the task of anticipating empirical paradoxes. Aware that the drive for change will also be provided by technological knowledge, we must acquire qualitative and quantitative data to enable a transition in the application of collective actions for paradigm change.

If the global trend emphasizes the acceleration of environmental, economic and social changes-amplifying the well-known gap between North and South-the interpretation of a new paradigm is to be understood as a bridge between weak and strong sustainability (Ayres, van den Bergh, \& Gowdy, 2001; Lucia, Duglio, \& Lazzarini, 2018; Neumayer, 2003) worldwide. It would be useful to redesign, with differentiated (analog and digital) tools, a Weltanschauung that is flexible and that can create interconnections between public and private policies and the different structures. Mainstreaming is required for innovation and the facing of global challenges. To recall an important example of Karl Popper's: "Science does not rest on a solid layer of rock. The bold structure of its theories rises, so to speak, over a swamp. It is like a building built on stilts (...). The fact that we desist from our attempts to dig deeper in piles does not mean that we have found solid ground. Simply, we stop when we are satisfied, and we believe that at least for the moment the supports are stable enough to support the structure" (Popper, 1934/1998, pp. 147-148). Sociology, which by its very nature is a "borderline" science, has the tools and techniques to dialogue with a translational approach, and cooperate in getting past the Pillars of Hercules of the digital era to reach a society capable of pursuing the needs of the present without compromising the ability of future generations to meet their own needs (Brundtland, 1987). 


\section{References}

Ayres, R. U., van den Bergh, J. C. J. M., \& Gowdy, J. M. (2001). Strong versus weak sustainability: Economics, natural sciences and "consilience". Environmental Ethics, 23(1), 155-168. https:// doi.org/10.5840/enviroethics200123225.

Bateson, G. (1972). Steps to an ecology of mind: Collected essays in anthropology, psychiatry. Chicago: Chicago University Press.

Bergström, Y. (2018). Sustainability, higher education of civil engineers and the art of social engineering in Sweden. In ISA World Congress of Sociology XIX. Retrieved from https://isaconf. confex.com/isaconf/wc2018/webprogram/Paper103643.html

Boudon, R. (1997). Metodologia della sociologia e delle scienze sociali. Milano: JakaBook.

Brundtland, G. (1987). Our common future. Oxford: Oxford University Press.

Cohen,Y.A. (1983). A theory and a model of social change and evolution. Journal of Anthropological Archaeology 2:2-12, Elsevier. https://doi.org/10.1016/0278-4165(83)90011-9

Espey, J. (2019). The missing ingredient for a better world: Data. Nature, 571, 299. New York: Springer.

Ferrarotti, F. (1968). Trattato di Sociologia. Torino: UTET.

Food Security Information Report (2019). Global Report on Food Crises. FAO. http://www.fsinplatform.org/sites/default/files/resources/files/GRFC_2019-Full_Report.pdf

Giovannini, E. (2018). L'utopia sostenibile. Roma-Bari: Laterza.

Global University Network for Innovation. (2018). Approaches to SDG 17 partnerships for the sustainable development. Barcelona: Métod. Retrieved from http://www.guninetwork.org/files/ approaches_to_sdg17-partnerships_for_the_sdgs.pdf

Horowitz, I. (1993). The decomposition of sociology. New York: Oxford University Press.

Lovelock, J., \& Appleyard, B. (2006). The revenge of Gaia: Why the earth is fighting back and how we can still save humanity. London: Penguin.

Lovelock, J., \& Appleyard, B. (2019). Novacene: The coming age of hyperintelligence. Boston: The MIT Press.

Lucia, M. G., Duglio, S., \& Lazzarini, P. (Eds.). (2018). Verso un'economia della sostenibilità. Lo scenario e le sfide. Milano: FrancoAngeli.

Luhmann, N. (1992). The concept of society. Thesis Eleven, 31(1), 67-80.

Magatti, M. (2017). Cambio di paradigma. Uscire dalla crisi pensando il futuro. Milano: Feltrinelli.

Morin, E. (1983). Il metodo: ordine, disordine, organizzazione. Milano: Feltrinelli.

Nativi, S., Santoro, M., Giuliani, G., \& Mazzetti P. (2019). Towards a knowledge base to support global change policy goals, International Journal of Digital Earth. https://doi.org/10.1080/17 538947.2018.1559367.

Neckel, S. (2017). The sustainability society: A sociological perspective. Culture, Practice \& Europeanization, 2(2), 46-52.

Neumayer, E. (2003). Weak versus strong sustainability: Exploring the limits of two opposing paradigms. Cheltenham: Edward Elgar Publishing.

OECD. (2019). Retrieved from https://read.oecd-ilibrary.org/governance/governance-as-an-sdgaccelerator_0666b085-en\#page19

Popper, K. (1998). La logica della scoperta scientifica. Torino: Einaudi. (ed. Or. 1934. The logic of scientific Discovery).

Rockström, J., Steffen, W., Noone, K., Persson, Å., Chapin, F. S., Lambin, E. F., et al. (2009). A safe operating space for humanity. Nature, 461(7263), 472-475.

Sachs, J. (2015). The age of sustainable development. New York: Columbia University Press.

Sannella, A. (2018). Introduzione. In L. Maciocia \& A. Sannella (Eds.), Crescere sostenibili e in salute. Strumenti per la promozione e lo sviluppo. Milano: FrancoAngeli.

Sannella, A. (2019). Sviluppo sostenibile e innovazione sociale per la promozione della salute. In M. Esposito \& A. Sannella (Eds.), Social innovation nelle politiche della sanità. Rivista Salute e Società, 2/19 (pp. 68-82). Milano: FrancoAngeli. 
Schrank, A. (2010). The sociology of development and the development of sociology. In Sociologica. Italian journal of sociology on line. 1/2010. https://doi.org/10.2383/32062

Shaker, R. (2015). The spatial distribution of development in Europe and its underlying sustainability correlations. Applied Geography, 63, 35. https://doi.org/10.1016/j.apgeog.2015.07.009

Steffen W, Richardson K, Rockström J, Cornell SE, Fetzer I, Bennett EM, Biggs R, Carpenter SR, Vries W de, Wit CA de, Folke C, Gerten D, Heinke J, Mace GM, Persson LM, Ramanathan V, Reyers B, Sörlin S (2015) Planetary boundaries: Guiding human development on a changing planet. Science 1259855. https://doi.org/10.1126/science.1259855

Stinchcombe, A. (1994). Disintegrated Disciplines and the Future of Sociology. Sociological Forum, 9(2), 279-291. Retrieved from http://www.jstor.org/stable/685046

Spence, M. (2019). The digital revolution of wellbeing. Retrieved August 3, 2019, from https://www.project-syndicate.org/commentary/digital-revolution-impact-on-wellbeingby-michael-spence-2019-06

UNESCO. (2015). Rethinking education: towards a global common good? http://www.unesco.org/ new/fileadmin/MULTIMEDIA/FIELD/Cairo/images/RethinkingEducation.pdf

WCED (1987). Our Common Future. World Commission on Environment and Development. Oxford University Press, Oxford

WHO. (2019). Retrieved July 12, 2019, from https://www.who.int/news-room/fact-sheets/detail/ drinking-water 


\section{Index}

A

Anarchy of production, 19

Anthropocene, 6, 12, 119

Anthropological shock, 109

\section{B}

Bauman' thought

in academic world, 35

consumption, 36

creative destruction, 36

creativity and innovation, 43

creativity and sociological imagination, $35-36$

economic conditions, 38

global and hyper-consumerist society,

$$
\text { 41-42 }
$$

on globalization, 36

humanism, 43

intellectual and public, 35

interpersonal relationships, 42

labor market, 37

liquid-modern society, 36

liquid relationships, 38-39

marketing, 40

social bonds and community, 40

social movement, 42

socio-cultural context, 37

socio-economic and cultural resources, 38

Bertelsmann Stiftung (BS), 51

Big Data and smart cities, 3

Blessing in disguise, 104

Bottom-up approach, 69, 74, 76
C

Capabilities approach, 54, 65

Capitalism, 31

Climate change, 55, 56, 61, 85

human-caused, 109

and relative syndromes, 87

Consumption

and production, 65

society, 43

and work, 36-38

Contemporary capitalism, 30

Cradle to Cradle (C2C) approach, 117-118

Cultural syndromes, 81, 83, 90

D

Democracy, 31

Detachment, 17

Diagnostic and Statistical Manual of Mental Disorders (DSM-5), 81

Durkheim, E.

static and naturalistic chosisme, 96

theoretical schemes, 21-22

and Weber's work, 9

$\mathbf{E}$

Ecological approach, 81

Economic competitiveness, 48

Ecosystem democracy, 80

Emancipatory catastrophism, 108

human actions, 103

micro-sociological data, 105

objective consequences, 105 
Emancipatory catastrophism (cont.) rationality, 106

and risk society, 111

secularization, 103-104

social actions, 107

social transformation, 104

sociological motivations, 110

Environmental justice approach, 55

Environmental Performance Index (EPI), 60

Environmental problem, 110

Environmental sustainability, 48

capitalism, 26

concept, 25

consumer society, 28

consumption and waste, society, 28-29

greenhouse effect, 25

Kondratiev's cycles, 26

sensitivities and awareness, 27-28

Equity, 9, 10, 12, 59, 60, 71

Ethical and moral approach, 49

European Neighbourhood Policy (ENP), 72

Europe 2020 strategy, 76

Evidence-based theoretical framework, 54-56

\section{F}

Financial capitalism, 29

Functionalism

aggregation and stratification, 17

Durkheim's theoretical schemes, 21

free-trade ideology, 20

ideological operation, 18-19

industrial and welfare society, 15

institutional and institutions, 16

organic and self-regulated system, 16

political sub-system, 20

scienscientific research tools, 18

social knowledge, 18

social system, 21

sociological theory, 15-16

structural-functionalist hypothesis, 19

G

Global climate risk, 108

Globalization, 10, 28, 29, 36, 37, 81, 84, 87, 90

Global Report on Food Crises 2019, 116

Global SDGs Index, 116

\section{H}

Human-caused climate change reality, 109
Human happiness, 40

Humanism, 43

I

Inequality, 54, 76, 87, 104, 115, 116, 120

Information and communication technologies (ICT), 12

Innovation, 43, 48, 60, 69, 117, 121

Internet of Things (IoT), 4

Inter-pillar model, 50

Interpretive model, 120

K

Kondratiev's cycles, 26, 29

L

Liquid Society, 36

Logical framework approach, 72, 73

Logical framework matrix

(LFM), 74

M

Marx's definition

economic and social formation, 117

Max Weber's methodology, 96-98

Merton's functionalism, 21-22

Millennium Development Goals

(MDGs), 49

Modernity

evolution, 6

Latour's description, 6

principles, 8-9

Multi-pillar model, 50

Multiple entry, 101

Mutating syndromes

cultural and social psychiatry, 85

dyscrasia, 86

heralds, 89

mental disorders, 86

migratory stress, 85

millenarianism, 85

rapidly, 86-87

slow mimetic, $87-88$

society's entropy, 85

syndrome's life, 88-89

$\mathbf{N}$

Narcissistic capitalism, 29 
O

Objectively Verifiable Indicator(s)

(OVIs), 75

One-pillar model, 50

$\mathbf{P}$

Parsons' theory, 21

Participation, 8, 54, 55, 57, 69, 72, 73, 76

Political-economic and cultural tools, 31

Postmodern societies, 83

Principal Component Analysis approach, 53, 55,56

Principles of Public Administration, 72

Project Cycle Management (PCM) model bottom-up approach, 69, 74, 76

economic crisis, 69-72

environmental sustainability, 75

Europe 2020 strategy, 76

five phases, 73

formulation period, 74

identification period, 74

LFM, 74

logical framework approach, 72, 73

OVIs, 75

project-design (see Project-design methods)

SMART, 75

US Agency of International Development, 73

Project-design methods

co-project, 70

ENP, 72

"essentially controversial notion", 70

handmade, 71

issues, 71

"new poverties", 71

PCM model, 71

SDGs, 72

Sigma Papers, 72

sustainability, 70

"the imperative of responsibility", 70

Psychopathological syndromes

culture-bound syndromes, 83

cybernetics (see Mutating syndromes)

DSM-5, 81, 83

ecological approach, 81

ecosystem democracy, 80

elusive phenomenology, 83

phenomenology, 82-84, 89, 90

postmodern societies, 83

scenarios on the move, $83-84$

subjects on the move, $82-83$
Q

Quality of life, 12

$\mathbf{R}$

Renewed structural-functionalist system, 118-119

Researcher involvement, 80

Risk society, 6, 27, 104, 111

\section{S}

Scientific forecasting, 121

Side effects, 104, 106-108, 110

Social analysis

action, 5

modernity, 4

thought and theoretical processing, 5-6

Social cohesion and balance, 48

Social generativity, 69

Social paradigm anthropocentric vision, 11

globalization, 10

implementations, 10-11

modernity, 8-9

network of physical objects, 11

theoretical and methodological approach, 9

time and space, 10

traditional approaches, 9-10

Social relations, 10, 12, 20, 42, 71, 101

Social research

critical distance and inevitable involvement, 98-99

historical context, 95

human experience, 100

intellectual construction, 95

Max Weber's methodology, 96-98

theory and model, 95-96

The Social System, 18

Social theory, 17

and awareness, 18

Bauman' thought (see Bauman' thought)

Social transformation, 4, 12, 104

Socio-institutional analysis, 16

Sociological functionalism, 15-16

Sociological theory, 15

Sociologists

and certainly, 35

efforts, 10

social space, 12

Sociology

origins, 4

and sustainable development 
Sociology (cont.) paradigmatic approach, 115 SDGs, 116

Space, 9-12, 38, 48, 55, 65, 81

Specific, Measurable, Available, Relevant, and Time-bound (SMART), 75

Street Corner Society, 100

Sustainability ecological conditions, 6 environmental concerns, 7

modern exuberance, 8

modernity, 7

sociology, 7

theoretical and methodological settings, $7-8$

WCED, 8

Sustainable development, 10, 32, 48-51, 54, $55,65,69,75$

Sustainable development goals (SDGs), 116 composite index, 50, 51, 53, 56

ecological justice, 52, 55, 56, 60, 61, 63, 65

economic competitiveness, 48

environmental sustainability, 48

EU countries, 61

evidence-based theoretical framework, 54-56

human well-being, 47, 49, 51, 52, 54-56, 59-62

indicators, 49-51, 53, 55, 57-59, 61

MDGs, 49

Principal Component Analysis approach, 53

social cohesion and balance, 48

social justice, 49, 52, 54, 55, 59-62 theoretical and methodological challenges, 50-53

three-pillar model, 49

Sustainable Development Solutions Network (SDSN), 51

Sustainable Governance Indicators (SGI), 59

\section{$\mathbf{T}$}

Talcott Parsons's AGIL model theory, 119

Theoretical functional model functionalism (see Functionalism)

Theoretical paths, 5

Three-pillar model, 50

Time management, 41 post-modern times, 84 and space, 10

Time-bound, 75

Translational sociology, 117-119

$\mathbf{U}$

Ulrich Beck's approach, 104

Unintended consequences, 104, 106, 110, 111

United Nations Development Programme (UNDP), 56

W

Welfare, 5, 15, 20, 21, 31, 37, 70, 76

World Commission on Environment and Development WCED), 8

World Health Organization (WHO), 82 